ANAIS DO III SIMPÓSIO PIAUIENSE MULTIPROFISSIONAL EM NEUROPEDIATRIA E NEONATOLOGIA

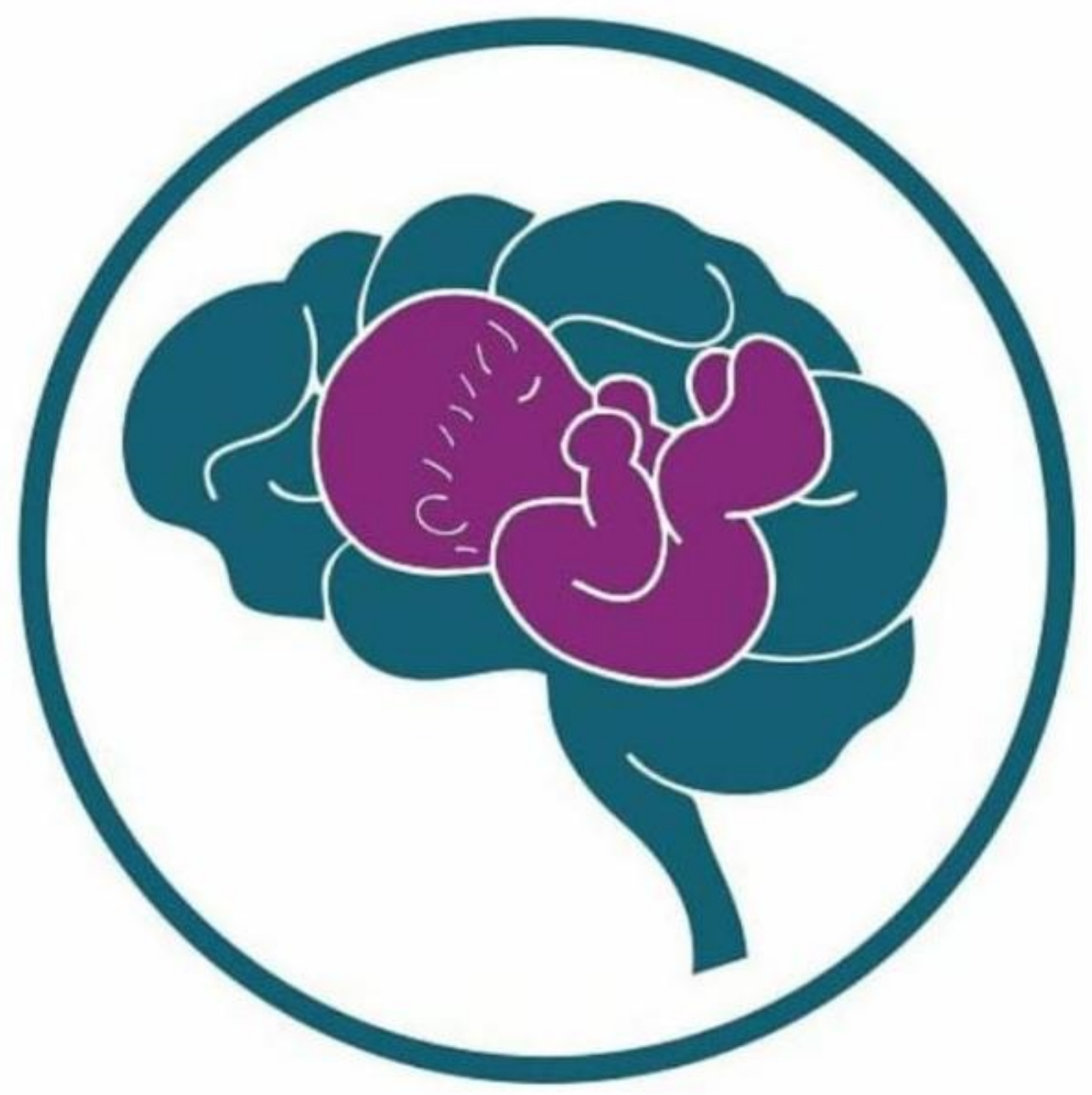

TERESINA - PI

2021 
ANAIS DO III SIMPÓSIO PIAUIENSE MULTIPROFISSIONAL EM NEUROPEDIATRIA E NEONATOLOGIA

ANAIS DO III SIMPÓSIO PIAUIENSE MULTIPROFISSIONAL EM NEUROPEDIATRIA E NEONATOLOGIA

$1^{\mathrm{a}}$ edição

TERESINA - 2021

Centro Universitário UniFacid 
ANAIS DO III SIMPÓSIO PIAUIENSE MULTIPROFISSIONAL EM NEUROPEDIATRIA E NEONATOLOGIA

REALIZAÇÃo

\section{CENTRO UNIVERSITÁRIO}

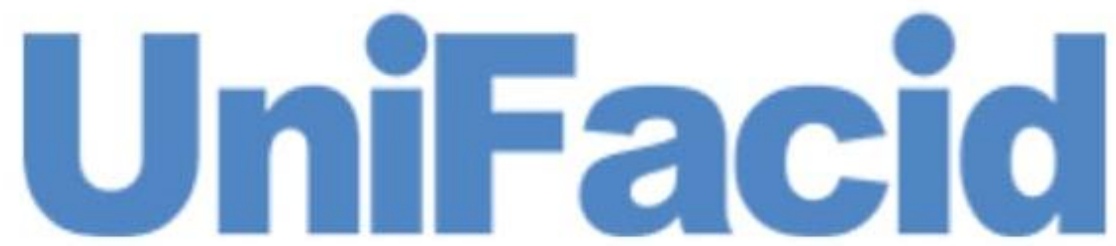

\section{APOIO}

\section{JCS HU-UFPI} JORחAL DE CIÊRCIAS DA SAÚDE DO HOSPITAL UNIUERSITÁRIO DA UNIUERSIDADE FEDERAL DO PIAUÍ 


\section{ANAIS DO III SIMPÓSIO PIAUIENSE MULTIPROFISSIONAL \\ EM NEUROPEDIATRIA E NEONATOLOGIA}

\section{FICHA TÉCNICA}

III Simpósio Piauiense Multiprofissional em Neuropediatria e Neonatologia

Instituição: Centro Universitário UniFacid

Realizado nos dias 26, 27 e 28 de Agosto de 2021

Plataforma: Doity Play

\section{MINICURSOS}

- Avaliação neuropsicológica infantil e seus diversos contextos. - Luana Ferro.

- Fisioterapia Neurofuncional e suas repercussões na unidade de terapia intensiva neonatal. - Katya Coeli da Costa Loiola.

- Crescimento infantil - Estímulos para o desenvolvimento cognitivo na infância. Aldenora Maria Ximenes Rodrigues.

- O cuidado singular da enfermagem na neuroproteção neonatal: da teoria à prática. Brenda Silveira Valles Moreira.

- Terapia nutricional e neonatologia. - Juliana Maria Libório Eulálio.

- Terapia Ocupacional e a confecção de recursos de baixo custo voltados para a estimulação cognitiva e motora de crianças. - Richelliany Julião dos Santos Cardoso.

- A pessoa com deficiência e a iniciação esportiva. - Childerico Robson.

\section{PROGRAMAÇÃO}

- Persistência dos reflexos primitivos e desenvolvimento neuropsicomotor. - Ana Flavia Machado de Carvalho.

- Os desafios da atuação farmacêutica em neuropediatria. - Gisele Lopes Cavalcante.

- Estimulação do desenvolvimento neuropsicomotor e o treino de habilidades em prematuros. - Vandelma Castro.

- O cuidado multidisciplinar da espasticidade através da rizotomia dorsal seletiva na paralisia cerebral. - Leonardo Rodrigues; Ana Petillo, Francisco Alencar; Izabel Cronemberger, Leylane Mendes. 
- As repercussões da covid-19 no desenvolvimento infantil. - André Sousa Rocha.

- Diálogos com a educação física inclusiva. - Marcio José.

- Corpo e imagem corporal de crianças com TEA. - Thanandra Rocha.

- Atraso da fala e autismo- definindo os conceitos de linguagem e como intervir precocemente em crianças autistas com e sem este atraso. - Christianne Porto; Bruno Roberto Duarte.

- Atuação do Terapeuta Ocupacional na Unidade de Cuidado Intermediário Neonatal Canguru (UNCICa). - Clarinda Vitória do Nascimento.

- Existe alguma relação entre prematuridade e odontologia?. - Aline Manfro.

- Desenvolvimento motor de crianças de 0 a 2 anos. - Renata Pereira da Silva.

- Terapia Nutricional e prematuridade: a importância do nutricionista, da admissão à alta na uti neonatal. - Marina Lins Mendes Pinto; Jaielison Yandro Pereira da Silva.

- A humanização do cuidado na unidade de terapia intensiva neonatal. - Ozirina Maria da Costa.

- Assistência ao RN em sala de parto e suporte CPAP precoce. - Fátima Lidiane Silva.

- Evidências Científicas sobre a Equoterapia: Um olhar multidisciplinar. - Natália Soares Oliveira. 


\section{ANAIS DO III SIMPÓSIO PIAUIENSE MULTIPROFISSIONAL EM NEUROPEDIATRIA E NEONATOLOGIA}

\section{DOCENTES ORGANIZADORES}

\section{Ana Flávia Machado de Carvalho (Presidente Docente)}

Gabriela Dantas Carvalho

Leide Maria Mendes da Silva Cavalcanti

\section{COMISSÃO ORGANIZADORA}

Sara Ferreira Lobato de Brito (Presidente Discente)

Abimael de Carvalho

Alessandra Maria Alves de Araújo

Alessandro Jhordan Lima Mendes

Alice Benicio do Nascimento

Amanda Sérvio Salazar

Ana Luísa Mendes Ribeiro

Ana Paula de Carvalho Souza

Ana Paula Silva Santana

Anne carolaynne Silva Santos

Augusto Felipe da Rosa Machado

Caroline Lago da Cruz

Dara Alice de Sousa Penha

\section{Denise Araújo Sousa (Vice-Presidente}

Discente)

Diva Nina Melo Machado

Eduarda Costa Barros

Emanuely Alvares Queiroz

Eryka Vaz Zagmignan

Fernanda Moraes Nogueira

Francisco Tassio Azeveo Teixeiro
Ingred Rayana Martins Costa E Silva

Jaíres Emanuele Nunes de Sousa

Jariane Carvalho Rodrigues

Jederson Valentim Silva

Jessica Maria Santos Dias

Jessyca Thayane de Sousa Oliveira

José Victor de Sousa Lira

Josiane Marques das Chagas

Joyce Leal Barroso

Juliane Nascimento Sousa

Kauana Stephany Sousa da Silva

Lairton Batista de Oliveira (Vice-

Presidente da Comissão Científica)

Larissa Carvalho Dias de Sousa

Laryssa Lima Santana

Letícia Carla Alves Vieira

Liandra Virgínia de Sousa Coêlho Sales

Lívia Sayuri Félix Mendes

Manoel Leonardo Tavares da Silva

Maria Aline Damasceno Silva

Maria Dhescyca Ingrid Silva Arruda

Maria do Socorro Sousa Santos de Oliveira

Maria Eugênia Macedo Teixeira

Maria Gabriella Macêdo dos Santos

Maria Josefa Borges

Mariana Silva Souza

Mykaelle Oliveira Sousa

Mylena Cardoso Sales

Rabrine da Silva Matos

Ramires dos Santos Moraes

Ranyelle Oliveira de Sousa 
Saint-Clair Asafe Araujo Neves

Samuel Soares Santana

Suzana Pereira Alves

Talyta da Silva Guimarães

Thais Cristine Lopes Pinheiro

Valéria Alves da Rocha (Presidente da

\section{Comissão Científica)}

Vanessa Maria dos Santos Castro Araújo

Vanessa Rayanne De Souza Ferreira

Vivia Rhavena Pimentel Costa

Wilson Sousa Junior

AVALIADORES

Ana Rafaela Silva Pereira

Bianca Maria Cardoso de Sousa Vieira

Camila de Castro Corrêa

Camila Rayllane Carvalho de Sousa

Camilla Siqueira de Aguiar

Caroline Taiane Santos da Silva
Cleiciane Remigio Nunes

Dalila Cinara Pereira da Silva

Denival Nascimento Vieira Júnior

Fernando Soares da Silva Neto

Gabriela Dantas Carvalho

Geísa de Morais Santana

Jaielison Yandro Pereira da Silva

Jenifer Grotro de Souza

Jéssika Roberta Firme De Moura Santos

Marina Lins Mendes Pinto

Mayara Macêdo Melo

Mirtaelly Francisca Aragão Carvalho

Nágila Silva Alves

Rauene Raimunda de Sousa

Sandra Tuany Alves de Morais

Stefânia Araújo Pereira

Talita Costa Barbosa

Vandelma Lopes de Castro

Victor Hugo Pereira Aragão 


\section{ANAIS DO III SIMPÓSIO PIAUIENSE MULTIPROFISSIONAL EM NEUROPEDIATRIA E NEONATOLOGIA}

\section{MENSAGEM DO PRESIDENTE}

O III Simpósio Piauiense Multiprofissional em Neuropediatria e Neonatologia (SIMPINEURONEO) é um evento universitário de caráter técnico-científico que tem como objetivo promover o conhecimento dos discentes, docentes e os profissionais da saúde acerca das inovações multiprofissionais em neuropediatria e neonatologia, como também discutir a atuação destes profissionais em suas diversas áreas de trabalho, possibilitar a troca de experiências e o aprendizado científico. O evento ocorreu nos dias 26,27 e 28 de agosto de forma online e teve como Instituição promotora o Centro Universitário UniFacid. Agradecemos imensamente aos palestrantes, participantes, comissão organizadora e ao Jornal de Ciências da Saúde do Hospital Universitário da Universidade Federal do Piauí - JCS HUUFPI pelo apoio e pela contribuição na publicação dos trabalhos científicos.

ANA FLÁ VIA MACHADO DE CARVALHO 
ANAIS DO III SIMPÓSIO PIAUIENSE MULTIPROFISSIONAL

EM NEUROPEDIATRIA E NEONATOLOGIA

A Coordenação do III Simpósio Piauiense Multiprofissional em Neuropediatria e Neonatologia não assume qualquer responsabilidade pelo teor ou possíveis erros de linguagem dos trabalhos divulgados nesta publicação, a qual recai, com exclusividade, sobre seus respectivos autores. 
ANAIS DO III SIMPÓSIO PIAUIENSE MULTIPROFISSIONAL

EM NEUROPEDIATRIA E NEONATOLOGIA

\section{SUMÁRIO}

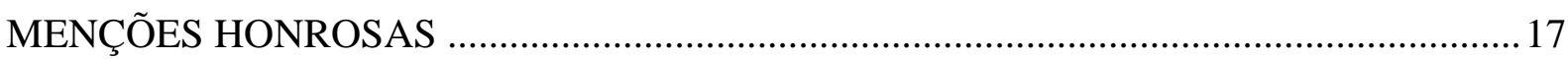

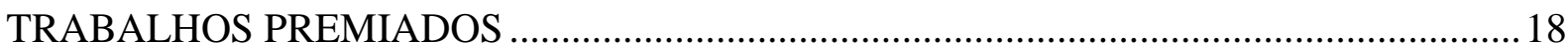

TRABALHOS NA MODALIDADE RESUMO SIMPLES ....................................................19

ANÁLISE BIOMECÂNICA NO BRINCAR COMO FERRAMENTA PROMISSORA DA TERAPIA OCUPACIONAL PEDIÁTRICA

A ASSISTÊNCIA MULTIPROFISSIONAL NO TRATAMENTO DA LIPOFUSCINOSE CERÓIDE NEURONAL EM CRIANÇAS

A INTERVENÇÃO DA TERAPIA OCUPACIONAL NO DESENVOLVIMENTO DO RECÉM-NASCIDO PRÉ-TERMO

ALTERAÇÕES NEUROLÓGICAS ASSOCIADAS A COVID-19: REVISÃO DE LITERATURA

ASSISTÊNCIA DE ENFERMAGEM EM CUIDADOS AO RECÉM NASCIDO PORTADOR DE ICTERÍCIA NEONATAL 28 ASSISTÊNCIA DE ENFERMAGEM NO CONTROLE DE INFECÇÕES HOSPITALARES EM UNIDADE DE TERAPIA INTENSIVA NEONATAL

ASSOCIAÇÃO ENTRE TRIAGEM DE RISCO NUTRICIONAL (STRONGKIDS) E INDICADORES ANTROPOMÉTRICOS DE PACIENTES PEDIÁTRICOS COM PARALISIA CEREBRAL

COMPLICAÇÕES DA SEQUÊNCIA RÁPIDA PARA INTUBAÇÃO INTRATRAQUEAL EM UNIDADE DE TERAPIA INTENSIVA NEONATAL

CRIAÇÃO E IMPLANTAÇÃO DE UMA PLANILHA ELETRÔNICA PARA GESTÃO EM LACTÁRIO SOBRE O RECEBIMENTO E DISPENSAÇÃO DE LEITE MATERNO ORDENHADO

EFEITOS DA FISIOTERAPIA OCULAR NO RECÉM - NASCIDO PREMATURO 38 EFEITOS DA REDE DE POSICIONAMENTO EM RECÉM-NASCIDOS PREMATUROS: UMA REVISÃO INTEGRATIVA 
ESTADO NUTRICIONAL DE CRIANÇAS E ADOLESCENTES COM PARALISIA CEREBRAL ADMITIDAS EM UM HOSPITAL UNIVERSITÁRIO DO MARANHÃO .... 42 FATORES DE RISCO ASSOCIADOS À SEPSE NEONATAL EM UNIDADES DE TERAPIA INTENSIVA: UMA REVISÃO INTEGRATIVA 44

FATORES PREDITORES DE LESÕES NA PELE DOS RECÉM-NASCIDOS INTERNADOS EM UNIDADE DE TERAPIA INTENSIVA: REVISÃO INTEGRATIVA 46 FISIOTERAPIA EM CUIDADOS PALIATIVOS NA ONCOLOGIA PEDIATRICA: REVISÃO DE LITERATURA

IMPORTÂNCIA DO ALEITAMENTO MATERNO NA ATUALIDADE E SEUS PRINCIPAIS DESAFIOS: UMA REVISÃO DE LITERATURA

INTERVENÇÕES DE ENFERMAGEM NA SEPSE NEONATAL: DO DIAGNÓSTICO AO TRATAMENTO. 52

KERNICTERUS: A IMPORTÂNCIA DE IDENTIFICAR PRECOCEMENTE A ICTERÍCIA GRAVE NO NEONATO COMO FORMA DE PREVENÇÃO 54 LOCALIZAÇÃO E AVALIAÇÃO DE APLICATIVOS MÓVEIS SOBRE ALEITAMENTO MATERNO: ESTUDO PILOTO 56 OS BENEFÍCIOS DA INTERVENÇÃO FISIOTERAPÊUTICA PRECOCE EM RECÉMNASCIDOS NO CONTEXTO DA UNIDADE DE TERAPIA INTENSIVA NEONATAL . 58 OS IMPACTOS DA EXPOSIÇÃO PARENTAL A PESTICIDAS NO NEURODESENVOLVIMENTO FETAL E INFANTIL 60 PERCEPÇÃO DE PUÉRPERAS NA VIVÊNCIA DO PERÍODO DE INTERNAÇÃO DE BEBÊS PREMATUROS EM UTI NEONATAL: REVISÃO BIBLIOGRÁFICA. 62 PERFIL EPIDEMIOLOGICO DOS CASOS DE SÍFILIS CONGENITA NO BRASIL 64 PROBLEMAS RESPIRATÓRIOS NO NEONATO DECORRENTE DE PARTO CESÁRIO 66

PROPOSTA PARA ELABORAÇÃO DE PROTOCOLO DE AVALIAÇÃO NA ENCEFALOPATIA CRÔNICA NÃO EVOLUTIVA. 69 REPERCUSSÕES DA COVID-19 EM NEONATOS: O QUE REVELAM AS PUBLICAÇÕES CIENTÍFICAS?

TERAPIA OCUPACIONAL NO PROCESSAMENTO SENSORIAL EM CRIANÇAS COM TRANSTORNO DO ESPECTRO AUTISTA 
USO DA TERAPIA DE PRESSÃO POSITIVA CONTINUA DAS VIAS AÉREAS EM RECÉM-NASCIDOS PREMATUROS COM DESCONFORTO RESPIRATÓRIO

TRABALHOS NA MODALIDADE RESUMO EXPANDIDO

A INFLUÊNCIA POSITIVA DA ESTIMULAÇÃO PRECOCE EM PREMATUROS EXTREMOS. 78

ANÁLISE DA TAXA DE OCUPAÇÃO DE LEITOS EM UMA UNIDADE DE CUIDADOS INTERMEDIÁRIOS E SEMI-INTENSIVOS NEONATAIS

ANÁlisE DA VARIAÇÃO DE FADIGA DURANTE O TRATAMENTO FISIOTERAPÊUTICO EM DISTROFIA MUSCULAR DE DUCHENNE: RELATO DE CASO

ANÁLISE DO DESPERDÍCIO E CUSTOS GERADOS PELO USO DE FÓRMULA LÁCTEA PARA PREMATUROS EM UMA UNIDADE DE CUIDADOS INTENSIVOS E SEMI-INTENSIVOS POR MEIO DE REGISTROS DIETÉTICOS

ASSISTÊNCIA DO ENFERMEIRO NA HIPOTERMIA TERAPÊUTICA PARA NEUROPROTEÇÃO DE NEONATOS COM ENCEFALOPATIA HIPÓXICOISQUÊMICA: REVISÃO INTEGRATIVA 98

ATUAÇÃO INTERPROFISSIONAL DOS CUIDADOS ÀS CRIANÇAS COM AUTISMO: UMA REVISÃO LITERÁRIA 103

BENEFÍCIOS DO MÉTODO CANGURU NO CONTEXTO DA INTERNAÇÃO EM UNIDADES DE TERAPIA INTENSIVA NEONATAL: REVISÃO INTEGRATIVA ........108 EFEITOS DA MUSICOTERAPIA NA REDUÇÃO DA SINTOMATOLOGIA DOLOROSA EM NEONATOS: REVISÃO INTEGRATIVA

INDICADORES DA QUALIDADE EM TERAPIA NUTRICIONAL ENTERAL NA NEONATOLOGIA: UMA REVISÃO INTEGRATIVA DA LITERATURA

MARCADORES INFLAMATÓRIOS E TERAPIA NUTRICIONAL NA SEPSE NEONATAL: UMA REVISÃO DA LITERATURA. 123

MÉTODO MÃE CANGURU - OS BENEFÍCIOS DE UM CUIDADO HUMANIZADO AO PRÉ-TERMO: UMA REVISÃO DA LITERATURA.

O POTENCIAL DA INTERVENÇÃO NUTRICIONAL SOBRE O AUTISMO EM CRIANÇAS

OS EFEITOS DA MUSICOTERAPIA NA SAÚdE DE RECÉM NASCIDOS PREMATUROS INTERNADOS EM UNIDADES DE TERAPIA INTENSIVA. 138 
PAPEL DO LEITE HUMANO NA ENTEROCOLITE NECROSANTE EM BEBÊS

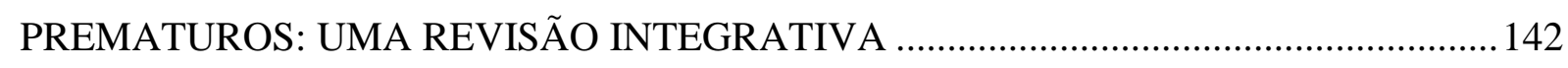
QUESTÕES ATUAIS NO TRATAMENTO FARMACOLÓGICO DO TRANSTORNO DO DÉFICIT DE ATENÇÃO E HIPERATIVIDADE EM CRIANÇAS . 147 REALIZAÇÃO DE UMA ATIVIDADE EDUCATIVA SOBRE AUTO-ORDENHA DE LEITE MATERNO EM MÃES ACOMPANHANTES DE BEBÊS INTERNADOS EM UNIDADES DE TERAPIA INTENSIVA NEONATAL: RELATO DE EXPERIÊNCIA ...153 RELATO DE EXPERIÊNCIA DA PARTICIPAÇÃO DE DISCENTES DE FISIOTERAPIA EM UM GRUPO DE ESTUdOS E EXTENSÃO DE FISIOTERAPIA EM NEONATOLOGIA 158

USO DA METODOLOGIA ATIVA "PROBLEM BASED LEARNING" NO ENSINO REMOTO DURANTE A PANDEMIA DA COVID-19 SOBRE NEONATOLOGIA EM UM GRUPO DE PESQUISA E ESTUdOS DE NUTRIÇÃO CLÍNICA: RELATO DE EXPERIÊNCIA. 163

USO DA FERRAMENTA LATCH PELO NUTRICIONISTA NA OBSERVAÇÃO DO ALEITAMENTO MATERNO NO BINÔMIO MÃE-BEBÊ DURANTE INTERNAÇÃO NA UCINCo: RELATO DE EXPERIÊNCIA 168 


\section{MENÇÕES HONROSAS}

$1^{\circ}$ Lugar: FATORES DE RISCO ASSOCIADOS À SEPSE NEONATAL EM UNIDADES DE TERAPIA INTENSIVA: UMA REVISÃO INTEGRATIVA

Autores: Lívia Sayuri Félix Mendes, José Marcos Fernandes Mascarenhas, Maria Dhescyca Ingrid Silva Arruda, Jessica Maria Santos Dias, Nerley Pacheco Mesquita, Cleiciane Remigio Nunes

$2^{\circ}$ Lugar: TERAPIA OCUPACIONAL NO PROCESSAMENTO SENSORIAL EM CRIANÇAS COM TRANSTRNO DE ESPECTRO AUTISTA

Autores: Eryka Vaz Zagmignan, Ana Paula Silva Santana, Manoel Leonardo Tavares da Silva, Nayara Moraes Nazar Melo, Clarinda Vitoria Aparecida Silva do Nascimento

$3^{\circ}$ Lugar: OS EFEITOS DA MUSICOTERAPIA NA SAÚDE DE RECÉM NASCIDOS PREMATUROS INTERNADOS EM UNIDADES DE TERAPIA INTENSIVA

Autores: Ana Paula de Carvalho Souza, Abimael de Carvalho, Vivia Rhavena Pimentel Costa, Janaína de Moraes Silva

$4^{\circ}$ Lugar: IMPORTÂNCIA DO ALEITAMENTO MATERNO NA ATUALIDADE E SEUS PRINCIPAIS DESAFIOS: UMA REVISÃO DE LITERATURA

Autores: Sillegiandia Batista da Silva, Mara Rúbia de Oliveira Bezerra 


\title{
TRABALHOS PREMIADOS
}

\author{
RESUMOS SIMPLES
}

$1^{\circ}$ Lugar: A IMPORTÂNCIA DA ASSISTÊNCIA MULTIPROFISSIONAL NO TRATAMENTO DA LIPOFUSCINOSE CERÓIDE NEURONAL EM CRIANÇAS

Autores: Angélica Jesus Rodrigues Campos, Girzia Sammya Tajra Rocha

$2^{\circ}$ Lugar: ESTADO NUTRICIONAL DE CRIANÇAS E ADOLESCENTES COM PARALISIA CEREBRAL ADMITIDAS EM UM HOSPITAL UNIVERSITÁRIO DO MARANHÃO.

Autores: Marília de Fátima Viana Alves, Fernanda Pereira de Castro, Marluce Alves Coutinho, Maria Milena Bezerra Sousa, Juliana Moreira da Silva Cruvel

$3^{\circ}$ Lugar: ASSISTÊNCIA DE ENFERMAGEM EM CUIDADOS AO RECÉM NASCIDO PORTADOR DE ICTERÍCIA NEONATAL.

Autores: Angelica Ribeiro do Nascimento Oliveira, Lucia Emanuele de Sousa Silva, Leticia de Oliveira Nascimento, Jaíres Emanuele Nunes de Sousa, Caroline Taiane Santos da Silva

\section{RESUMOS EXPANDIDOS}

$1^{\circ}$ Lugar: ASSISTÊNCIA DO ENFERMEIRO NA HIPOTERMIA TERAPÊUTICA PARA NEUROPROTEÇÃO DE NEONATOS COM ENCEFALOPATIA HIPÓXICOISQUÊMICA: REVISÃO INTEGRATIVA.

Autores: Nadia Maia Pereira, Diêgo Afonso Cardoso Macêdo de Sousa

$2^{\circ}$ Lugar: PAPEL DO LEITE HUMANO NA ENTEROCOLITE NECROSANTE EM BEBÊS PREMATUROS: UMA REVISÃO DA LITERATURA.

Autores: Larissa de Alcântara Santos, Sabrina Mércia Belarmino Gomes, Thalita Oliveira de Melo, Maria Eduarda Wanderley de Barros Silva, Nayane Gabriela Ferreira Macêdo e Silva, Tamires Alcântara Dourado Gomes Machado

$3^{\circ}$ Lugar: ANÁlISE DO DESPERDÍCIO E CUSTOS GERADOS PELO USO DE FÓRMULA LÁCTEA PARA PREMATUROS EM UMA UNIDADE DE CUIDADOS INTENSIVOS E SEMI-INTENSIVOS POR MEIO DE REGISTROS DIETÉTICOS.

Autores: Mateus Fernandes da Silva, Taelyson Costa de Medeiros, Sabrina Mércia Belarmino Gomes, Raissa Mislaine Santos da Silva, Larissa de Alcântara Santos, Jaielison Yandro Pereira da Silva 


\section{TRABALHOS NA MODALIDADE RESUMO SIMPLES}




\section{ANÁLISE BIOMECÂNICA NO BRINCAR COMO FERRAMENTA PROMISSORA DA TERAPIA OCUPACIONAL PEDIÁTRICA}

Manoel Leonardo Tavares da Silva ${ }^{1}$; Ana Paula Silva Santana²; Eryka vaz zagmignan ${ }^{3}$; Nayara Moraes Nazar Melo ${ }^{4 ;}$ Clarinda Vitoria Aparecida Silva do Nascimento ${ }^{5}$

1,2,3,4 Graduando em Terapia Ocupacional pelo Centro Universitário UniFacid, Teresina, Piauí, Brasil.

${ }^{5}$ Terapeuta Ocupacional pelo Centro Universitário UniFacid, Teresina, Piauí, Brasil.

Área Temática: Multiprofissional.

E-mail do autor para correspondência: leo.tavares3333@gmail.com.

INTRODUÇÃO: A Terapia Ocupacional é uma profissão que tem como principal objetivo promover bem-estar e qualidade de vida aos indivíduos, capacitando-os para realizar suas ocupações de forma autônoma e independente. Na pediatria irá intervir no brincar, atividade que é fundamental para o desenvolvimento da criança. Já a Biomecânica é a ciência que investiga os efeitos das forças internas e externas sobre os corpos vivos. Sabe-se que nas brincadeiras o corpo está em constante ação das forças mecânicas, isto demonstra a necessidade dos conhecimentos biomecânicos para o terapeuta ocupacional pediátrico. OBJETIVOS: O objetivo deste estudo foi analisar a importância da análise biomecânica no brincar na intervenção terapêutica ocupacional. METODOLOGIA: Este é um estudo de revisão de literatura onde realizou-se uma busca de artigos nas bases de dados: SciELO, Biblioteca Virtual em Saúde-BVS e Google Acadêmico. Utilizando os termos combinados em português e inglês: Terapia Ocupacional, Biomecânica e Brincar. Os critérios de inclusão foram: artigos que abordam a temática em português ou língua estrangeira. Como critério de exclusão optou-se por não utilizar textos incompletos. RESULTADOS E DISCUSSÃO: Para o Terapeuta Ocupacional a Biomecânica trará subsídios a respeito dessas forças atuantes no corpo da criança e, assim, poder usá-las ao seu favor para promover um melhor desempenho motor no brincar com técnicas de conservação de energia mecânica, facilitar a realização de atividades através da vantagem mecânica e da sinergia dos músculos bi e poli articulados, evitar sobrecargas durante as brincadeiras, além de estimular os componentes de desempenho motor que apresentam déficits. CONCLUSÃO: Conclui-se que a análise biomecânica é de extrema importância para a prática da Terapia Ocupacional no brincar, visto que essa análise promove conhecimento acerca da mecânica corporal e, com isso, o profissional pode favorecer melhores condições para o desempenho do brincar. 
Palavras-chave: Biomecânica, Brincar, Terapia Ocupacional.

\section{REFERÊNCIAS}

MIETO, F. S. R.; BRUNELLO, M. I. B.; SILVA, C. D. Procedimentos de avaliação da qualidade do brincar na prática da terapia ocupacional: um estudo exploratório. Revista de Terapia Ocupacional da Universidade de São Paulo, 24(2), p. 95-102, 2014.

NASCIMENTO, M. M., SOUZA JUNIOR, J. M. Nível de aptidão física de escolares, entre 10 e 14 anos de idade, integrantes das atividades do pet-biomecânica, em Petrolina-PE, região do sertão nordestino. Revista CPAQV - Centro de Pesquisas Avançadas em Qualidade de Vida. v. 9. nº. 2., p. 1-12, 2017.

PAIVA, T. S. Análise de variáveis clínicas e biomecânicas relacionadas à hipotonia em crianças com Síndrome de Down. 47 f. Trabalho de Conclusão de Curso (Bacharelado em Fisioterapia) - Universidade de Brasília, Brasília, 2017.

PINHEIRO, M. F. G.; GOMES, C. L. Abordagens do brincar em cursos de graduação na área da saúde: educação física, fisioterapia e terapia ocupacional. Revista Movimento. Porto Alegre, v. 22, n. 2, p. 555-566, abr.-jun. de 2016.

TEIXEIRA, N. M. P.; LOURENÇO, P. B.; COSTA, E. F.; OLIVEIRA, L. S. M.; CRUZ, D. A. Desenvolvimento neuropsicomotor e o brincar de crianças em uma unidade de educação infantil. Revista de Terapia Ocupacional da Universidade de São Paulo, 30(2), p. 116-123, 2019. 


\section{A ASSISTÊNCIA MULTIPROFISSIONAL NO TRATAMENTO DA LIPOFUSCINOSE CERÓIDE NEURONAL EM CRIANÇAS}

Angélica Jesus Rodrigues Campos $^{1}$; Girzia Sammya Tajra Rocha ${ }^{2}$

${ }^{1}$ Graduanda em Enfermagem pela Universidade Federal do Piauí - UFPI, Teresina, Piauí, Brasil.

${ }^{2}$ Enfermeira. Mestre em Enfermagem pela Universidade Federal do Piauí - UFPI, Teresina, Piauí, Brasil.

Área Temática: Multiprofissional.

E-mail do autor para correspondência: camposangelica128@yahoo.com.br

INTRODUÇÃO: A Lipofuscinose Ceróide Neuronal (CLN) constitui um grupo de doenças neurodegenerativas de herança autossômica recessiva caracterizadas pelo depósito anormal de uma substância autofluorescente de lipopigmentos. Três dos quatro principais subtipos dessa patologia são manifestados na primeira infância e comprometem o desenvolvimento motor e cognitivo da criança, sendo indispensável o acompanhamento multiprofissional. Portanto, pensar a interprofissionalidade no cuidado da Lipofuscinose Ceróide Neuronal configura uma oportuna estratégia para a melhoria da qualidade de vida dos pacientes. OBJETIVOS: Descrever como se dar a assistência multiprofissional no tratamento da Lipofuscinose Ceróide Neuronal em crianças. METODOLOGIA: Trata-se de uma revisão integrativa da literatura, com abordagem descritiva e exploratória nas bases de dados PubMed e Scielo. Como critérios de inclusão foram selecionados os estudos publicados em português, inglês e espanhol entre os anos de 2019 e 2021 que atendessem à temática, a partir da aplicação do operador booleano “AND” e dos descritores: Assistência Multiprofissional, Criança e Lipofuscinose Ceróide Neuronal. Assim, foram encontrados 16 artigos, e, ao excluir os que estavam repetidos e divergiam da proposta, três artigos responderam ao objetivo proposto. RESULTADOS E DISCUSSÃO: Baseado nos estudos analisados, obteve-se manifestações de variadas ordens decorrentes da atrofia cerebral e cerebelar causada pela doença, como deterioração intelectual, hipotonia, ataxia, convulsões mioclônicas, perda visual progressiva e desordens no andar e na fala, demandando intervenções diversas. CONCLUSÃO: O presente estudo elucidou a importância do conhecimento da variedade de sintomas da Lipofuscinose Ceróide Neuronal como medida para compreender e efetivar o tratamento da forma correta e garantir o bemestar das crianças. Tendo em vista as consequências da neurodegeneração, o atendimento multiprofissional é fundamental para minimizar as possíveis complicações que a doença possa 
causar, respeitando a dignidade e a autonomia do paciente mediante o gerenciamento das condições biopsicossociais do paciente, a discussão do prognóstico e o apoio à família.

Palavras-chave: Assistência Multiprofissional. Criança. Lipofuscinose Ceróide Neuronal.

\section{REFERÊNCIAS}

KOHLSCHÜTTER, A. et al. Current and Emerging Treatment Strategies for Neuronal Ceroid Lipofuscinoses. CNS Drugs, v 33, p. 315-325, 2019

NUNES, A. et al. A Case Report on the Challenging Diagnosis of Neuronal Ceroid Lipofuscinosis Type 2 (CLN2). J. inborn errors metab. screen, v 8, 2020

SPECCHIO, N. et al. Neuronal Ceroid Lipofuscinosis: Potential for Targeted Therapy. Drugs, v 81, n. 1, p. 101-123, 2021 


\section{A INTERVENÇÃO DA TERAPIA OCUPACIONAL NO DESENVOLVIMENTO DO RECÉM-NASCIDO PRÉ-TERMO}

Ana Paula Silva Santana1; Eryka Vaz Zagmignan²; Manoel Leonardo Tavares ${ }^{3}$; Nayara Melo ${ }^{4}$; Clarinda ${ }^{5}$

1,2,3,4 Graduando em Terapia Ocupacional pelo Centro Universitário UniFacid, Teresina, Piauí, Brasil.

${ }^{5}$ Terapeuta Ocupacional pelo Centro Universitário UniFacid, Teresina, Piauí, Brasil.

Área Temática: Multiprofissional.

E-mail do autor para correspondência: santanapaula9410@ gmail.com

INTRODUÇÃO: O bebê prematuro é aquele que nasce antes das 37 semanas, ou seja, prétermo, sendo que a maioria ocorre espontaneamente devido a complicações causadas por gravidez múltipla, infecções ou doenças crônicas. O baixo peso é um fator que preocupa, pois é um grande desafio conseguir fazer uma recuperação nutricional nos primeiros dias de vida. É neste sentido que a inserção do terapeuta ocupacional se caracteriza por não só buscar os aspectos curativos da criança, mas, cuidar das relações interpessoais e sociais. OBJETIVO: Revisar a literatura relacionada a intervenção da terapia ocupacional na atuação neonatal com pacientes pré-termos. METODOLOGIA: Este estudo de revisão bibliográfica realizou uma busca nas bases de dados: SciELO (Scientific Electronic Library of Medicine), revistas como a RevisbraTO (Interinstitutional Brazilian Journal of Occupational Therapy) e Cadernos Brasileiros de Terapia ocupacional, através das palavras-chaves: terapia ocupacional, neonatal e recém-nascido prematuro. Utilizou-se como critério de inclusão artigos com a temática em português que discorrem sobre a intervenção da terapia ocupacional no desenvolvimento do recém-nascido e como critério de exclusão optou-se por não utilizar textos incompletos e que não discorrem sobre a intervenção da terapia ocupacional. RESULTADOS E DISCUSSÃO: O Terapeuta ocupacional é um profissional fundamental na equipe multidisciplinar, ele está inserido dentro da equipe do método canguru com objetivo de buscar qualidade na atenção prestada à gestante, ao recém-nascido e à família, promovendo, a partir de uma abordagem humanizada, o contato pele a pele entre a mãe/pai e o bebê. Portanto, é de fundamental importância para o processo de desenvolvimento, atuando nas avaliações e orientações aos profissionais. O resultado dessas práticas auxilia no desenvolvimento precoce das crianças. CONCLUSÃO: Conforme a literatura, conclui-se que a atuação do terapeuta ocupacional na unidade neonatal é de suma importância na estimulação precoce dos bebês, na humanização 
do ambiente neonatal, no apoio adequado aos pais quanto a ansiedade e o vínculo com os bebês, através do favorecimento da percepção das capacidades dos mesmos, e das orientações quanto às condutas e posturas adequadas para o aleitamento materno.

Palavras-chaves: Terapia ocupacional. Neonatal. Recém-nascido prematuro.

\section{REFERÊNCIAS}

Morimoto S.Y.U, Dos Santos D.D.A, Leite V.M.M. Atuação do terapeuta ocupacional em uma unidade neonatal do Recife . Rev. Interinst. Bras. Ter. Ocup. Rio de Janeiro. 2020. v.4(1): 116-122. https://revistas.ufrj.br/index.php/ribto/article/viewFile/27972/pdf

JOAQUIM, R. H. V. T; SILVESTRINI, M. S; MARINI, B. P. R. Grupo de mães de bebês prematuros hospitalizados: experiência de intervenção de Terapia Ocupacional no contexto hospitalar. Cad. Ter. Ocup. UFSCar, São Carlos, v. 22, n. 1, p. 145-150, 2014.

http://dx.doi.org/10.4322/cto.2014.016

PERUZZOLO, D. L; ESTIVALET, K. M; MILDNER, A. R; DA SILVEIRA, M. C; Participação da Terapia Ocupacional na equipe do Programa de Seguimento de Prematuros Egressos de UTINs. Cad. Ter. Ocup. UFSCar, São Carlos, v. 22, n. 1, p. 151-161, 2014. http://dx.doi.org/10.4322/cto.2014.017

CORREIA, L. A; ROCHA, L. L. B; DITTZ, E. S; Contribuições do grupo de terapia ocupacional no nível de ansiedade das mães com recém-nascidos prematuros internados nas unidades de terapia intensiva neonatal. Cad. Bras. Ter. Ocup., São Carlos, v. 27, n. 3, p. 574583, 2019. https://doi.org/10.4322/2526-8910.ctoAO1694

PERUZZOLO, D. L; BARBOSA, D. M, DE SOUZA, A. P. R; Terapia Ocupacional e o tratamento de bebês em intervenção precoce a partir de uma Hipótese de Funcionamento Psicomotor: estudo de caso único Cad. Bras. Ter. Ocup., São Carlos, v. 26, n. 2, p. 409-421, 2018 https://doi.org/10.4322/2526-8910.ctoAO1155 


\section{ALTERAÇÕES NEUROLÓGICAS ASSOCIADAS A COVID-19: REVISÃO DE LITERATURA}

Ramires dos Santos Moraes ${ }^{1}$; Ávylon Luan Silva Lima²; Caroline Lago da Cruz³ ${ }^{3}$ Abimael de Carvalho ${ }^{4}$; Suzana Pereira Alves ${ }^{5}$; Janaina de Moraes Silva ${ }^{6}$.

${ }^{1,2,3}$ Graduando em Fisioterapia pelo Centro Universitário UniFacid, Teresina, Piauí, Brasil.

${ }^{4}$ Graduando em Fisioterapia pela Universidade Estadual do Piauí- UESPI, Teresina, Piauí, Brasil.

${ }^{5}$ Graduanda em Enfermagem pela Christus Faculdade do Piauí-CHRISFAPI, Piripiri, Piauí, Brasil.

${ }^{6}$ Fisioterapeuta. Universidade Estadual do Piauí, Teresina, Piauí, Brasil.

Área Temática: Outros

E-mail do autor para correspondência: ramiresmoraes16@gmail.com

INTRODUÇÃO: Sabe-se que o SARS-CoV-2 possui a capacidade de infectar diferentes células do corpo humano, destarte para as células do sistema nervoso central. Nesse sentido, estudos já comprovam a existência de sintomas neurológicos em pacientes com COVID-19, tais como anosmia, disgeusia, tontura e consciência prejudicada. OBJETIVO: Identificar, na literatura científica, as alterações neurológicas associadas a Covid-19. METODOLOGIA: Revisão de literatura, realizada nas bases de dados Lilacs, Medline e Scielo, no mês de maio de 2021. Utilizou-se os seguintes termos identificados no Decs: "Manifestações Neurológicas, Covid-19 e Sinais Clínicos" combinados por meio dos operadores booleanos "AND" e "OR". Incluiu-se produções científicas na modalidade artigo original, condizentes com o objetivo proposto, publicadas entre janeiro de 2020 a maio de 2021 nos idiomas inglês e português. Excluíram-se relatos de caso, revisões e estudos duplicados. Foram encontrados 28 estudos, contudo, após a adoção dos critérios de elegibilidade, sete foram incluídos. RESULTADOS E DISCUSSÃO: Os sintomas neurológicos encontrados nos estudos apresentam um certo de grau de equivalência, dentre os sintomas neurológicos leves destacam-se a cefaleia, anosmia, disgeusia, náuseas, irritabilidade e consciência prejudicada são relatados na grande maioria dos estudos analisados. Destaca-se também que a Covid-19 pode predispor a doenças cerebrovasculares agudas em pessoas com que apresentam algum tipo de comorbidades, tais como, Hipertensão Arterial Sistêmica (HAS) e/ou Diabetes Mellitus (DM). Nos estudos analisados, os pacientes apresentaram os sintomas neurológicos em média 3 a 4 dias após o início dos sintomas respiratórios, a paresia de hemiface, disartria, hemiparesia, perda do nível 
de consciência, hemipoestesia e ataxia são sintomas encontrados em menor frequência. CONSIDERAÇÕES FINAIS: Os achados comprovam a existência de alterações neurológicas associadas a Covid-19, sendo que estas variam conforme a gravidade da doença. Palavras-chave: Manifestações neurológicas. COVID-19. Sinais Clínicos.

\section{REFERÊNCIAS}

BRITO, D. B. L. A. et al. Achados neurológicos, alterações sensoriais da função olfativa, gustativa e auditiva em pacientes com Covid-19: uma revisão literária. Revista Eletrônica Acervo Saúde, Recife, Vol.Esp.46, e4174. Junho/julho 2020.

BRITO, W. G. F.; SILVA, J. P. D. O. Impactos neuropatológicos da COVID-19. Braz. J. Hea. Rev., Curitiba, v. 3, n. 3, p.4227-4235 may./jun. 2020.

GAMA, B. D. S.; CAVALCANTE, K. N. Pandemia do covid-19: acometimento neurológico e os impactos cerebrais. Braz. J. Hea. Rev. Curitiba, v. 3, n. 6, p.19000-19006. nov./dez. 2020.

NUNES, M. J. M. et al. Alterações Neurológicas associadas a Covid-19: uma Revisão Sistemática. Rev Neurocienc, Mossoró-RN, 2020;28:1-22 


\section{ASSISTÊNCIA DE ENFERMAGEM EM CUIDADOS AO RECÉM NASCIDO PORTADOR DE ICTERÍCIA NEONATAL}

Angelica Ribeiro do Nascimento Oliveira ${ }^{1}$; Lucia Emanuele de Sousa Silva ${ }^{1}$; Leticia de Oliveira Nascimento ${ }^{1}$; Jaíres Emanuele Nunes de Sousa ${ }^{1}$; Caroline Taiane Santos da Silvar ${ }^{2}$

${ }^{1}$ Graduanda em enfermagem pelo Centro Universitário Mauricio de Nassau, Teresina, Piauí, Brasil.

${ }^{2}$ Enfermeira graduada pela Universidade Salvador (UNIFACS), Salvador, Bahia, Brasil. Aréa Temática: Multiprofissional.

E-mail do autor para correspondência: angelicalribeiro.ar19@gmail.com

INTRODUÇAO: O termo icterícia corresponde à alteração da pigmentação amarelada da pele e mucosas, em consequência do acréscimo acumulado de bilirrubina, sendo bastante comum em recém-nascidos, atinge cerca de $25-70 \%$ dos $\mathrm{RN}$ de termo. O médico pediatra faz o diagnóstico da patologia, e o enfermeiro é responsável pelos cuidados de enfermagem ao RN portador de Icterícia Neonatal, devendo atuar com humanização durante todo o processo assistido pelo mesmo. OBJETIVOS: Identificar os cuidados na assistência de enfermagem ao RN portador de Icterícia Neonatal disponíveis na literatura científica. METODOLOGIA: Trata-se de uma revisão bibliográfica Integrativa da literatura, com abordagem qualitativa. A seleção e obtenção dos artigos foi realizada através das bases de dados Scientific Eletronic Library Online (SCIELO) e National Library Of Medice (MEDLINE), com os descritores: "Assistência de enfermagem", "recém-nascido", "icterícia neonatal". Obteve-se como achados 127 artigos. Foram incluídos estudos completos, gratuitos, nos idiomas português e inglês publicados entre os anos de 2016 a 2021. Em contrapartida, foram excluídos os manuscritos que estavam em desacordo com a temática proposta e repetidos nas bases de dados. Após aplicação dos critérios de inclusão e exclusão foram selecionados 10 estudos para análise. RESULTADOS E DISCUSSAO: O cuidado do enfermeiro começa na detecção e diagnostico precoce da ictericia neonatal do RN, apos o diagnostico a assistencia continua durante o tratamento. $\mathrm{O}$ tratamento mais utilizado é a fototerapia, por ser um metodo não invasivo, no entanto e necessario alguns cuidados como distância adequada da lâmpada e proteção da radiação do equipamento; proteção ocular; cuidado com a pele, olhos e principalmente, à temperatura e eliminações intestinais, sendo necessario realização de balanço hidrico, visando futuras complicações, observa-se apos a fototerapia não deve-se aplicar óleos e pomadas para evitar a queimadura da pele. CONSIDERAÇOES FINAIS: 
Percebeu-se, que a icterícia neonatal é uma patologia frequente, mas requer muitos cuidados, e o enfermeiro tem um papel de suma importância no tratamento e na orientação quanto aos cuidados inerentes ao neonato. Desta forma, é essencial que o enfermeiro tenha conhecimento da patologia, tratamento e possiveis complicações, garantindo a segurança e proteção dos recem nascidos.

Palavras-chave: Assistência de enfermagem, Recém-nascido, Icterícia neonatal.

\section{REFERENCIAS BIBLIOGRÁFICAS:}

CARVALHO, F. T. S.; ALMEIDA, M. V. Icterícia neonatal e os cuidados de enfermagem: relato de caso. Revista health residencies jornal v. 1 n. 8, 2020.

GUTIERREZ, N. S. Assistência de enfermagem em cuidados com neonatos portadores de icterícia: revisão integrativa. Revista Científica Multidisciplinar Núcleo do Conhecimento. Ano 04, Ed. 01, Vol. 07, pp. 130-152, 2019.

SILVA, A. M. N.; PALUMBO, I. C. B.; ALMADA, C. B. Conhecimento da equipe de enfermagem sobre fototerapia no setor de alojamento conjunto de um hospital escola da zona norte de Sp. J Health Sci Inst. v. 37 n. 3 p. 213-17, 2019. 


\section{ASSISTÊNCIA DE ENFERMAGEM NO CONTROLE DE INFECÇÕES HOSPITALARES EM UNIDADE DE TERAPIA INTENSIVA NEONATAL}

Maria Dhescyca Ingrid Silva Arruda ${ }^{1}$; Rosa Vitória Silva de Pinho²; Fernanda Beatriz Freitas dos Santos ${ }^{3}$; Lainnys da Silva Ribeiro ${ }^{4}$; Caroline Taiane Santos da Silva ${ }^{5}$, Vitória Vilas Boas Silva Bomfim 6

${ }^{1}$ Graduanda em Enfermagem pela Faculdade São Francisco da Paraíba (FASP), Cajazeiras, Paraíba, Brasil; 2, 39raduanda em Enfermagem pela Universidade Salvador (UNIFACS), Salvador, Bahia, Brasil;

${ }^{4}$ Graduanda em Enfermagem pela Universidade Veiga de Almeida- UVA, Rio de Janeiro, Rio de Janeiro, Brasil;

${ }^{5}$ Enfermeira. Graduada pela Universidade Salvador (UNIFACS). Salvador, Bahia, Brasil;

${ }^{6}$ Enfermeira. Graduada pelo Centro Universitário Jorge Amado (UNIJORGE). Salvador, Bahia, Brasil.

Área Temática: Neonatologia.

E-mail do autor para correspondência: dhescycaingrid20@gmail.com

INTRODUÇÃO: As Infecções Relacionadas à Assistência à Saúde (IRAS) nas Unidades de Terapia Intensiva Neonatal (UTIN) são aquelas adquiridas no período intraparto (origem materna e manifesta em 48 horas de vida), durante a hospitalização, ou 48 horas após a alta, com exceção das infecções transplacentárias. Devido à alta incidência de IRAS, no Brasil, estima-se que 3\% a 15\% dos pacientes hospitalizados desenvolvem Infecção Hospitalar (IH). Configura-se como importante causa de morbidade e mortalidade em recém-nascidos prematuros que permanecem por longos períodos de internação na UTIN. De acordo com o Ministério da Saúde, as infecções hospitalares são descritas como aquelas adquiridas após a admissão do paciente e que se manifestam durante a internação ou após a alta, quando puder ser relacionada com a internação ou a procedimentos hospitalares. A equipe de enfermagem encontra-se presente nos cuidados direto ao paciente, portanto devem trabalhar junto a Comissão de Controle de Infecção Hospitalar (CCIH), para detectar possíveis falhas a fim de melhorar a qualidade de vida do RN. OBJETIVO: Identificar como é realizada a assistência de enfermagem para o controle de infecção hospitalar em unidade de terapia intensiva neonatal. METODOLOGIA: Trata-se de uma revisão integrativa realizada a partir da base de dados Literatura Latino-Americana e do Caribe em Ciências da Saúde (LILACS), Bases de Dados em Enfermagem (BDENF), através dos Descritores em Ciências da Saúde (DeCS): 
"Infecção Hospitalar", "Enfermagem Neonatal”, “Unidades de Terapia Intensiva Neonatal”, "Cuidados de Enfermagem". Combinados pelos operadores booleanos "AND” e "OR".Como critérios de inclusão: estudos que contemplassem a temática, originais, disponíveis online, na íntegra, em português e inglês, publicados entre 2011 e 2021; e de exclusão: artigos repetidos nas bases de dados. Foram encontrados na literatura científica 103 estudos que abordam a temática. Após a aplicabilidade foram selecionados 9 artigos para compor a revisão. RESULTADOS E DISCUSSÃO: Após análise dos artigos foram encontradas as seguintes categorias analíticas: lavagem das mãos, foi a categoria mais abordada nos estudos que evidenciam que isso está associado há uma grande prevalência dos casos de internação hospitalar entre os neonatos, isso ocorre devido a existência de microrganismos que são resistentes e acontece devido a não realização da lavagem das mãos. Prematuridade como fator de risco devido às fragilidades apresentadas pelo neonato pois muitas vezes são portadores de cardiopatias, problemas imunológicos e malformações que são resultantes do menor número de consultas durante o pré-natal que dificulta o rastreamento dessas patologias e consequentemente o recém-nascido fica mais suscetível à adquirir uma infecção no âmbito hospitalar. Medidas utilizadas pela Enfermagem para controle dessas infecções envolvem a higienização correta dos aparelhos, equipamentos e cuidados assistenciais prestados ao bebê. CONSIDERAÇÕES FINAIS: A partir disso, percebe-se que deve haver a busca de estratégias e monitoramento das realizações da higienização correta das mãos, das incubadoras e isso seja repassado para os pais para que esses cuidados sejam tomadas e consequentemente a diminuição dessas infecções que irão possibilitar uma maior qualidade de vida e segurança ao recém-nascido no âmbito da unidade de terapia intensiva.

Palavras-chave: Infecção Hospitalar. Enfermagem Neonatal. Unidades de Terapia Intensiva Neonatal. Cuidados de Enfermagem.

\section{REFERÊNCIAS}

TOMAZ, Viviane de Sousa; CAMPOS NETO, Francisco Herculano; ALMEIDA, Paulo César de; et al. Medidas de prevenção e controle de infecções neonatais: opinião da equipe de enfermagem. Rev. RENE, p. 271-278, 2011.

VELÁSQUEZ, Carlos; SANTILLÁN, Marta; MENDOZA, Elina; et al. Sepsis neonatal por Chryseobacterium meningosepticum. Revista Peruana de Medicina Experimental y Salud Publica, v. 25, n. 4, pág. 439-441, 2008.

Redução do risco de infecção no berçário de terapia intensiva: uma revisão das práticas de cuidado ao paciente que impactam o risco de infecção no atendimento global de neonatos hospitalizados. J Perinat Neonatal Nurs , p. E2 - E2, 2016 


\section{ASSOCIAÇÃO ENTRE TRIAGEM DE RISCO NUTRICIONAL (STRONGKIDS) E INDICADORES ANTROPOMÉTRICOS DE PACIENTES PEDIÁTRICOS COM PARALISIA CEREBRAL}

Marília de Fátima Viana Alves ${ }^{1}$; Fernanda Pereira de Castro ${ }^{1}$; Tatiana Abreu Barros ${ }^{1}$, Bruna de Melo Silva ${ }^{1}$; Juliana Moreira da Silva Cruvel $^{2}$

${ }^{1}$ Residente do Hospital Universitário da Universidade Federal do Maranhão (HUUFMA)

${ }^{2}$ Nutricionista do HUUFMA, Mestra em Saúde Coletiva do PGSC-UFMA, São Luís, Maranhão.

Área Temática: Nutrição

E-mail do autor para correspondência: vianafatyma@gmail.com

INTRODUÇÃO: Crianças com paralisia cerebral (PC) são reconhecidas como pacientes de risco para desnutrição. Para prevenir a desnutrição, principalmente a intra-hospitalar, o risco nutricional deve ser identificado precocemente, preferencialmente no momento da admissão, de forma que a intervenção nutricional adequada possa ser iniciada. OBJETIVO: Verificar a associação da triagem de risco nutricional realizada pelo STRONGkids com os indicadores antropométricos de crianças com PC. MATERIAIS E MÉTODOS: Estudo transversal, retrospectivo, realizado com 26 formulários de nutrição de pacientes internados em um hospital de referência do Maranhão, no período de 2017 a 2020. Foram analisados os diagnósticos de risco nutricional do STRONGkids cuja classificação é de acordo com o escore: baixo risco de desnutrição $=0$, moderado $=1$ a 3 , alto $=4$ a 5 . Os indicadores antropométricos analisados foram: o índice de massa corporal para idade (IMC/I) e a estatura para idade (E/I). A classificação foi por meio das curvas de crescimento da OMS (2006) em < 2 anos (ponto de corte escore- $Z<-2$ ) e as curvas Brooks et al. (2011) para > 2 anos (ponto de corte: percentil < 10). Para análise da associação foi aplicado o teste exato de Fisher devido a frequência esperada $<5$, com nível de significância adotado de 5\%. O trabalho foi aprovado pelo Comitê de Ética em Pesquisa do HUUFMA (parecer $n^{\circ}$. 4.240.637). RESULTADOS: Os pacientes apresentaram média de idade de 6,6 $\pm 4,0$ anos e 69,2\% (n=18) eram do sexo masculino. Passaram pela triagem nutricional em até 72 horas, 92,3\% $(n=24)$ dos pacientes. O STRONGkids identificou que 46,1\% (n=12) e 50,0\% (n=13) das crianças eram de risco nutricional, moderado e alto, respectivamente. Quanto à avaliação antropométrica, 34,6\% $(n=9)$ dos pacientes foram diagnosticados com desnutrição e 23,1\% (n=6) baixa E/I. Entre os classificados como desnutridos pelo IMC/I, 77,7\% (n=7) também foram classificados como 
de alto risco nutricional pelo STRONGkids com associação estatisticamente significante ( $\mathrm{p}=0,018)$. Não foi observada associação entre o indicador E/I e a triagem de risco nutricional. CONCLUSÃO: A classificação de risco nutricional realizada pelo STRONGkids associou-se com o indicador IMC/I. Porém, estudos que avaliem a validade do STRONGkids em pacientes com PC são necessários para aplicação na rotina hospitalar.

Palavras-chave: Paralisia Cerebral. Avaliação Nutricional. Triagem.

\section{REFERÊNCIAS}

CARAM, A. L. A. et al. Estado nutricional de crianças com paralisia cerebral. Rev. Nutr., Campinas, v. 23, n. 2, mar-abr. 2010.

HARTMAN, C. et al. Malnutrition screening tools for hospitalized children. Curr Opin Clin Nutr Metab Care., v. 15, p.303-9, 2012.

BROOKS, J. et al. Low weight, morbidity, and mortality in children with cerebral palsy: new clinical growth charts. Pediatrics, Elk Grove Village, v. 128, n. 2, p. 299-307, 2011. 


\section{COMPLICAÇÕES DA SEQUÊNCIA RÁPIDA PARA INTUBAÇÃO INTRATRAQUEAL EM UNIDADE DE TERAPIA INTENSIVA NEONATAL}

${ }^{1}$ Yasmin Maria Mello Lima; Maria Dhescyca Ingrid Silva Arruda; Jackeline Araújo da Silva Oliveira; ${ }^{4}$ Lívia Sayuri Félix Mendes; ${ }^{5}$ Mariana Silva Souza; ${ }^{6}$ Vitória Vilas Boas da Silva

Bomfim

${ }^{1,3}$ Universidade Salvador (UNIFACS). Salvador, Bahia, Brasil.

2 Faculdade São Francisco da Paraíba, Cajazeiras, Paraíba, Brasil.

${ }^{4}$ Graduanda em Fisioterapia, Centro Universitário INTA, Sobral, Ceará, Brasil.

${ }^{5}$ Graduanda em Enfermagem, Christus Faculdade do Piauí, Piauí, Brasil.

${ }^{6}$ Centro Universitário Jorge Amado (UNIJORGE). Salvador, Bahia, Brasil.

Área Temática: Neonatologia

E-mail para correspondência: yasminmellohy@gmail.com

INTRODUÇÃO: A sequência rápida de intubação intratraqueal (SRI) é definida como um procedimento utilizado frequentemente na Unidade de Terapia Intensiva Neonatal (UTIN), que deve ser manuseado por profissionais capacitados e exige o uso de agentes farmacológicos que possam auxiliar na redução da dor e desconforto causado, o bloqueador neuromuscular irá atuar diretamente para facilitar a realização da intubação. OBJETIVO: Descrever as complicações em decorrência da sequência rápida de intubação intratraqueal na unidade de terapia intensiva neonatal. METODOLOGIA: Trata-se de uma revisão integrativa da literatura realizada através das bases de dados Literatura Latino-Americana e do Caribe em Ciências da Saúde (LILACS), Banco de Dados em Enfermagem (BDENF) e Medical Literature Analysis and Retrieval System Online (MEDLINE), através dos seguintes Descritores em Ciências da Saúde (DeCS): "Intubação Intratraqueal”, "Unidade de Terapia Intensiva" e "Recém-Nascido". Combinados entre si pelo operador booleano AND. Como critérios de inclusão: artigos disponíveis na íntegra, nos idiomas português, espanhol e inglês, que abordassem a temática, nos últimos cinco anos. Como critérios de exclusão: artigos que não contemplavam o tema e estudos repetidos nas bases de dados. A partir da busca inicial com os descritores e operador booleano definidos, foram encontrados 18 estudos nas bases selecionadas e após aplicar os critérios de inclusão e exclusão, foram selecionados 7 estudos para compor a revisão. Adotou-se como pergunta norteadora: "Quais são as principais complicações ocasionadas pela sequência rápida de intubação intratraqueal na unidade de terapia intensiva?" RESULTADOS E DISCUSSÃO: A literatura evidencia que as principais 
complicações durante a intubação no recém-nascido são risco de hipoxemia, parada cardiorrespiratória, trauma de vias aéreas e a presença de arritmias. A terapia farmacológica também interfere drasticamente durante a realização do procedimento, de modo que, algumas medicações podem causar uma rigidez torácica que irá comprometer a realização da intubação. Essas intercorrências muitas vezes são ocasionadas pelo manejo inadequado da intubação e da sequência de intubação rápida (SRI), já que são utilizadas justamente em ocorrências de insuficiência respiratória, obstrução de vias aéreas inferiores dentre outros cenários que serão necessárias intervenções para reverter. E consequentemente interfere significativamente na qualidade de vida do Neonato devido que ocasiona pioras no quadro clínico e a inclusão de novos procedimentos com a finalidade de garantir uma instabilidade no quadro clínico. CONCLUSÃO: Diante disso, percebe-se que para haver a redução dessas complicações os profissionais envolvidos na assistência prestada ao neonato devem buscar estratégias que possibilitem a ampliação do planejamento para realização da intubação, tais como, anamnese e exame físico minucioso, avaliação do quadro clínico do recém-nascido pois alguns possuem malformações e isso pode ser um fator de risco há mais e o monitoramento da realização da sequência de intubação rápida para que haja uma maior complexidade que vise a redução dessas complicações e posteriormente o fornecimento de uma qualidade de vida e assistência humanizada.

Palavras-chave: Intubação Intratraqueal; Complicações; Recém-Nascido

\section{REFERÊNCIAS}

MARTINS, Karina Camargos; OLIVEIRA, Adrianne Mary Leao Sette e; FERREIRA, Alexandre Rodrigues. Sequência rápida de intubação: uma abordagem prática para o pediatra em situações de urgência. v. 23, n. 2, pág. 213-220,.

DANSKI, Mitzy Tannia Reichembach; MINGORANCE, Priscila; JOHANN, Derdried Athanasio; et al . Incidência de complicações locais e fatores de risco associados ao cateter intravenoso periférico em neonatos. Rev. Esc. Enferm. USP , p. 22-28, 2016.

MEDEIROS, Flávio do Valle Andrade; ALVES, Valdecyr Herdy; VALETE, Cristina Ortiz Sobrinho; et al . Procedimentos invasivos e sepse in recém-nascidos de muito baixo peso: estudo descritivo. Braz online j. Nurs. (Online) , p. 704-712, 2016. 


\section{CRIAÇÃO E IMPLANTAÇÃO DE UMA PLANILHA ELETRÔNICA PARA GESTÃO EM LACTÁRIO SOBRE O RECEBIMENTO E DISPENSAÇÃO DE LEITE MATERNO ORDENHADO}

Taelyson Costa de Medeiros ${ }^{1}$; Thalita Oliveira de Melo ${ }^{1}$; Sabrina Mércia Belarmino Gomes ${ }^{1}$; Mateus Fernandes da Silva ${ }^{1}$; Jaielison Yandro Pereira da Silva ${ }^{2}$

${ }^{1}$ Graduandos em Nutrição pelo Centro de Educação e Saúde da Universidade Federal de Campina Grande, Cuité, Paraíba, Brasil.

${ }^{2}$ Nutricionista e Pós-graduado em Assistência à Saúde Materno-Infantil pelo Programa de Residência Multiprofissional da Universidade Federal do Rio Grande do Norte, Santa Cruz, Rio Grande do Norte, Brasil.

Área Temática: Nutrição.

E-mail: taelysoncosta@ hotmail.com

INTRODUÇÃO: A adequada alimentação e nutrição torna-se indispensável para recuperação da saúde de bebês prematuros, destacando-se assim, o leite materno. No âmbito de uma unidade de cuidados intensivos e semi-intensivos neonatais as mães são encorajadas a realizarem a auto-ordenha de leite materno o qual pode ser ofertado em um momento posterior desde que seja mantido em condições adequadas. Uma das alternativas é armazenar sob refrigeração no lactário. Logo, as lactaristas devem realizar o registro de recebimento e dispensação desse leite, sendo em muitos casos realizado de forma manuscrita. OBJETIVOS: Diante disso, objetivou-se descrever o processo de criação e implantação de uma planilha eletrônica para gestão em lactário sobre o recebimento e dispensação de leite materno ordenhado. METODOLOGIA: Tratou-se de um estudo descritivo, do tipo relato de experiência vivenciada no processo de criação e implantação de uma ferramenta eletrônica para controle dietético do lactário de um hospital universitário no interior do Rio Grande do Norte. Utilizou-se o Microsoft Excel® para criação da planilha a qual foi toda operacionalizada por meio do uso de determinadas fórmulas e funções do próprio software. Ao final de cada mês foi possível obter um panorama geral sobre as frequências e volumes recebidos e distribuídos de leite materno ordenhado. Realizou-se um treinamento teórico com as lactaristas para o adequado uso da planilha, sendo implantada logo após. RESULTADOS E DISCUSSÃO: Mudanças de rotina, assim como, implantação de novas ferramentas pode ser eficazes para a melhoria do serviço desde que bem planejadas. A planilha otimizou o serviço das lactaristas, além de contribuir também para a gestão hospitalar por meio de um 
panorama geral dos registros, auxiliando também, na segurança do paciente. A tecnologia está cada vez mais presentes nos serviços de saúde sendo uma peça fundamental para aprimorar registros e dados, melhorando assim, o controle de documentos e arquivos. CONSIDERAÇÕES FINAIS: Portanto, observou-se que a criação e implantação da ferramenta promoveu benefícios tanto em nível assistencial quanto administrativo, por meio da melhora da qualidade do serviço prestado.

Palavras-chave: Prematuro. Recém-nascido. Registro eletrônico de Saúde.

\section{REFERÊNCIAS}

BRASIL. Ministério da Saúde (BR). Portaria Nº 930, de 10 de maio de 2012. Define as diretrizes e objetivos para a organização da atenção integral e humanizada ao recém-nascido grave ou potencialmente grave e os critérios de classificação e habilitação de leitos de Unidade Neonatal no âmbito do Sistema Único de Saúde (SUS). Diário Oficial da União, Brasília (DF), 2012.

CORDEIRO, T. L. R. et al. Prontuário eletrônico como ferramenta pra a sistematização da assistência de enfermagem no serviço de urgência/emergência: percepção dos enfermeiros. Revista Espaço para a Saúde, Curitiba. p. 29-41, 2019. Disponível em: https://docs.bvsalud.org/biblioref/2019/12/1046407/3revisado-rev-esp-para-a-saude-6481315-1-ed.pdf. Acesso: 02 jun. 2021.

PIOVACARI, S. M. F.; FIGUEIRA, V. A. C. R.; POTENZA, A. L. S. Segurança alimentar: Lactário. Einstein Educação Continuada em Saúde, [s. l.], v. 7, n. 4, p. 216-218, 2009. Disponível em: http://apps.einstein.br/revista/arquivos/PDF/1511-EC_v7n4p216-8.pdf. Acesso: 19 maio 2021.

SILVA, J. Y. P.; EUFRÁSIO, R. M.; AMORIM, N.C. M.; VIERA, V. B. Aprimoramento de planilha eletrônica para requisição de gêneros perecíveis: uma contribuição para o serviço de uma unidade de alimentação e nutrição. In: ONE, G. M. C. Nutrição interativa. João Pessoa: IMEA, 2019. 1268 p. Cap. 13. 


\section{EFEITOS DA FISIOTERAPIA OCULAR NO RECÉM - NASCIDO PREMATURO}

Caroline Lago da Cruz ${ }^{1}$; Keylane Kelle Pereira Mendes ${ }^{2}$; Thayson Brito Leal ${ }^{3}$; Fernanda Santana Nunes $^{4}$; Ramires dos Santos Moraes ${ }^{5}$; Ana Flávia Machado de Carvalho ${ }^{6}$

1,2,3,4,5 Graduanda em Fisioterapia pelo Centro Universitário Unifacid, Teresina, Piauí, Brasil.

${ }^{6}$ Fisioterapeuta. Doutora em Engenharia Biomédica pela Universidade do Vale do Paraíba Univap, São Jose dos Campos, São Paulo, Brasil.

Área Temática: Multiprofissional.

E-mail do autor para correspondência: lago.caroline16@gmail.com.

INTRODUÇÃO: A Fisioterapia ocular atua na motilidade ocular avaliando e mensurando as alterações oculomotoras, e através de exercícios melhoram a função ocular. A visão tem grande importância no desenvolvimento da criança. Ao nascer, podem sofrer mudanças pela prematuridade das estruturas do cérebro responsáveis pela visão e retinianas associadas aos movimentos oculares. A estimulação visual com um conjunto de processos que trabalham a capacidade e perceptiva visual, aplicada nos primeiros meses de vida promove resultados que auxiliam no desenvolvimento neuropsicomotor. OBJETIVO: Descrever a importância da fisioterapia ocular e os efeitos da estimulação visual no recém-nascido prematuro. METODOLOGIA: Trata-se de uma revisão integrativa da literatura realizado em maio de 2021 nos portais e bases de dados SciELO, Pubmed, LILACS e Google Scholar, utilizando os descritores em saúde "eye physiotherapy", "visual stimulation" e "infant newborn", sendo incluídos os artigos publicados nos últimos 5 anos, em português e inglês, com títulos e resumos relacionados com a temática e delineamento de informações para a presente revisão. RESULTADOS E DISCUSSÃO: De 265 artigos encontrados apenas 5 entraram neste estudo. As crianças prematuras são mais susceptíveis a desenvolver alterações oculares como o estrabismo, retinopatia da prematuridade, alterações refratárias por alterações neurológicas, toxidade pela luz e falta de estímulo sensório-visual nas primeiras semanas de vida. Não as estimular desde o nascimento pode contribuir para um atraso no desenvolvimento psicomotor, sensorial e até social. A Fisioterapia Ocular através da estimulação visual com uma série de exercícios visuais e corporais, traz benefícios como o despertar da consciência visual e o desenvolvimento global da criança. Repercutindo na melhoria da coordenação visual e controle postural, aumentando a acuidade visual, estimulando as vias condutoras da visão e minimizando os efeitos da visão subnormal, beneficiando a interação da criança com o meio de aprendizagem aumentando consequentemente a sua qualidade de vida. CONCLUSÃO: A fisioterapia ocular 
assume um papel importante dentro da reabilitação visual, quando aplicada precoce, se torna fundamental no tratamento e prevenção dos distúrbios visuais e complicações associadas a primeira infância.

Palavras-Chaves: Fisioterapia; Estimulação Visual; Recém-Nascido Prematuro.

\section{REFERÊNCIAS:}

ARAÚJO, M. C., Comportamento visual e o desenvolvimento motor de crianças prematuras. Monografia (Graduação) - Curso de Bacharelado em Terapia Ocupacional - Universidade Federal da Paraíba, João Pessoa, 2018. Disponível em:

https://repositorio.ufpb.br/jspui/handle/123456789/12175. Acesso em: 16 de maio de 2021.

FERREIRA, K. S.; SILVA, J. P.; MACIEL, D. M. V. L., Estratégias de intervenção precoce em recém-nascidos prematuros na Unidade de Terapia Intensiva Neonatal: uma revisão de literatura. Scire Salutis: Anais do Fórum Perinatal de Obstetrícia, 2018. v. 8, n. 2. Disponível em: https://sustenere.co/index.php/sciresalutis/article/view/CBPC2236-9600.2018.002.0007. Acesso em: 16 de maio de 2021.

FONTINELE, A. G. M. et al., Reabilitação Oculomotora: novos desafios na prática clínica fisioterapêutica. Anais do III CIPEEX - Ciência para a redução das desigualdades, 2018. v. 2. Disponível em: http://anais.unievangelica.edu.br/index.php/CIPEEX/article/view/2947. Acesso em 16 de maio de 2021.

SOUSA, A. T. S. et al. The effect of visual stimulation in children with down syndrome. Research, Society and Development, [S. 1.], v. 9, n. 12, p. e39091210558, 2020. DOI: 10.33448/rsdv9i12.10558. Disponível em: https://rsdjournal.org/index.php/rsd/article/view/10558. Acesso em: 16 de maio de 2021.

TACCA, J.; FERREIRA, D. G.; FAGUNDES, S. L, Práticas fisioterapêuticas na acuidade visual com ênfase na miopia e no astigmatismo. Fisioterapia Brasil, 2020. v. 21 n. 1. INSS 2526-9747. Disponível em:

https://portalatlanticaeditora.com.br/index.php/fisioterapiabrasil/article/view/3263. Acesso em: 16 de maio de 2021. 


\section{EFEITOS DA REDE DE POSICIONAMENTO EM RECÉM-NASCIDOS PREMATUROS: UMA REVISÃO INTEGRATIVA}

Thayson Brito Leal ${ }^{1}$; Fernanda Santana Nunes ${ }^{2}$; Ramires dos Santos Moraes ${ }^{3}$; Caroline Lago da Cruz ${ }^{4}$; Keylane Kelle Pereira Mendes ${ }^{5}$; Cristina Cardoso da Silva ${ }^{6}$.

1,2,3,4,5 Graduando em Fisioterapia pelo Centro Universitário UniFacid, Teresina, Piauí, Brasil.

${ }^{6}$ Fisioterapeuta. Mestre em Ciências e Saúde pela Universidade Federal do Piauí - UFPI, Teresina, Piauí, Brasil.

Área Temática: Seguimento do recém-nascido.

Email do autor: thayson.leal10@gmail.com

INTRODUÇÃO: A Rede de posicionamento ou posicionamento de Hammock é um método simples para posicionamento terapêutico do recém-nascido pré-termo (RNPT) na unidade de terapia intensiva neonatal (UTIN) que simula a posição intrauterina e contribui para o desenvolvimento neurocomportamental e muscular do prematuro. OBJETIVOS: Avaliar a eficácia da rede de posicionamento na assistência ao RNPT. METODOLOGIA: Trata-se de uma revisão integrativa da literatura, com busca nas bases de dados Scielo, Lilacs e Pubmed. A pesquisa foi realizada no período entre março e abril de 2021 utilizando os descritores: posicionamento do paciente, recém-nascido prematuro e Unidade de terapia intensiva neonatal, nas línguas inglesa e portuguesa relacionado por meio do operador booleano "and", os artigos selecionados foram do ano de 2016 a 2021. Foram selecionados 9 artigos, dos quais apenas 5 contemplaram os critérios de inclusão. RESULTADOS E DISCUSSÃO: Os estudos mostraram que o posicionamento do RNPT na rede é uma intervenção simples, barata e uma medida eficaz no processo de humanização na UTIN trazendo benefícios como: melhora da dor, estado de sono-vigília, diminuição do nível de estresse, redução da frequência cardíaca, frequência respiratória, e saturação de oxigênio. Além de um melhor desenvolvimento motor e sensorial. CONCLUSÃO: A rede de posicionamento é um método eficaz e seguro que proporciona benefícios, e uma medida terapêutica não farmacológica para a humanização das UTIN.

PALAVRAS-CHAVES: Posicionamento do paciente. Recém-nascido prematuro. Unidade de Terapia Intensiva Neonatal.

\section{REFERÊNCIAS}


COSTA, K .S. F, et al. Hammock and nesting in preterm infants: randomized controlled trial. Revista Brasileira Enfermagem, v. 72, p. 96-102, 2019.

COSTA, K. S. F, et al. Rede de descanso e ninho: comparação entre efeitos fisiológicos e comportamentais em prematuros. Revista Gaúcha de Enfermagem, v. 37, p. 1-9, 2016.

JESUS, V. R, OLIVEIRA, P. M. N, AZEVEDO, V. M. G. O. Effects of hammock positioning in behavioral status, vital signs, and pain in preterms: a case series study. Brazilian Journal of Physical Therapy, v. 22, n. 4, p. 304-309, 2018. 
ESTADO NUTRICIONAL DE CRIANÇAS E ADOLESCENTES COM PARALISIA CEREBRAL ADMITIDAS EM UM HOSPITAL UNIVERSITÁRIO DO MARANHÃO

Marília de Fátima Viana Alves ${ }^{1}$; Fernanda Pereira de Castro ${ }^{1}$; Marluce Alves Coutinho ${ }^{2}$; Maria Milena Bezerra Sousa ${ }^{2}$; Juliana Moreira da Silva Cruvel ${ }^{3}$

${ }^{1}$ Residente do Hospital Universitário da Universidade Federal do Maranhão (HUUFMA)

${ }^{2}$ Nutricionista do HUUFMA, São Luís, Maranhão.

${ }^{3}$ Nutricionista do HUUFMA, Mestra em Saúde Coletiva do PGSC-UFMA, São Luís, Maranhão.

Área Temática: Nutrição

E-mail do autor para correspondência: vianafatyma@gmail.com

INTRODUÇÃO: As crianças portadoras de paralisia cerebral (PC) tendem a ser desnutridas e apresentarem déficit de crescimento. Diante disso, a avaliação do seu estado nutricional é fundamental para identificar aquelas desnutridas ou com risco de desnutrição, possibilitando assim, uma intervenção nutricional precoce e apropriada. OBJETIVO: Verificar o estado nutricional de crianças com PC admitidas em um hospital universitário do Maranhão. MATERIAIS E MÉTODOS: Estudo transversal, retrospectivo, realizado com pacientes com PC, que foram admitidos em um hospital universitário do Maranhão no período de 2017 a 2020. Foram utilizados dados secundários de uma planilha de Excel disponível pelo setor de nutrição clínica com informações referentes à idade, sexo, peso e estatura e classificação do estado nutricional a partir dos indicadores antropométricos: Índice de Massa Corporal para idade (IMC/I), Peso para Idade (P/I), Peso para Estatura (P/E) e Estatura para Idade (E/I). O estado nutricional foi avaliado através das curvas de crescimento da OMS (2006) para crianças menores de 2 anos e das curvas Brooks et al. (2011) para os maiores de 2 anos. A análise dos dados foi feita através do programa estatístico Stata. O trabalho foi aprovado pelo Comitê de Ética em Pesquisa do HUUFMA (parecer $n^{\circ}$. 4.240.637). RESULTADOS: Foram encontrados dados de 26 pacientes, a maioria do sexo masculino 69,2\% ( $n=18), 19,2 \%(n=5)$

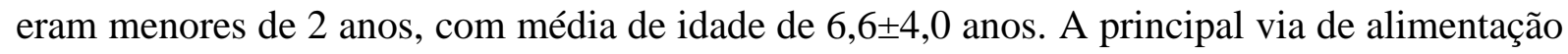
foi a oral, $65,4 \% \quad(n=17)$, seguido pela gastrostomia $34,6 \% \quad(n=9)$. Os indicadores antropométricos demonstraram que: segundo o IMC/I, 65,4\% das crianças apresentavam estado nutricional adequado e 34,6\% (n=9) desnutrição; quanto o P/I, 3,8\% (n=1), excesso de peso, 61,5\% (n=16), peso adequado e 34,6\% (n=9), desnutrição; P/E, 60\% $(n=3)$ das crianças menores de 2 anos estavam desnutridas e $40 \%(n=2)$, peso adequado; conforme a $E / I, 76,9 \%$ 
$(\mathrm{n}=20)$ apresentavam estatura adequada e 23,1\% (n=6) baixa estatura. CONCLUSÃO: Apesar de haver maior proporção de pacientes com via oral de alimentação e com estado nutricional adequado, observou-se um alto percentual de criança fora dos níveis de adequação. A PC pode predispor a criança e o adolescente a uma série de complicações alimentares e de saúde, interferindo, assim, em uma nutrição adequada.

Palavras-chave: Estado Nutricional. Criança. Paralisia Cerebral.

\section{REFERÊNCIAS:}

BROOKS, J. et al. Low Weight, Morbidity, and Mortality in Children With Cerebral Palsy: New Clinical Growth Charts. Pediatrics, Elk Grove Village, v. 128, n.2, p 299-307, 2011.

HOLANDA, L.S. Consumo alimentar, avaliação do peso e da composição corporal: um estudo em crianças com paralisia cerebral. Dissertação (Mestrado em saúde da criança e do adolescente) - Universidade Federal de Pernambuco. Recife, 2017.

SOUSA, K.T. et al. Avaliação do estado nutricional e frequência da complicações associadas à alimentação em pacientes com paralisia cerebral tetraparética espástica. Rev.Paul.Pediatri. São Paulo, v.38, p. 1-9, 2020. 


\section{FATORES DE RISCO ASSOCIADOS À SEPSE NEONATAL EM UNIDADES DE TERAPIA INTENSIVA: UMA REVISÃO INTEGRATIVA}

Lívia Sayuri Félix Mendes ${ }^{1}$; José Marcos Fernandes Mascarenhas²; Maria Dhescyca Ingrid Silva Arruda ${ }^{3}$ J Jessica Maria Santos Dias ${ }^{4}$; Nerley Pacheco Mesquita ${ }^{5}$ Cleiciane Remigio Nunes ${ }^{6}$

${ }^{1}$ Graduanda em Fisioterapia pelo Centro Universitário INTA-UNINTA, Sobral, Ceará, Brasil.

${ }^{2}$ Graduando em Enfermagem pela Christus Faculdade do Piauí - CHRISFAPI, Piripiri, Piauí, Brasil.

${ }^{3}$ Graduanda em Enfermagem pela Faculdade São Francisco da Paraíba - FASP, Cajazeiras, Paraíba, Brasil.

${ }^{4}$ Graduanda em Fisioterapia pela Faculdade UNINASSAU - Teresina, Piauí, Brasil.

${ }^{5}$ Graduanda em Enfermagem pela Universidade Estadual do Piauí - UESPI, Picos, Piauí, Brasil.

${ }^{6}$ Enfermeira graduada pelo Centro Universitário Estácio de Sergipe e especialização em saúde coletiva pela Faculdade FAVENI, Aracaju, Sergipe, Brasil.

Área Temática: Outros.

E-mail do autor para correspondência: livya.mendessp@gmail.com

INTRODUÇÃO: A sepse neonatal é caracterizada por uma síndrome resultante de um quadro de infecção sistêmica que acomete recém-nascidos de até 28 dias de vida, especialmente os que necessitam de permanência nas Unidades de Terapia Intensiva Neonatal (UTIN). As manifestações clínicas incluem instabilidade da temperatura, taquipneia, convulsões, hipóxia, má perfusão e hipotonia, podendo acarretar diversas sequelas na criança. Apesar dos crescentes estudos na área, ainda há grande incidência de óbitos por sepse neonatal, relacionados principalmente à dificuldade em identificar e minimizar a exposição aos fatores de risco associados. OBJETIVO: Descrever os fatores de risco associados à sepse neonatal em Unidades de Terapia Intensiva. METODOLOGIA: Revisão integrativa de literatura realizada em maio de 2021, nas bases de dados LILACS, PUBMED e SciELO. Os descritores utilizados para busca foram: "sepse neonatal", "fatores de risco" e "unidade de terapia intensiva neonatal", combinados pelo operador booleano AND. Incluíram-se estudos dos últimos 5 anos (2016-2021), nos idiomas português e inglês, disponíveis gratuitamente na íntegra e excluiu-se estudos secundários e duplicados nas bases de dados. A amostra inicial foi de 80 estudos, dos quais 18 compuseram a amostra final. RESULTADOS E 
DISCUSSÃO: De acordo com os estudos observados, diversos fatores de risco podem estar associados à ocorrência de sepse neonatal em Unidades de Terapia Intensiva, como: prematuridade, baixo peso ao nascer, baixo índice de APGAR, presença de anomalias congênitas, transmissão vertical pela mãe com pouca profilaxia intraparto ou profilaxia incompleta, internação prolongada em UTIN, realização de procedimentos invasivos na UTIN, como cânula traqueal, cateter de longa permanência ou punções, que gerem infecções, e procedimentos de reanimação neonatal. CONCLUSÃO: A ocorrência de sepse neonatal na UTIN pode ser associada à exposição a diversos fatores de risco, sejam eles maternos, do próprio recém-nascido ou da permanência na UTIN, necessitando de intervenções multiprofissionais que garantam a qualidade dos cuidados e instalações de saúde para minimizar os fatores de risco evitáveis.

Palavras-chave: Sepse neonatal. Fatores de risco. Unidade de Terapia Intensiva Neonatal.

\section{REFERÊNCIAS}

JIANG, S.; YANG, C.; YANG, C.; YANG, W.; I ; SHAH, P. S.; LEE, S.K.; CAO, Y. Epidemiology and microbiology of late-onset sepsis among preterm infants in China, 20152018: A cohort study. Internacional Journal of infectious Diseases, v.96, n. 1, 2020.

PUOPOLO, K. M. Neonatal sepsis evaluation across the pond. Archives of Disease in Childhood, v.79, v.3, 2020.

SCHMATZ, M; SRINIVASAN, L.; GRUDMEIER, R. W.; ELCI, O. U.; WEISS, S.L.; MASINO, A. J.; TREMOGLIE, M.; OSTAPENKO, S.; HARRIS, M. C. Surviving Sepsis in a Referral Neonatal Intensive Care Unit: Association between Time to Antibiotic Administration and In-Hospital Outcomes. Journal of Pediatric, v.217, n.1, 2020. 


\section{FATORES PREDITORES DE LESÕES NA PELE DOS RECÉM-NASCIDOS INTERNADOS EM UNIDADE DE TERAPIA INTENSIVA: REVISÃO INTEGRATIVA}

Jandra Alves Lima ${ }^{1}$, Sarah Maria Osório de Carvalho ${ }^{2}$, Polyana Norberta Mendes ${ }^{3}$

${ }^{1,2}$ Graduanda em Enfermagem pelo Centro Universitario Santo Agostinho, Teresina, Piauí, Brasil.

${ }^{3}$ Enfermeira. Mestre em Enfermagem pela Universidade Federal do Piaui.

Aréa Temática: Multiprofissional

E-mail do autor para correspondência: jandra1997lima@ hotmail.com

INTRODUÇÃO: O cuidado com a pele dos recém-nascidos deve ser contínuo durante toda a sua internação na unidade de terapia intensiva, seja na forma direta ou indireta. Aproximadamente $80 \%$ da morbimortalidade dos neonatos está relacionada a traumas ou alterações na função normal da pele, em decorrência de sua imaturidade funcional, associada ao manejo inadequado dos profissionais. OBJETIVO: Identificar os fatores preditores de lesões na pele dos recém-nascidos internados em Unidade de Terapia Intensiva. METODOLOGIA: Revisão integrativa, realizada durante o mês de março de 2021. As buscas ocorreram nas bases de dados MEDLINE, LILACS, BDENF, via BVS, por meio do uso dos Descritores em ciências da Saúde (DECS) e os Medical Subject Headings (MESH): UTI Neonatal; Neonato; Ferimentos; Lesões; (Intensive Care Units Neonatal); (Infantil Newborn); (Wounds and Injuries); combinados através dos operadores booleanos OR e AND. Incluíram-se artigos nos idiomas português, inglês e espanhol, disponíveis na íntegra e publicados nos últimos 5 anos. Foram excluídos artigos duplicados e que não abordavam a temática de interesse. Inicialmente, identificaram-se 289 artigos e após a aplicação dos critérios de inclusão e exclusão resultaram 6 artigos para análise. RESULTADOS: Os estudos evidenciam que os fatores de risco para o surgimento de lesões na pele do neonato, estão relacionadas em sua maioria, pelas patologias, uma vez que ao se realizar a mudança de decúbito que a principal forma de prevenção pode ocorrer uma instabilidade hemodinâmica. Além dos múltiplos cateteres, feridas cirúrgicas, estomias, ventilação mecânica, medicações vasopressoras, entre outros, tais, dispositivos clínicos, suportes mecânicos não invasivos e invasivos, quando há o uso prolongado e incorreto destes, podem gerar o aparecimento de lesões na pele. CONCLUSÃO: Diante dos resultados obtidos nos estudos, pode-se observar a 
relevância de medidas preventivas para a proteção da pele dos recém-nascidos na unidade terapia intensiva. Além do mais, a necessidade de um planejamento que restabeleça a assistência aos mesmos, onde seja pautada na humanização, na integridade do cuidado e no acompanhamento intenso, para tal sugere-se que haja uma capacitação pra tais profissionais, em que vise substancialmente treiná-los sobre o manejo dos cateteres e drenos, para que assim a prevenção através da mudança de decúbito seja rotina na UTIN.

Palavras-chave/Descritores: UTI neonatal. Neonato. Ferimentos e lesões. Área Temática: Livre

\section{REFERÊNCIAS}

CHAVES, A. C. F. et al. Cuidados e manutenção da integridade da pele do neonato prematuro. Rev. De enfermagem UFPE. Recife, v. 13, n. 2, p. 378-384, 2019. Disponível em: https://periodicos.ufpe.br/revistas/revistaenfermagem/article/view/237974/32831. Acesso em: 10 de março de 2021.

CELL et al. Prevenção de úlcera de pressão em neonatos com ventilação mecânica não invasiva. Gerokomos. Barcelona,2020.

FARIA et al. Lesões cutâneas em neonato em terapia intensiva neonatal. Rev. Enfermagem global. Murcia, 2018. 


\section{FISIOTERAPIA EM CUIDADOS PALIATIVOS NA ONCOLOGIA PEDIATRICA: REVISÃO DE LITERATURA}

Keylane Kelle Pereira Mendes ${ }^{1}$; Caroline Lago da $\mathrm{Cruz}^{2}$; Fernanda Santana Nunes ${ }^{3}$, Thayson Brito Leal $^{4}$, Ramires dos Santos Moraes ${ }^{5}$, Juçara Gonçalves de Castro ${ }^{6}$.

${ }^{1,2,3,4,5}$ Graduando em Fisioterapia pelo Centro Universitário Unifacid, Teresina, Piauí, Brasil.

${ }^{6}$ Fisioterapeuta. Mestre em Engenharia Biomédica pela Universidade do Vale do Paraíba UNIVAP, São José dos Campos, São Paulo, Brasil.

Área Temática: Multiprofissional.

E-mail do autor para a correspondência: keylanekelle@ hotmail.com

INTRODUÇÃO: A Organização Mundial de Saúde define cuidados paliativos como uma terapêutica que previne e alivia o sofrimento, através da identificação e manejo correto da dor, estendendo seu cuidado para aspectos físicos, psicossociais, e espirituais do paciente e seus familiares, a partir de uma abordagem em equipe multiprofissional. A Fisioterapia tem o papel de suma importância em trazer benefícios na melhora e no manejo dos sintomas como a dor, fadiga, complicações osteomioarticulares, estresse psicofísico, e disfunções pulmonares e alterações neurológicas, oferecendo conforto e evitando complicações. OBJETIVOS: Conhecer a atuação da Fisioterapia no atendimento de pacientes oncológico pediátricos em cuidados paliativos, com ênfase nas técnicas mais adotadas e os principais benefícios. METODOLOGIA: Trata-se de uma revisão integrativa de literatura. Foi realizada busca nas bases de dados SciELO, Pubmed e Lilacs, através dos descritores em Ciências e Saúde: "Palliative Care", "Pediatrics", "Physical Therapy Specialty", "Neoplasms", sendo incluídos os artigos publicados de 2012 a 2021 e baseados na temática desta revisão, e excluídos os artigos referentes a oncologia em adultos. RESULTADOS E DISCUSSÃO: Foram identificados 50 artigos e após aplicação do critérios de exclusão, 5 foram incluídos nessa revisão. As técnicas e os recursos fisioterapêuticos como a cinesioterapia, eletroterapia, termoterapia, terapia manual, massagem e órtese podem ser utilizados sozinhos ou em associação com acupuntura, técnicas de relaxamento e respiração com o objetivo de melhora da qualidade de vida do paciente, assim como o alívio dos sintomas que os afligem, promovendo sua independência funcional. Que se mostrou benéfico para o alivio da dor. CONCLUSÃO: Os procedimentos de meios físicos, eletrotérmicos e ortopédicos pela fisioterapia mostram-se benefícios ao paciente, além de métodos de distração e relaxamento. Ainda não há um consenso sobre quais são os melhores recursos que se aplicam no alívio da 
dor em cuidados paliativos. É uma construção diária na atenção a estes pacientes. Vale ressaltar que há poucos estudos relacionados a atuação da fisioterapia em cuidados paliativos, principalmente em pacientes pediátricos, a atuação desses profissionais e de suma importância na reabilitação dessas crianças.

PALAVRAS CHAVES: Oncologia. Pediatria. Fisioterapia. Cuidados paliativos.

\section{REFERÊNCIAS:}

OLIVEIRA, R. A. (coord.). Cuidado Paliativo. Conselho Regional de Medicina do Estado de São Paulo (Cremesp). São Paulo: 2008. E-book. ISBN: 978-85-89656-15-3. Disponível: http://www.cremesp.org.br/library/modulos/publicacoes/pdf/livro_cuidado\%20paliativo.pdf. Acesso em: 27 de maio de 2021.

KUTNER J.S. M. et al. Massagem terapêutica versus simples toque para melhorar a dor e o humor em pacientes com câncer avançado: um estudo randomizado. Revista Latinoamericano de Enfermagem. 2008;149(6):369-79. Disponível em: https://pubmed.ncbi.nlm.nih.gov/18794556/. Acesso em 27 de maio de 2021.

SCHINZARI, N.; SANTOS, F. Assistência à criança em cuidados paliativos na produção científica brasileira. Revista Paulo Pediatria, v. 32, n. 1, p. 99-106, 2014. Disponível em: https://www.scielo.br/j/rpp/a/T94437kFYfLYKBkp65GbTBF/?lang=pt\&format=pdf. Acesso em: 27 de maio de 2021. 


\section{IMPORTÂNCIA DO ALEITAMENTO MATERNO NA ATUALIDADE E SEUS PRINCIPAIS DESAFIOS: UMA REVISÃO DE LITERATURA}

Sillegiandia Batista da Silva ${ }^{1}$, Mara Rúbia de Oliveira Bezerra²

${ }^{1}$ Graduando em Nutrição pelo Centro Universitário do Planalto de Araxá - UNIARAXÁ, Várzea Alegre, Ceará, Brasil

${ }^{2}$ Nutricionista. Mestranda em Nutrição pela Universidade Federal do Rio Grande do Norte UFRN, Natal, Rio Grande do Norte, Brasil

Área Temática: Aleitamento materno

E-mail do autor para correspondência: sillegiandiabatista10@gmail.com

INTRODUÇÃO: Os benefícios do aleitamento materno (AM) para a criança e a mãe são conhecidos e comprovados cientificamente. $\mathrm{O}$ valor nutricional, a proteção imunológica e o menor risco de contaminação contribuem para redução da morbimortalidade infantil. Dessa forma, as crianças amamentadas adoecem menos. Além disso, o AM também oferece inúmeros benefícios para as mães, como menor risco de câncer de mama, maior intervalo entre gestações e perda de peso. OBJETIVOS: Identificar as principais dificuldades enfrentadas na realização do AM ao recém-nascido na atualidade. METODOLOGIA: Tratase de uma revisão bibliográfica a partir da busca de artigos científicos utilizando três bases de dados: LILACS, SciELO e PubMed utilizando os seguintes descritores: aleitamento materno, recém-nascido e dificuldades. Para selecioná-los, os critérios de inclusão foram: artigos disponíveis online, na íntegra, publicados em português e inglês, no período de 2018 a 2021, pertinentes à temática. RESULTADOS E DISCUSSÃO: A Organização Mundial da Saúde (OMS) recomenda que o aleitamento materno seja exclusivo nos primeiros 6 meses de vida, e complementado por outros alimentos por 2 anos ou mais. Amamentar é um direito das mulheres e existem políticas sociais que protegem esse direito. Alguns estudos encontraram associação negativa entre o trabalho e o AM, referindo como principal causa a ausência de apoio à amamentação no local de trabalho. A participação em programas de apoio a amamentação, consultas com profissionais de saúde e apoio do companheiro foram intervenções importante para a continuação do AM. Já entre os fatores causadores do desmame precoce, destacam-se: volta ao trabalho ou ao estudo, trauma mamilar e dor, baixo nível de escolaridade da genitora, e o aumento da idade da criança. CONCLUSÃO: Dado o exposto, evidenciasse a importância do estímulo ao AM e as dificuldades que são encontradas 
pelos profissionais de saúde para repassar as informações corretas quanto a essa prática, pois, a maioria das mães precisam trabalhar fora e acabam interrompendo o aleitamento.

Palavras-chaves: Aleitamento Materno. Recém-Nascido. Dificuldade do aleitamento materno

FERREIRA, Hellen Lívia Oliveira Catunda et al. Fatores Associados à adesão ao aleitamento materno exclusivo. Ciencia \& saude coletiva, v. 23, p. 683-690, 2018.

LIMA, Ariana Passos Cavalcante; DA SILVA NASCIMENTO, Davi; MARTINS, Maísa Mônica Flores. A prática do aleitamento materno e os fatores que levam ao desmame precoce: uma revisão integrativa. Journal of Health \& Biological Sciences, v. 6, n. 2, p. 189-196, 2018.

CAMPOS, Paola Melo et al. Contato pele a pele e aleitamento materno de recém-nascidos em um hospital universitário. Revista Gaúcha de Enfermagem, v. 41, n. SPE, 2020.

NARDI, Adriana Lüdke et al. Impacto dos aspectos institucionais no aleitamento materno em mulheres trabalhadoras: uma revisão sistemática. Ciência \& Saúde Coletiva, v. 25, p. 1445$1462,2020$. 


\section{INTERVENÇÕES DE ENFERMAGEM NA SEPSE NEONATAL: DO DIAGNÓSTICO AO TRATAMENTO}

Maria Dhescyca Ingrid Silva Arruda ${ }^{1}$; João Felipe Tinto Silva²; Mariana Silva Souza ${ }^{3}$; José Mateus Bezerra da Graça ${ }^{4}$; Lívia Sayuri Félix Mendes ${ }^{5}$; Caroline Taiane Santos da Silva ${ }^{6}$

${ }^{1}$ Graduanda em Enfermagem, Faculdade São Francisco da Paraíba, Cajazeiras, Paraíba, Brasil. ${ }^{3}$ Graduanda em Enfermagem, Christus Faculdade do Piauí, Brasil.

${ }^{2}$ Graduando em Enfermagem, Centro Universitário de Ciências e Tecnologias do Maranhão, Caxias, Maranhão, Brasil.

${ }^{4}$ Graduando em Enfermagem, Centro Universitário de Patos, Patos, Paraíba, Brasil.

${ }^{5}$ Graduanda em Fisioterapia, Centro Universitário INTA, Sobral, Ceará, Brasil.

${ }^{6}$ Enfermeira graduada pela universidade Salvador Sócia Administrativa da EnfClinic- Clínica de Enfermagem.

Área temática: Multiprofissional

E-mail de Correspondência: dhescycaingrid20@gmail.com

INTRODUÇÃO: A sepse neonatal é uma infecção bacteriana no sangue do neonato e é uma patologia grave que é uma das causas importantes de morbimortalidade entre os recémnascidos. Pode se manifestar através de sinais inespecíficos e variados, tais como, diarréia, convulsões, icterícia, instabilidade na temperatura corporal, quadros de apneia e bradicardia. A enfermagem atua diretamente nos cuidados prestados a esses pacientes, de modo que visam reconhecer os sintomas iniciais para que seja dado um diagnóstico e tratamento correto para que seja aplicado às intervenções necessárias. OBJETIVO: Descrever as intervenções utilizadas pela equipe de enfermagem do diagnóstico ao tratamento. METODOLOGIA: Trata-se de uma revisão integrativa da literatura realizada através das bases de dados Scientific Electronic Library Online (SciELO), Literatura Latino-Americana e do Caribe em Ciências da Saúde (LILACS), Banco de Dados em Enfermagem (BDENF) e Medical Literature Analysis and Retrieval System Online (MEDLINE), através dos seguintes Descritores em Ciências da Saúde (DeSC): "Cuidados de Enfermagem”, "Enfermagem”, "Sepse Neonatal". Combinados entre si pelo operador booleano AND. Como critérios de inclusão: artigos disponíveis na íntegra, nos idiomas português, espanhol e inglês, que abordassem a temática, de 2016 a 2021. Como critérios de exclusão foram estudos repetidos nas bases de dados. RESULTADOS E DISCUSSÕES: A partir da busca inicial, foram encontrados 127 estudos nas bases selecionadas e após aplicar os critérios de inclusão e 
exclusão, foram selecionados 10 estudos para compor a revisão. A equipe de enfermagem atua na solicitação de exames laboratoriais como contagem de neutrófilos total e imaturo onde irá apresentar uma alteração após o surgimento dos sintomas, hemograma, proteína $\mathrm{C}$ reativa que auxilia no rastreamento dessa infecção bacteriana. $\mathrm{O}$ tratamento varia de acordo com a classificação da sepse, ou seja, fármacos como ampicilina é usado na precoce que irá ter uma eficácia maior no período e na tardia é antibioticoterapia que são voltados para infecções hospitalares que foram adquiridas, e neste caso são administrados vancomicina ou cefalosporinas e isso contribui para o fornecimento de uma maior qualidade de vida. As intervenções devem ser aplicadas logo no início dos sintomas para que seja realizado um rastreamento para fechar o diagnóstico, sendo assim, os achados clínicos e laboratoriais refletem significativamente no desfecho do quadro clínico. A literatura também evidencia que a permanência de neonatos no ambiente hospitalar é um fator de risco para o surgimento da sepse. CONSIDERAÇÕES FINAIS: Diante disso, conclui-se que a enfermagem é indispensável na assistência prestada à esses bebês e faz-se necessário a inclusão da participação dos familiares para que haja um amparo emocional. A equipe preocupa-se com a atenção humanizada com os parentes, tendo um cuidado integral e holístico para que haja uma comunicação sobre os procedimentos que serão realizados, medicamentos e condutas para que seja ofertado um ambiente agradável e acolhedor.

Palavras-chave: Adesão à Medicação; Cuidados de Enfermagem; Diagnóstico; Enfermagem; Recém-Nascido.

\section{REFERÊNCIAS}

RUBARTH, Lori Baas; CHRISTENSEN, Carla M.; RILEY, Cheryl. Bacterial sepsis in the neonate. Nurse Pract, p. 25-32, 2017.

OLIVEIRA, Cecília Olívia Paraguai de; SOUZA, Juliana Raquel Silva; MACHADO, Regimar Carla; et al . Fatores de risco para sepse neonatal em unidade de terapia: Estudo de evidência. Cogitare enferm , p. 01-09, 2016.

RUBARTH, Lori Baas; CHRISTENSEN, Carla M .; RILEY, Cheryl. Sepse bacteriana no recém-nascido. Enfermeira Prática , p. 25-32, 2017. 


\title{
KERNICTERUS: A IMPORTÂNCIA DE IDENTIFICAR PRECOCEMENTE A ICTERÍCIA GRA VE NO NEONATO COMO FORMA DE PREVENÇÃO
}

\author{
Allana Ribeiro Marquetti ${ }^{1}$; Maria Luiza Campos de Souza²
}

${ }^{1}$ Graduanda em Medicina pela Universidade Vila Velha - UVV, Vila Velha, Espírito Santo, Brasil.

${ }^{2}$ Graduada em Odontologia pela Universidade Vale do Rio Doce - UNIVALE, Governador Valadares, Minas Gerais, Brasil.

Área Temática: Seguimento do recém-nascido.

E-mail do autor para correspondência: allana.marquetti@gmail.com

INTRODUÇÃO: A icterícia fisiológica é uma manifestação clínica de cor amarelada em pele e mucosas, muito comum em neonatos. Esse sinal é causado pelo aumento de bilirrubina sérica total (TSB). Em níveis bem elevados, a bilirrubina pode provocar danos cerebrais com distúrbios neurológicos irreversíveis caracterizando o quadro de Kernicterus. A realização da triagem neonatal, pontuada nos fatores de risco para icterícia é um método eficiente capaz de diminuir a incidência de hiperbilirrubinemia grave. OBJETIVO: $O$ principal objetivo desse estudo é entender sobre a importância do reconhecimento precoce da icterícia grave como forma de prevenção do kernicterus. METODOLOGIA: Trata-se de uma revisão bibliográfica realizada através da base de dados MEDLINE. Os descritores "Kernicterus", "Jaundice" e "Bilirubin" foram obtidos através do Descritores em Ciências da Saúde. Os critérios de inclusão foram textos totalmente gratuitos, publicados nos últimos 10 anos, nas línguas portuguesa e inglesa, direcionados à recém-nascidos e à espécie humana. Foram excluídos textos que fugissem do tema, ou publicados antes de 2011. Inicialmente, 796 artigos foram encontrados, após critérios de inclusão e exclusão, 5 artigos foram escolhidos para compor o estudo. RESULTADOS E DISCUSSÃO: Neonatos que possuem aumento severo da TSB estão em risco de desenvolver Kernicterus, em que a bilirrubina se liga, primariamente, ao globo pálido, porém também ao hipocampo, aos corpos nucleares e subtálamo causando neurotoxicidade, a qual se manifesta como paralisia cerebral, convulsões, postura arqueada e perda auditiva neurossensorial de forma permanente. Assim, torna-se fundamental atentar para fatores contribuintes à elevação da TSB, como prematuridade, hematomas, a amamentação e realizar a quantificação da bilirrubina sérica total ou transcutânea em neonatos que apresentam icterícia. CONCLUSÃO: Dessa forma, deve-se preconizar a 
identificação da icterícia neonatal, efetuando o tratamento apropriado prevenindo um agravo do desenvolvimento para o Kernicterus.

Palavras-Chaves: Kernicterus. Icterícia. Bilirrubina.

\section{REFERÊNCIAS}

GEEST, B. Et al. Triagem e tratamento para reduzir a hiperbilirrubinemia grave em bebês na atenção primária (STARSHIP): um protocolo de ensaio randomizado controlado com agrupamento escalonado fatorial. BMJ Open. 2019 April 20; Disponível em: < https://bmjopen.bmj.com/content/9/4/e028270>.Acesso em 11 de maio 2021.

HANNEKE, Brits. Et al. A prevalência de icterícia neonatal e fatores de risco em neonatos saudáveis a termo no National District Hospital em Bloemfontein. African Journal of Primary Health Care \& Family Medicine. 2018 April 12; Disponível em: < https://phcfm.org/index.php/phcfm/article/view/1582/2455>. Acesso em 11 de maio 2021.

HANSEN, T, W; Prevenção de sequelas de neurodesenvolvimento da icterícia no recémnascido. Wiley Online Library, 2011 September; Disponível em:< https://onlinelibrary.wiley.com/doi/full/10.1111/j.1469-8749.2011.04059.x>. Acesso em 11 de maio 2021.

MUCHOWSKI, K; Avaliação e tratamento da hiperbilirrubinemia neonatal. American Family Physician, 2014 June 1; Disponível em: < https://www.aafp.org/afp/2014/0601/p873.html>. Acesso em 11 de maio 2021. 


\title{
LOCALIZAÇÃO E AVALIAÇÃO DE APLICATIVOS MÓVEIS SOBRE ALEITAMENTO MATERNO: ESTUDO PILOTO
}

\author{
Stephanie Ribeiro Silva ${ }^{1}$, Joice Carrilho Fernandes ${ }^{1}$, Camila de Castro Corrêa ${ }^{2}$
}

\author{
${ }^{1}$ Aluna da Universidade de Brasília - UnB \\ ${ }^{2}$ Professora doutora do Centro Universitário Planalto do Distrito Federal - UNIPLAN
}

\section{RESUMO:}

A internet tem possibilitado um acesso fácil, rápido e gratuito a informações, por meio de smartphones, tablets e computadores. Um meio de fornecer e otimizar o compartilhamento de conhecimentos da área da saúde é o uso de aplicativos móveis. O uso de aplicativos móveis na área de aleitamento materno é uma estratégia importante visando a disseminação de comportamentos mais favoráveis a esta prática, auxiliando na saúde materno-infantil. Desta forma, o presente estudo teve o objetivo de localizar aplicativos móveis disponíveis para smartphones no português brasileiro relacionados ao aleitamento materno. Foram realizadas duas buscas de aplicativos tanto para IOS disponibilizados na plataforma Apple Store e para Android contidos na plataforma Play Store, utilizando os termos "amamentação" e "aleitamento". Foram excluídos aplicativos em outros idiomas. Os critérios analisados foram avaliações e gratuidade. Os aplicativos foram localizados por duas juízas. Foram encontrados 63 aplicativos da Play Store e 42 na Apple Store na primeira e na segunda busca. Foram excluídos 9 aplicativos da Apple Store e 21 da Play Store. Na Apple Store, 36 aplicativos são gratuitos e 6 são pagos, um recebeu 1 estrela, cinco receberam 2 estrelas, seis receberam 3 estrelas, 16 receberam 4 estrelas, sete receberam 5 estrelas e sete não foram avaliados. $\mathrm{Na}$ Play Store, 40 aplicativos são gratuitos e 2 são pagos. Quatro aplicativos foram avaliados com 3 estrelas, 30 foram avaliados com 4 estrelas, quatro aplicativos receberam 5 estrelas e quatro aplicativos não tiveram avaliação. A continuidade deste estudo realizará a avaliação da qualidade técnica destes aplicativos. Sendo assim, pôde-se notar que existiram aplicativos móveis na temática do aleitamento materno para os dois tipos de smartphones, sendo a maioria de acesso gratuito e classificados como quatro ou cinco estrelas pela população em geral.

PALAVRAS-CHAVE: Amamentação, aplicativos móveis, aleitamento materno, avaliação, dispositivos móveis. 


\section{REFERÊNCIAS BIBLIOGRÁFICAS:}

DIAS, S. T. et al. Qual o papel da Atenção Primária à Saúde diante da pandemia provocada pela COVID-19?. Epidemiol. Serv. Saúde, 29, 2, 2020.

DINIZ, C. M. M. et al. Contribuições dos aplicativos móveis para a prática do aleitamento materno: revisão integrativa. Act Paul Enferm, 32, 5, set-out, 2019.

MANUAL DE TELESSAÚDE PARA ATENÇÃO BÁSICA / ATENÇÃO PRIMÁRIA À SAÚDE, 2012.

TENÓRIO L. C. F. R. M. et al. A Educação em Saúde através das novas tecnologias da informação e da comunicação: uma análise da (re) orientação de nativos digitais no ciberespaço. Rev Cient Interdisc., 1, 1, p. 179-92, jul-set, 2014. 


\section{OS BENEFÍCIOS DA INTERVENÇÃO FISIOTERAPÊUTICA PRECOCE EM RECÉM-NASCIDOS NO CONTEXTO DA UNIDADE DE TERAPIA INTENSIVA NEONATAL}

Ramires dos Santos Moraes ${ }^{1}$; Keylane Kelle Pereira Mendes²; Abmael de Carvalho ${ }^{3}$; Vivia Rhavena Pimentel Costa ${ }^{4}$; Suzana Pereira Alves ${ }^{5}$; Janaina de Moraes Silva ${ }^{6}$.

${ }^{1,2}$ Graduandos em Fisioterapia pelo Centro Universitário UniFacid, Teresina, Piauí, Brasil.

${ }^{3,4}$ Graduandos em Fisioterapia pela Universidade Estadual do Piauí- UESPI, Teresina, Piauí, Brasil.

${ }^{5}$ Graduanda em Enfermagem pela Christus Faculdade do Piauí-CHRISFAPI, Piripiri, Piauí, Brasil.

${ }^{6}$ Fisioterapeuta. Universidade Estadual do Piauí, Teresina, Piauí, Brasil.

Área Temática: Fisioterapia

E-mail do autor para correspondência: ramiresmoraes16@gmail.com

INTRODUÇÃO: A intervenção fisioterapêutica precoce tem como objetivo detectar, diminuir e se possível reverter o atraso no desenvolvimento neuropsicomotor e respiratório do prematuro, através de programas que ofereçam estímulos, facilitem conquistas de habilidades e promovam aprendizados sobre os padrões motores apropriados para os primeiros anos de vida. OBJETIVO: Investigar os benefícios da intervenção fisioterapêutica precoce em recém-nascidos inseridos em Unidade de Terapia Intensiva Neonatal. METODOLOGIA: Revisão de literatura, realizada nas bases de dados Lilacs, Medline e Scielo, no mês de junho de 2021. Utilizou-se os seguintes termos identificados no Decs: "Intervenção Precoce (Early intervention)", 'Fisioterapia (Physiotherapy)', e 'Unidade de Terapia Intensiva Neonatal (Intensive care units neonatal)", combinados com os operadores booleanos "AND" e "OR". Incluiu-se ensaios clínicos e relatos de casos clínicos, condizentes com o objetivo proposto, publicados nos últimos sete anos nos idiomas inglês e português. Excluíram-se revisões e artigos duplicados. RESULTADOS E DISCUSSÃO: Foram encontrados 98 artigos, contudo, após adoção dos critérios de elegibilidade, restaram 25 que tiveram seus resumos analisados, destes, 10 foram pré-selecionados e lidos na íntegra. Posteriormente, oito foram selecionados. O desenvolvimento neuropsicomotor é um aspecto importante para o desenvolvimento da criança, porém, o impacto do ambiente das UTIs neonatais gera preocupação quanto a esse desenvolvimento, pois o estresse, a dor, a estimulação sensorial inadequada e os procedimentos invasivos são rotinas neste período de internação, além da 
menor idade gestacional e peso que também interferem. Neste cenário, a assistência fisioterapêutica precoce é primordial para diminuir os riscos de sequelas neurofuncionais, auxiliar na organização corporal e adaptação extrauterina, otimizar padrões sensoriais, potencializar a neuroplasticidade cerebral, otimizar padrão respiratório, favorecer padrões posturais adequados ao desenvolvimento motor fisiológico, minimizar stress ambiental e prevenir deformidades e contraturas. Assim, instituir esse programa é uma estratégia viável para potencializar o desenvolvimento adequado desses recém-nascidos inseridos na UTIN. CONSIDERAÇÕES FINAIS: Através da intervenção fisioterapêutica precoce se pode promover um significativo resultado no desenvolvimento adequado de neonatos inseridos em Unidade de Terapia Intensiva Neonatal.

Palavras-chave: Intervenção Precoce. Fisioterapia. Unidade de Terapia Intensiva Neonatal.

\section{REFERÊNCIAS:}

ATAIIDE, V. P et al. Ofurô em recém-nascidos pré-termo de baixo peso: relato de experiência. ASSOBRAFIR Ciência, São Paulo, v.7, n.2, p.13- 22, 2016.

SILVA, A. A atuação da fisioterapia através da estimulação precoce em bebês prematuros. Revista. Eletrônica. Atualiza Saúde, Salvador, v. 5, n. 5, p. 29-36, jan./jun. 2017.

THEIS, R. C. S.; GERZSON, L. R.; ALMEIDA, C. S. A atuação do profissional fisioterapeuta em unidades de terapia intensiva neonatal. Cinergis, Santa Cruz do Sul, 17(2):168-176, abr./jun. 2016. 


\section{OS IMPACTOS DA EXPOSIÇÃO PARENTAL A PESTICIDAS NO NEURODESENVOLVIMENTO FETAL E INFANTIL}

${ }^{1}$ Ana Paula de Carvalho Souza; ${ }^{2}$ Jaíres Emanuele Nunes de Sousa; ${ }^{3}$ Mariana Silva Souza;

${ }^{4}$ Rumana de França Almeida; ${ }^{5}$ Vivia Rhavena Pimentel Costa; ${ }^{6}$ Janaína de Moraes Silva.

1, 4, 5 Graduanda em Fisioterapia pela Universidade Estadual do Piauí, Teresina, Piauí, Brasil.

${ }^{2}$ Graduanda em Enfermagem pelo Centro Universitário Unifacid, Teresina, Piauí, Brasil.

${ }^{3}$ Graduanda em Enfermagem pela Christus Faculdade do Piauí- CHRISFAPI, Teresina, Piauí, Brasil.

${ }^{6}$ Fisioterapeuta e PhD em Ciências Biomédicas pela Universidade Federal do Piauí, Teresina, Piauí, Brasil.

Área Temática: Multiprofissional

E-mail do autor para correspondência: anapaula.cvlh@gmail.com

INTRODUÇÃO: Antes da concepção, no útero ou pós-natal, crianças podem ser afetadas pela exposição dos pais a pesticidas. Apesar de em níveis mais baixos, são mais vulneráveis por suas características fisiológicas e comportamentais. O cérebro do feto e da criança está se desenvolvendo de forma rápida, tornando-se mais suscetível a efeitos mais duradouros, como a interrupção da arquitetura ou circuito cerebral, déficits neurocomportamentais, menor perímetro cefálico, problemas de atenção e distúrbios no neurodesenvolvimento. OBJETIVOS: Identificar os impactos da exposição parental a pesticidas no neurodesenvolvimento fetal e infantil. MATERIAIS E MÉTODOS: Trata-se de uma revisão integrativa, realizada por meio das bases de dados Biblioteca Virtual em Saúde (BVS), PubMed e periódicos CAPES, utilizando-se os descritores "Infant, Newborn AND Pesticide Exposure”. Foram incluídos artigos entre os anos de 2016 a 2021, em todos os idiomas, de forma completa e disponíveis nas bases de dados, selecionando estudos de coorte, longitudinal e de caso-controle. Excluindo os estudos em andamento ou que investigassem a exposição a metais, radiação ou outros tipos de substâncias que não fossem pesticidas. RESULTADOS E DISCUSSÃO: Encontrou-se um total de 1.923 estudos dos quais foram selecionados seis. Foi analisada a influência da exposição a pesticidas domésticos, ocupacionais, herbicidas, fungicidas, repelentes, organofosforados e não organofosforados. Alguns estudos não especificaram os tipos de pesticidas investigados. Foram analisadas a exposição através do leite materno e da exposição doméstica ou ocupacional dos pais. A exposição a pesticidas em um dos estudos não identificou alterações no perímetro cefálico, 
enquanto em outro foi observado redução dessa medida nos bebês. Um estudo mostrou alteração na função auditiva, outro associou com o aumento do surgimento de transtorno do espectro autista e dois estudos não mostraram associação com o surgimento de tumores do sistema nervoso central (SNC). CONSIDERAÇÕES FINAIS: Por meio dos achados que compõem esta revisão, identificou-se que a exposição parental a pesticidas pode impactar no feto e na criança, em um menor perímetro cefálico, em alterações na função auditiva e em aumento de transtornos do espectro autista, não impactando no surgimento de tumores do SNC.

Palavras- Chave: Recém Nascido; Neurodesenvolvimento; Exposição Parental; Pesticidas.

\section{REFERÊNCIAS BIBLIOGRÁFICAS}

COSTE, A. et al., Parental occupational exposure to pesticides and risk of childhood cancer in Switzerland: a census-based cohort study. BMC Cancer. v. 20, n.1, p. 819, 2020.

ENGEL, S. M. et al., Exposição pré-natal a pesticidas organofosforados e neurodesenvolvimento infantil aos 24 meses: uma análise de quatro coortes de nascimento. Perspectiva de saúde da Environ. v. 124, p. 822-830, 2016.

ONDINE, S. et al., Prenatal and infant exposure to ambient pesticides and autism spectrum disorder in children: population based case-control study. BMJ Clinical research ed vol. 364, p. 1962, 2019.

PATEL, D. M, et al., International Childhood Cancer Cohort Consortium. Parental occupational exposure to pesticides, animals and organic dust and risk of childhood leukemia and central nervous system tumors: Findings from the International Childhood Cancer Cohort Consortium (I4C). Int J Cancer. v. 146, n. 4, p. 943-952, 2020.

SOESANTI, F. et al,. The effect of non-organophosphate household pesticides exposure during pregnancy on infants birth sizes and growth rate: a cohort study. BMC Pregnancy Childbirth. v. 20, n. 1, p. 476, 2020 


\section{PERCEPÇÃO DE PUÉRPERAS NA VIVÊNCIA DO PERÍODO DE INTERNAÇÃO DE BEBÊS PREMATUROS EM UTI NEONATAL: REVISÃO BIBLIOGRÁFICA}

Abimael de Carvalho ${ }^{1}$; Vivia Rhavena Pimentel Costa ${ }^{1}$; Sarah Lays Campos da Silva ${ }^{1}$; Ramires dos Santos Morais²; Mariana Silva Souza33 Janaina Morais Silva4.

${ }^{1}$ Graduandos em Fisioterapia pela Universidade Estadual do Piauí. Teresina, Piauí, Brasil. ${ }^{2}$ Graduanda em Fisioterapia pelo Centro Universitário UNIFACID. Teresina, Piauí, Brasil. ${ }^{3}$ Graduanda em Enfermagem pela Christus Faculdade do Piauí (CHRISFAPI). Piripiri, Piauí, Brasil.

${ }^{4}$ Fisioterapeuta. Universidade do Vale do Paraíba (UNIVAP). São José dos Campos, São Paulo, Brasil.

Área Temática: Multiprofissional

E-mail do autor para correspondência: abimaeldecarvalho123@ gmail.com

INTRODUÇÃO: a rotina em que os bebês prematuros são submetidos na Unidade de Terapia Intensiva Neonatal (UTIN), além de influenciar no seu desenvolvimento, torna-se para as mães um processo angustiante, e muitas vezes faz com que se sintam inseguras, devido à falta de conhecimento em relação ao quadro clínico do filho. OBJETIVO: revisar a literatura científica acerca da percepção de puérperas na vivência do período de internação de bebês prematuros em UTIN. METODOLOGIA: revisão bibliográfica, realizada nas bases Lilacs, Scielo e Trip database, em maio de 2021. Termos identificados no Decs: Intensive care units neonatal, Prematurity e Maternal and child health que foram combinados por meio dos operadores booleanos "AND" e 'OR'. Critérios de inclusão: estudos exploratórios descritivos, publicados entre 2011 e 2021 nos idiomas inglês e português que abordam o tema proposto. Excluíram-se relatos de casos clínicos, estudos de revisão e artigos indisponíveis na íntegra. Os artigos duplicados foram contabilizados uma única vez. RESULTADOS E DISCUSSÃO: encontrou-se 122 artigos. Desses, 21 foram pré-selecionados para leitura de títulos e resumos e 11 lidos na íntegra. Por fim, 5 foram selecionados. A vivência das puérperas é marcada pelo trauma do parto e que estas compreendem o desfecho "parto prematuro" sob a relação de causa e efeito. Por outro lado, expressam também que o cuidado em unidade de tratamento intensivo propicia a reabilitação dos bebês para o convívio familiar. Além dos sentimentos de angústia, dúvida e insegurança, ao visitarem o filho prematuro, as mães sentem estranhamento, pois ficam presas ao bebê idealizado na gestação muitas vezes não condizente com o bebê real, prematuro e frágil. Isso torna-se ainda mais difícil, porque a 
mãe pós parto não se encontra preparada emocionalmente e fisicamente capaz de interagir com o filho nesse estado. Algumas puérperas demonstram insegurança e desconhecimento nos cuidados com o filho prematuro, acentuados pela inadequação de informação oferecida pelos profissionais de saúde, gerando quadro de depressão pós-parto. CONSIDERAÇÕES FINAIS: portanto, a vivência na internação do RN em uma UTIN interfere negativamente na separação da díade mãe-bebê e nos sentimentos maternos vivenciados. Logo há necessidade da integralidade em saúde do cuidado e humanização da relação entre mãe e bebê.

Palavras-chave: Intensive care units neonatal; Prematurity; Maternal and child health.

\section{REFERÊNCIAS}

BASEGGIO, D. B et al. Vivências de mães e bebês prematuros durante a internação neonatal. Temas psicol., Ribeirão Preto, v. 25, n. 1, p. 153-167, mar. 2017.

RIBEIRO, C. V.; SOARES, M. C.; TORRES, A. A. P. significados da prematuridade para mães de bebês internados em unidade de terapia intensiva neonatal. Rev Enferm UFPE online., Recife, v. 8, n. 9, p. 06-11, set., 2014.

SIQUEIRA, M. B. C.; DIAS, M. A. B. A percepção materna sobre vivência e aprendizado do cuidado de um bebê prematuro. Epidemiol. Serv. Saúde, Brasília, v. 20, n. 1, p. 27-36, mar. 2011. 


\section{PERFIL EPIDEMIOLOGICO DOS CASOS DE SÍFILIS CONGENITA NO BRASIL}

Jaíres Emanuele Nunes de Sousa ${ }^{1}$; Andreia Tomaz da Silva ${ }^{2}$; Antônia Shabrinna Silva Resende $^{3}$; Angelica Ribeiro do Nascimento ${ }^{4}$; Fernanda Noleto Santos ${ }^{5}$; Reberson do Nascimento Ribeiro ${ }^{6}$

1,2,3 Graduanda em Enfermagem pelo Centro Universitário UniFacid, Teresina, Piauí, Brasil.

${ }^{4}$ Graduanda em Enfermagem pelo Centro Universitário Maurício de Nassau.

${ }^{5}$ Graduanda em Odontologia pelo Centro Universitário UniFacid, Teresina, Piauí, Brasil.

${ }^{6}$ Enfermeiro pelo Centro Universitário UniFacid, Teresina, Piauí, Brasil.

Área Temática: Multiprofissional.

E-mail do autor para correspondência: emanuelejaires@ gmail.com

INTRODUÇÃO: A sífilis congênita (SC) caracteriza-se como uma doença infectocontagiosa pelo Treponema pallidum, resultando da disseminação hematogênica na gestante infectada não-tratada ou inadequadamente tratada para o seu concepto, por via transplacentária, podendo causar má formação do feto, aborto e até a morte do bebê. OBJETIVO: Realizar uma análise do perfil epidemiológico acerca dos casos de sífilis congênita no Brasil no período de 2017 até 2020. METODOLOGIA: Trata-se de um estudo epidemiológico descritivo prospectivo histórico realizado entre os meses de março e abril de 2021. Os dados epidemiológicos foram obtidos a partir do Departamento de Informática do sus (DATASUS) referente aos casos de sífilis congênita notificados nos períodos de 2017 a 2020. Para melhor discussão dos dados, foi realizado buscas na base de dados da Scientific Electronic Library Online (SciELO). Os dados obtidos foram organizados em tabelas no programa Microsoft Office Excel®, para uma melhor analise e interpretação do perfil epidemiológico dessa doença no Brasil. RESULTADO E DISCUSSÃO: Diante da análise, pôde-se observar que a SC representa índices epidemiológicos significativos. No Brasil, no período entre 2017 a 2020 foram notificados 198.314 casos/ 1000 Nascidos Vivos (NV de sífilis em gestantes, demonstrando uma queda nos últimos dois anos. Mostraram-se que a faixa etária da mãe mais frequente foi de 20 a 29 anos com grau de escolaridade entre $5^{\mathrm{a}}$ a $6^{\mathrm{a}}$ série completa. Ademais, a taxa de incidência em menores de 1 ano de idade variando de 8,5 (=24. 962/1000NV) em 2017 a 8,2 (= 24.130/ 1000NV) em 2019. Outros parâmetros relevantes do perfil epidemiológico da sífilis congênita no Brasil foram o diagnóstico no primeiro trimestre de gestação em decorrência da realização do pré-natal e solicitação dos exames VDRL ou teste 
rápido. O tratamento tardio somado a não adesão do parceiro ao tratamento contribuem para alta taxa de incidência da doença. CONCLUSÃO: Apesar da diminuição dos casos de SC nos últimos anos, a doença ainda representa um grave problema de saúde pública. Assim, torna-se necessário melhorias relacionadas a assistência ao pré-natal e maior efetividade na implementação de Políticas Públicas de combate a sífilis como rastreamento precoce durante o pré-natal com testagem e tratamento da gestante positiva e parceiro.

Palavras-Chave: Sífilis Congênita. Cuidado Pré-Natal. Treponema Pallidum.

\section{REFERENCIAS:}

AZEREDO, Lidiane Grutzmacher et al. Congenital syphilis: an integrative research / Sífilis congênita: uma pesquisa integrativa. Revista de Pesquisa: Cuidado é Fundamental Online, [S.1.], v. 13, p. 336-341, mar. 2021. ISSN 2175-5361. Disponível em: <http://seer.unirio.br/index.php/cuidadofundamental/article/view/8605>. Acesso em: 05 abr. 2021. doi:http://dx.doi.org/10.9789/2175-5361.rpcfo.v13.8605

DALLA, Costa Favero; MARINA, Luiza et al. Sífilis congênita e gestacional: notificação e assistência pré-natal. Arquivos de Ciências da Saúde, [S.1.], v. 26, n. 1, p. 2-8, jul. 2019. ISSN 2318-3691. Disponível em:

<https://www.cienciasdasaude.famerp.br/index.php/racs/article/view/1137>. Acesso em: 05 abr. 2021. doi: https://doi.org/10.17696/2318-3691.26.1.2019.1137.

GASPAR, Pâmela Cristina et al. Protocolo Brasileiro para Infecções Sexualmente Transmissíveis 2020: testes diagnósticos para sífilis. Epidemiologia e Serviços de Saúde [online]. 2021, v. 30, n. spe1. Disponível em: <https://doi.org/10.1590/S16794974202100006.esp1>. ISSN 2237-9622. https://doi.org/10.1590/S16794974202100006.esp1. Acesso em: 07 de abr. 2021. 


\section{PROBLEMAS RESPIRATÓRIOS NO NEONATO DECORRENTE DE PARTO CESÁRIO}

1Tâmara Karine da Silva; ${ }^{2}$ Renata Porangaba Cavalcante; ${ }^{3}$ Lívia Maria da Silva Gomes; ${ }^{4}$ Luiza Diogo da silva dos santos; ${ }^{5}$ Maria Dhescyca Ingrid Silva Arruda; Vitória Vilas Boas da Silva Bomfim ${ }^{6}$

${ }^{1}$ Graduanda de Enfermagem pela Sociedade de Ensino Universitário do Nordeste (SEUNE), Maceió, Brasil.

${ }^{2}$ Graduanda de Enfermagem pelo Centro Universitário Mario Pontes Juca (UMJ) , Maceió, Brasil.

${ }^{3}$ Graduanda de Enfermagem pela Faculdade Nova Esperança (FACENE/FAMENE), João Pessoa, Brasil.

${ }^{4}$ Graduanda de enfermagem pela Universidade Salvador (UNIFACS), Salvador, Bahia, Brasil. ${ }^{5}$ Graduanda de Enfermagem pela Faculdade São Francisco da Paraíba (FASP), Cajazeiras, Paraíba, Brasil.

${ }^{6}$ Enfermeira, Graduada pelo Centro Universitário Jorge Amado (UNIJORGE). Salvador, Bahia, Brasil.

Área temática: Neonatologia

E-mail do autor: tamarakarine1@ hotmai.com

INTRODUÇÃO: Desempenhando o comparativo referente ao quantitativo de partos normais e o de partos cesarianos, o número de partos por esta via, realizados no Brasil, é bem maior que o daquela. O Ministério da saúde realiza campanhas incentivadoras todos os anos e capacitações profissionais para diminuir o alto número de cesarianas realizadas anualmente, pois, o parto normal deve ser a primeira opção caso não haja risco para a mãe e o bebê. Estudos apontam que a cesariana traz várias complicações para o neonato e para a mãe. Infere-se que neonatos que nasceram por essa via estão mais propensos a desenvolverem distúrbios respiratórios, como, por exemplo, asma e alergias respiratórias. Além disso, há um grande número de óbitos de gestantes, assim como várias ocorrências de complicações pósparto, ademais, o tempo de recuperação (pós-cirúrgico) é bem maior quando se trata de parto por via cesariana.O acesso à informação e à educação em saúde deve ser para todos, pois, algumas mulheres realizam o parto cesariano antes de completar 40 semanas de gestação, mesmo sem entrar em trabalho de parto, por falta de conhecimento ou por medo de sofrer a "dor-do-parto" ou, ainda, por influência de alguns profissionais da saúde. Essas mulheres não 
têm ciência que isso pode trazer consequências sérias para elas ou para seus bebês. OBJETIVO: Identificar e descrever os problemas respiratórios no neonato decorrente de parto cesário. METODOLOGIA: Trata-se de uma revisão integrativa da literatura realizada através das bases de dados Scientific Electronic Library Online (SciELO), Literatura LatinoAmericana e do Caribe em Ciências da Saúde (LILACS), Banco de Dados em Enfermagem (BDENF) e Medical Literature Analysis and Retrieval System Online (MEDLINE), através dos seguintes Descritores em Ciências da Saúde (DeCS): "Neonatologia", "Problemas respiratórios", "Cesárea". Combinados entre si pelo operador booleano "AND'. Como critérios de inclusão: artigos disponíveis na íntegra, no idioma português, que abordassem a temática, nos últimos cinco anos. Como critérios de exclusão: artigos que não contemplavam o tema e estudos repetidos nas bases de dados. A partir da busca inicial com os descritores e operador booleano definidos, foram encontrados 13 estudos nas bases selecionadas e após aplicar os critérios de inclusão e exclusão, foram selecionados 6 estudos para compor a revisão. RESULTADOS E DISCUSSÃO: A literatura evidencia que partos cesáreos contribuem significativamente para o aumento das taxas de morbimortalidade materna e neonatal mas isso refere-se às cesáreas realizadas desnecessariamente, ou seja, quando não há orientação médica, de modo que, isso pode causar problemas respiratórios no neonato e implicar na qualidade de vida devido precisar de intervenções medicamentosa para a redução dessas complicações, o que irá prolongar a sua permanência no ambiente hospitalar. Muitos casos de problemas respiratórios são tratados com corticóides antenatal que tem a finalidade de diminuir a prevalência dessas patologias respiratórias que acometem o bebê. CONCLUSÃO: Diante disso, conclui-se que há necessidade do repasse claro e objetivo de informações sobre as possíveis complicações e consequências do parto cesáreos precoces e desnecessário, e faz-se necessário a atuação da equipe multiprofissional para preparar essa gestante psicologicamente para lidar com essas situações, dialogar sobre o parto normal e desconstruir o estigma e respeitar sempre a vontade da mulher para que seja garantido uma maior qualidade de vida e uma assistência humanizada para que seja dado todo o suporte necessário durante toda a gestação.

Palavras-chave: Neonatologia; Problemas Respiratórios; Cesáreas.

\section{REFERÊNCIAS:}

CAMARA, B.F. et al. Cesariana a pedido materno. Rev. Col. Bras. Cir. 2016; 43(4): 301310. 
Costa BC, Vecchi AA, GranzottoJA, Lorea CF, Mota DM, Albernaz EP, et al. Análise comparativa de complicações do recém-nascido prematuro tardio em relação ao recémnascido a termo. Bol Cient Pediatr. 2015;04(2):33-7.

OLIVEIRA, L.C. et al. Mortalidade neonatal: causas e fatores associados. Saúde em Redes. 2020; 6(3):113-127.

Soares Enio, Menezes Greice. Fatores associados à mortalidade neonatal precoce: análise de situação no nível local. Epidemiol. Serv. Saúde. Brasilia. 2010. 


\section{PROPOSTA PARA ELABORAÇÃO DE PROTOCOLO DE AVALIAÇÃO NA ENCEFALOPATIA CRÔNICA NÃO EVOLUTIVA}

Jéssica Rayane Sena de Sousa, Graduanda em Fonoaudiologia pelo Centro Universitário Uninovafapi, Teresina, Piauí, Brasil.

Larissa Lopes Santos Gualter, Graduanda em Fonoaudiologia pelo Centro Universitário Uninovafapi, Teresina, Piauí, Brasil

Karine Medeiros Coelho Carvalho, Fonoaudióloga. Doutora em Biologia Celular e Molecular aplicada a saúde pela ULBRAS/RS, Teresina, Piauí, Brasil.

Área Temática: Multiprofissional.

E-mail do autor para correspondência: rayaneorki@gmail.com

INTRODUÇÃO: A encefalopatia crônica não evolutiva (ECNE) descreve um grupo de distúrbios do desenvolvimento, os quais envolvem principalmente alterações de postura e movimentos, podendo causar uma série de limitações. Tais alterações são atribuídas a distúrbio não progressivo que ocorre no desenvolvimento fetal ou no cérebro infantil até o final do segundo ano de vida. OBJETIVOS: O objetivo deste estudo consistiu na elaboração de um protocolo para direcionar a avaliação fonoaudiológica nos pacientes portadores da ECNE. METODOLOGIA: O estudo foi elaborado com base em publicações e documentos de autores renomados da área de Encefalopatia Crônica Não Progressiva, através das análises de 7 artigos científicos encontrados nas bases de dados Scielo e Bireme, buscando textos relacionados à temática escolhida. Dos artigos encontrados, todos atenderam ao critério de inclusão: publicações em textos completos em português e que contemplam a temática, publicados entre os anos de 2011 a 2018. Para tanto, foram utilizados os seguintes descritores: Fonoaudiologia, Avaliação, Encefalopatia Crônica Não Progressiva. O segundo passo foi levantar protocolos fonoaudiológicos já existentes utilizados em diferentes serviços, que avaliam os aspectos relacionados ao sistema estomatognático. Levando-se em conta os protocolos já existentes, foram identificados os principais pontos sobre a ECNE e os itens julgados relevantes foram incluídos. RESULTADOS E DISCUSSÃO: O protocolo proposto é constituído por cinco partes: Identificação, reflexos orais, estruturas, funções e observações gerais. Permitindo um diagnóstico correto e um bom processo interventivo. CONCLUSÃO: O protocolo de Avaliação Fonoaudiológica da ECNE é baseado em uma proposição teórica e depende de sua aplicação populacional por diferentes profissionais para testar a confiabilidade 
e a validade do instrumento. A contribuição aqui apresentada busca uma forma de contemplar, de maneira mais completa possível, a avaliação fonoaudiológica dos portadores da ECNE, norteando a atuação fonoaudiológica e consolidando sua atuação baseada em evidências. A segunda fase dessa pesquisa será experimental.

Palavras-chave: Fonoaudiologia. Avaliação. ECNE.

\section{REFERÊNCIAS}

QUEIROZ, Ítala da Piedade et al. Validação do protocolo de avaliação neurofuncional para Comunicação Alternativa e Ampliada. Revista CEFAC, v. 20, n. 3, p. 291-303, 2018.

DE OLIVEIRA CONDE, Marcela et al. Dificuldades alimentares na paralisia cerebral: proposta de um protocolo. Revista CEFAC, v. 18, n. 2, p. 426-438, 2016.

Cesa, Carla Ciceri, Helena Bolli Mota, and Lenisa Brandão. "Proposta de um protocolo de análise conversacional de comunicação suplementar e alternativa." Revista CEFAC 19.4 (2017): 455-464. 


\section{REPERCUSSÕES DA COVID-19 EM NEONATOS: O QUE REVELAM AS PUBLICAÇÕES CIENTÍFICAS?}

Vivia Rhavena Pimentel Costa ${ }^{\mathbf{1}}$; Abimael de Carvalho ${ }^{\mathbf{1}}$; Ana Paula de Carvalho Souza ${ }^{\mathbf{1}}$; Ramires dos Santos Morais²; Suzana Pereira Alves ${ }^{3}$; Janaina de Morais Silva ${ }^{4}$.

${ }^{1}$ Graduandos em Fisioterapia pela Universidade Estadual do Piauí. Teresina, Piauí, Brasil. ${ }^{2}$ Graduanda em Fisioterapia pelo Centro Universitário UniFacid. Teresina, Piauí, Brasil. ${ }^{3}$ Graduanda em Enfermagem pela Christus Faculdade do Piauí (CHRISFAPI). Piripiri, Piauí, Brasil.

${ }^{4}$ Fisioterapeuta. Universidade Estadual do Piauí, Teresina, Piauí, Brasil.

Área Temática: Multiprofissional

E-mail do autor para correspondência: viviarhavena@ outlook.com

INTRODUÇÃO: O coronavírus (SARS CoV-2), é o agente etiológico da atual infecção pandêmica, recebe seu nome do inglês coronavírus da síndrome respiratória aguda grave. Este vírus produz infecções respiratórias (BAGUEIRO et al, 2020). Existem poucos casos positivos de Covid-19 em neonatos foram confirmados e relatados, além disso, em grande parte desse público, ocorre ausência de sintomas, quando estes surgem, variam de leves a moderados. Contudo, observa-se a necessidade de maiores investigações a respeito desta infecção em recém-nascidos. OBJETIVOS: Identificar, na literatura científica, evidências sobre as repercussões da Covid-19 em neonatos. METODOLOGIA: O estudo consiste em uma revisão integrativa. As buscas foram operacionalizadas por meio das bases de dados SciELO (Scientific Electronic Library Online), Medline (Medical Literature Analysis and Retrievel System Online) e Lilacs(Literatura Latino-Americano e do Caribe de Informação em Ciências da Saúde). Foram utilizados os descritores "Neonato", "Infecções por coronavirus", "Complicações em saúde" em combinação com o conector aditivo "AND”. O estudo teve como questão norteadora "Quais as principais evidências disponíveis na literatura científica sobre as repercussões da Covid-19 em neonatos?"' Incluiu-se ensaios clínicos publicados nos idiomas inglês e português condizentes com o objetivo proposto, sem recorte temporal. Por sua vez, buscou-se excluir os editoriais, textos incompletos e artigos de revisão. Foram identificadas 11 referências. Contudo, após a adoção dos critérios de elegibilidade, obteve-se seis estudos que tiveram seus resumos analisados. Destes, quatro foram préselecionados para leitura na íntegra. Posteriormente, estes foram incluídos na presente revisão. RESULTADOS E DISCUSSÃO: Os estudos selecionados apontam por 
unanimidade que os recém-nascidos parecem ser significativamente menos afetados pela Covid-19 do que indivíduos adultos. No entanto, a falta de evidências de alta qualidade para essa situação e o ritmo constante de informações novas e conflitantes têm sido um desafio para a terapia intensiva neonatal. Ademais, os achados mostram que o potencial de transmissão vertical intrauterino da Covid-19 no primeiro e no segundo trimestres ainda é pouco conhecido. Alguns autores encontraram amostras negativas, por técnicas de RT-PCR em diferentes materiais coletados de recém-nascidos, filhos de mães com Covid confirmada. Ressalta-se ainda que a maioria dos neonatos apresentam ausência de sintomas, quando surgem, se apresentam de forma moderada. CONSIDERAÇÕES FINAIS: Os recémnascidos parecem ser significativamente menos afetados pela Covid-19 do que os adultos, apresentando sintomas leves ou moderados. Por ser um tema pouco explorado, sugere-se o desenvolvimento de novos estudos.

Palavras-chave: Neonato. Infecções por coronavirus. Complicações em Saúde.

\section{REFERÊNCIAS}

BAGUERO, H et al. Sepsis neonatal tardía por SARS CoV-2. Biomédica, v. 40; n. 2, p. 4049, 2020.

IDSZUN, A et al. Neonatal Early-Onset Infection With SARS-CoV-2 in 33 Neonates Born to Mothers With COVID-19 in Wuhan, China. JAMA Pediatrics, v. 174, n. 7, 2020.

SHANE, C et al. A Pediatric Infectious Diseases Perspective of Severe Acute Respiratory Syndrome Coronavirus 2 (SARS-CoV-2) and Novel Coronavirus Disease 2019 (COVID-19) in Children. jpids vol. 9 (November), 2020. 


\section{TERAPIA OCUPACIONAL NO PROCESSAMENTO SENSORIAL EM CRIANÇAS COM TRANSTORNO DO ESPECTRO AUTISTA}

Eryka Vaz Zagmignan; Ana Paula Silva Santana²; Manoel Leonardo Tavares da Silva 3; Nayara Moraes Nazar Melo ${ }^{4}$ Clarinda Vitoria Aparecida Silva do Nascimento ${ }^{5}$

${ }^{1,2,3,4}$ Graduando em Terapia Ocupacional pelo Centro Universitário UniFacid, Teresina, Piauí, Brasil.

${ }^{5}$ Terapeuta Ocupacional pelo Centro Universitário UniFacid, Teresina, Piauí, Brasil.

Área Temática: Multiprofissional.

E-mail do autor para correspondência: erykazag2014@gmail.com

INTRODUÇÃO: O Transtorno do Espectro Autista (TEA) é um distúrbio do neurodesenvolvimento que se caracteriza por alterações presentes desde idade muito precoce, com comprometimento na área sensorial. Crianças com TEA respondem a experiências sensoriais de forma diferente de seus pares sem deficiência, vivenciam dificuldades na percepção, integração e modulação de suas respostas a estímulos sensoriais diários, e essas dificuldades estão presentes ao longo da vida com impacto significativo nas atividades de vida diária. Dessa forma, é válido a intervenção da terapia ocupacional nessa disfunção. OBJETIVOS: A proposta foi revisar a literatura relacionada a terapia ocupacional na alteração sensorial no transtorno do espectro autista. METODOLOGIA: Realizou-se uma busca de artigos nas bases de dados: SciELO (Scientific Electronic Library of Medicine), Biblioteca Virtual em Saúde-BVS e Cadernos Brasileiro de Terapia ocupacional, utilizando-se os termos combinados em português e inglês: terapia ocupacional, sensorial e autismo. Como critério de inclusão foram selecionados dez artigos dos últimos dez anos que discorreram sobre a presença de alterações sensoriais em indivíduos com TEA, e de exclusão artigos que não se discorreram desse tema. RESULTADOS E DISCUSSÃO: O processamento sensorial pode ser comprometido de forma leve, moderada ou intensa, manifestado pela hipersensibilidade ou hiposensibilidade das informações trazidas pelos sistemas vestibular, proprioceptivo, tátil, visual, auditivo, gustativo e olfativo. Portanto, nas intervenções de Terapia Ocupacional envolve atividades sensoriais específicas para ajudar a criança a responder apropriadamente à luz, som, toque e outras informações. Isso inclui pinturas, manuseio de texturas sólidas, liquidas, macias, dentre outras atividades sensoriais. O resultado dessas práticas auxilia no desenvolvimento do processo sensorial da criança. CONCLUSÃO: Segundo a literatura, o TEA não tem cura. Entretanto, a estimulação precoce aproveita o 
período sensitivo determinado pelas janelas de oportunidades no cérebro da criança, uma vez que nos primeiros anos de vida a formação sináptica apresenta maior velocidade. Conclui-se que, quanto mais precoce o diagnóstico e o plano terapêutico são estabelecidos, mais resultados satisfatórios é possível.

Palavras-chave: Terapia Ocupacional. Sensorial. Autismo.

\section{REFERÊNCIAS}

POSAR, Annio. Alterações sensoriais em crianças com transtorno do espectro do autismo. J. Pediatr. (Rio J.) vol.94 no.4 Porto Alegre jul./ago. 2018.

Diretrizes de Atenção à Reabilitação da Pessoa com Transtornos do Espectro do Autismo. (2013). Brasília: Ministério da Saúde, Secretaria de Atenção à Saúde.

MONTEIRO, Rubiana Cunha et al. Percepção de Professores em Relação ao Processamento Sensorial de Estudantes com Transtorno do Espectro Autista. Rev. bras. educ. espec., Bauru, v. 26, n. 4, p. 623-638, Oct. 2020.

ONZI, Franciele Zanella; GOMES, Roberta de Figueiredo. TRANSTORNO DO ESPECTRO AUTISTA: A IMPORTÂNCIA DO DIAGNÓSTICO E REABILITAÇÃO. Revista Caderno Pedagógico, [S.1.], v. 12, n. 3, dez. 2015. ISSN 1983-0882.

American Psychiatric Association. Manual de diagnóstico e estatistico de transtornos mentais: DSM-V. 5. ed. Porto Alegre: Artmed; 2014. 848 p.

SCHWATZMAN, J. S. Autismo Infantil. In. SALIM, M. C; JUNQUEIRA, L. C.U. Autismo Infantil e as intervenções terapêuticas não medicamentosas - Autistic Disorder and non-drug therapeutic intervention Trastorno Autístico y las intervenciones no farmacológicas terapêutica. São Paulo, 2010 


\section{USO DA TERAPIA DE PRESSÃO POSITIVA CONTINUA DAS VIAS AÉREAS EM RECÉM-NASCIDOS PREMATUROS COM DESCONFORTO RESPIRATÓRIO}

Jaíres Emanuele Nunes de Sousa ${ }^{1}$; Antônia Shabrinna Silva Resende ${ }^{2}$; Andreia Tomaz da Silva ${ }^{3}$;Ana Paula de Carvalho ${ }^{4}$;Milton de Castro Fontes Junior ${ }^{5}$; Reberson do Nascimento Ribeiro ${ }^{6}$

${ }^{1,2,3}$ Graduanda em enfermagem pelo Centro Universitário UniFacid, Teresina, Piauí, Brasil.

${ }^{4}$ Graduanda em Fisioterapia pela Universidade Estadual do Piauí - UESPI, Teresina, Piauí, Brasil.

${ }^{5}$ Graduando em Enfermagem pelo Instituto de Ensino Superior Multiplo -IESM, Timon, Maranhao, Brasil.

${ }^{6}$ Enfermeiro pelo Centro Universitário UniFacid, Teresina, Piauí, Brasil.

Aréa Temática: Seguimento do recém-nascido.

E-mail do autor para correspondência: emanuelejaires@ gmail.com

INTRODUÇÃO: A Pressão Positiva Continua das Vias Aéreas (CPAP) consiste em uma pressão contínua durante todo o ciclo respiratório, prevenindo o colapso dos alvéolos e promovendo uma respiração mais homogênea. É uma terapia gasosa que vem sendo estudada como alternativa no tratamento precoce de recém-nascido com problemas respiratórios. OBJETIVOS: Identificar, na literatura cientifica, a eficácia do tratamento com CPAP em recém-nascidos prematuros com desconforto respiratório. METODOLOGIA: Trata-se de uma revisão integrativa da literatura. A busca foi realizada através de pesquisa nas bases de dados da Literatura Latino-Americana e do Caribe em Ciências da Saúde (LILACS), e Sistema Online de Busca e Análise de Literatura Médica (MEDLINE) via Biblioteca Virtual em Saúde (BVS) usando os descritores: “ Pressão Positiva Continua nas vias aéreas”, Prematuro", "Desconforto Respiratório do Recém-nascido". Para seleção e obtenção dos artigos foram aplicados os seguintes critérios de inclusão: trabalhos completos publicados no recorte temporal de 2016 até a atualidade, nos idiomas português, inglês e espanhol. Encontrando um total de 457 estudos. E foram excluídos trabalhos não gratuitos para download, fora do recorte temporal e que não contemplava o objetivo proposto no presente estudo, contemplando um total de 15 estudos para analise final. RESULTADOS E 
DISCUSSÃO: De acordo com a analise dos estudos, o tratamento precoce na sala de parto com CPAP mostrou-se eficaz reduzindo a necessidade de ventilação mecânica, tempo de internação hospitalar e morbimortalidade no período neonatal. Ademais, essa terapia contribui para prevenção de atelectasias, melhorando a função pulmonar, preservando as propriedades do surfactante. As evidencias mostraram que o tipo CPAP nasal administrado em bolhas fornece benefícios extras com relação aos outros tipos (com uso do respirador e dispositivo BiPAP, proporcionando ao recém-nascido com síndrome do desconforto respiratório uma pressão positiva continua. É importante salientar que o uso inadequado dessa terapia gasosa pode trazer ao bebê, como obstrução nasal por edema, sangramento nasal, deformidades e necrose de septo nasal. CONSIDERAÇÕES FINAIS: O uso da terapia de pressão positiva continua, mostrou-se uma alternativa eficaz para tratamento de desconforto respiratório em bebê prematura,sendo essencial monitorização e conhecimento das técnicas para aplicabilidade pelos profissionais de saúde.

Palavras-chave: Pressão Positiva Continua nas vias aéreas. Prematuro. Desconforto Respiratório do Recém-nascido.

\section{REFERENCIAS:}

Ho JJ, Subramaniam P; Davis, PG. Pressão positiva contínua nas vias aéreas (CPAP) para desconforto respiratório em bebês prematuros. Cochrane Database of Systematic Reviews. Disponivel em: doi 10.1002 / 14651858.CD002271.pub3. Acessado em 05 de abril de 2021.

Mwatha, AB; Mahande, M; Olomi, R. John, B. Philemon, R. Resultados do tratamento de Pumani bolha-CPAP versus oxigenoterapia entre bebês prematuros que apresentam dificuldade respiratória em um hospital terciário na Tanzânia - ensaio randomizado. Disponivel em: https://doi.org/10.1371/journal.pone.0235031. Acesado em 10 de abril de 2021.

Guedes, Bruna Luizy dos Santos et al. Continuous positive pressure on aircraft in neonates: care provided by the nursing teama a Article extracted from the da monograph - The Care of the Newborn under Use of Continuous Positive Airway Pressure: Vision of the Nursing Team. Authorship of Bruna Luizy dos Santos Guedes. Federal University of Alagoas. 2017. Escola Anna Nery [online]. 2019, v. 23, n. Disponível em: <https://doi.org/10.1590/21779465-EAN-2018-0122>. Acessado em 15 de abril de 2021. 
TRABALHOS NA MODALIDADE RESUMO EXPANDIDO 


\section{A INFLUÊNCIA POSITIVA DA ESTIMULAÇÃO PRECOCE EM PREMATUROS EXTREMOS}

Manuela Luiza de Souza Fernandes ${ }^{1}$; Bruna Alacoque Amorim Lima ${ }^{2}$; Mariana Oliveira Nascimento $^{3}$; Suely Moura Melo ${ }^{4}$

${ }^{1}$ Graduanda em Medicina pelo Centro Universitário UniFacid, Teresina,Piauí,Brasil.

${ }^{2}$ Graduanda em Medicina pelo Centro Universitário Unifacid, Teresina,Piauí, Brasil.

${ }^{3}$ Graduanda em Medicina pelo Centro Universitário Unifacid, Teresina,Piauí, Brasil.

${ }^{4}$ Graduada em Química, Doutora em Biotectologia pela Universidade Federal do Piauí UFPI,Teresina, Piauí, Brasil.

Aréa Temática: Multiprofissional.

E-mail do autor para correspondência: manuelalsfernandes@ outlook.com

\section{INTRODUÇÃO:}

A Organização Mundial da Saúde (OMS) considera prematura, ou pré-termo, a criança com menos de 37 semanas de gestação. A idade gestacional e o peso ao nascimento constituem os principais fatores determinantes de complicações neonatais e se relacionam à deficiência na evolução pós-natal. Algumas complicações neonatais têm sido frequentemente apontadas como possíveis fatores de risco para o desenvolvimento neurológico e intelectual anormais. $\mathrm{O}$ sistema nervoso central (SNC) infantil apresenta um dinamismo evolutivo muito intenso e, para entender seu processo de desenvolvimento e amadurecimento, é essencial a correlação entre a estrutura e a função, ou seja, o desenvolvimento de determinada função depende do amadurecimento de seu substrato neural anatômico correspondente. Cada fase do desenvolvimento e crescimento cerebral tem seu tempo e não ocorre individualmente, sobrepondo-se à evolução da gestação.

O nascimento prematuro interrompe a evolução normal desses eventos e as crianças nascidas prematuramente são consideradas de risco em relação ao neurodesenvolvimento e às incapacidades funcionais, uma vez que os prematuros apresentam tecido adiposo reduzido, tônus muscular diminuído, a cabeça é relativamente grande em relação ao tórax, caixa torácica deficiente e abdômen distendido. Devido o atraso da maturação do Sistema Nervoso e do processo de mielinização, têm-se as complicações neurológicas, logo, com o intuito de evitá-las, o tratamento especializado, através da estimulação precoce, torna-se necessário para permitir que a criança possa experimentar movimentos e posturas normais desde o 
nascimento, favorecendo o desenvolvimento mais perto possível do normal a esses recémnascidos.

A Estimulação Precoce objetiva o desenvolvimento sensório-motor, cognitivo, afetivo do bebê prematuro e também a integração família-bebê. Nesse viés, o presente estudo possui acentuada relevância para o meio acadêmico e profissional, pois argumenta a importância da estimulação precoce a fim de estimular o desenvolvimento psicomotor da criança e proporcioná-la maior qualidade de vida.

\section{OBJETIVOS:}

\subsection{OBJETIVO GERAL}

Verificar os benefícios da estimulação precoce em bebês prematuros com lesão cerebral.

\subsection{OBJETIVOS ESPECÍFICOS}

- Analisar dados na literatura relativos a melhor forma de realização da estimulação precoce em prematuros;

- Abordar dados da literatura relativos a importância da estimulação precoce no desenvolvimento de crianças que sofreram lesão no sistema nervoso ainda imaturo;

- Identificar os beneficios advindos com a intervenção da fisioterapia no tratamento;

\section{METODOLOGIA:}

Trata-se de uma revisão de literatura tipo narrativa de assuntos pertinentes ao tema. A base de dados eletrônicas selecionadas foram BVS (Biblioteca Virtual em Saúde) e LILACS (Literatura Latino-Americana em Ciências da Saúde). Os critérios de inclusão foram: artigos publicados de 2016 a 2020, disponíveis na íntegra e em português, inglês ou espanhol. Excluíram-se teses, dissertações e artigos duplicados. Os descritores utilizados foram: degeneração neural, estimulação precoce, neoplasticidade. Tal campo de pesquisa é amplo e recente, o que permite que ainda haja perguntas e incertezas, portando foram selecionadas as referências de maior impacto no tema.

\section{RESULTADOS E DISCUSSÃO:}

Prematuros extremos possuem tendência ao desenvolvimento de padrões anormais de postura, movimento e tônus postural anormal, somado ao alto risco de deficiência neurológica. Dessa forma, a estimulação precoce em prematuros deve ser iniciada nos primeiros meses de vida, aproveitando a plasticidade cerebral, a fim de que o tônus seja normalizado, acarretando a troca das sensações anormais pelas normais, fazendo-as serem absorvidas e mantidas o maior tempo possível. Quanto maior o período após o nascimento para início da estimulação precoce, maiores são as chances de um descompasso no desenvolvimento sensorial-motor, 
esquema corporal, percepção e noção espacial, comprometendo a capacidade de foco e desenvolvimento cognitivo do paciente.

O tratamento fisioterapêutico inicia-se na análise da sensibilidade, motricidade, postura em repouso, movimentos ativos, anormalidades, deformidades e reflexos da criança, para que suas necessidades sejam determinadas e seja criado um programa de reabilitação para o desenvolvimento de habilidades que compensem suas deficiências. São métodos amplos que podem adequar-se as necessidades individuais, partindo desde alongamentos, mobilizações intra-articulares, massoterapia e exercícios passivos, o tratamento precoce é globalizado. Desse modo, não só mantém ou aumenta a amplitude de movimento, melhora as habilidades cognitivas e de memória, reduz a espasticidades e normaliza o tônus postural, como também é capaz de orientar a família, prevenir deformidades e instalações de doenças pulmonares ou outras intercorrências. Ademais, ainda torna a reintegração social da criança mais fácil, otimizando de modo geral a vida do paciente. Observamos a mudança no decorrer de um ano de estimulação precoce ( Fotos 1 e 2).

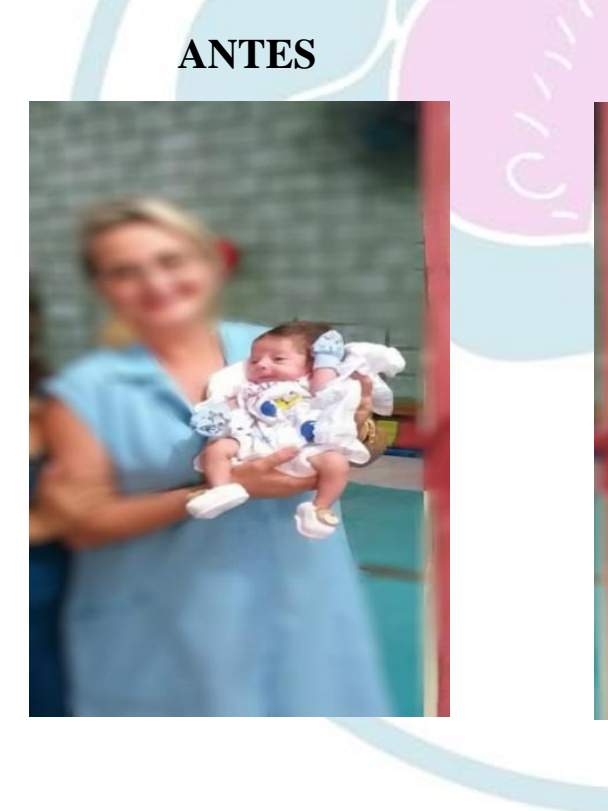

Fonte: Das autoras

Foto 1 - ausência de controle postural e hipotonia da musculatura posturais

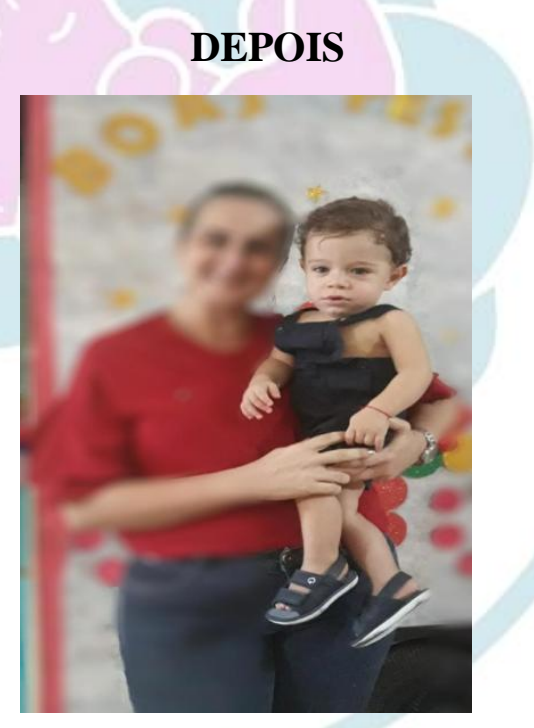

Fonte: Das autoras

Foto 2 - bom controle do tronco com padrão de mudanças 


\section{CONCLUSÃO}

Ao final da elaboração deste artigo, pode-se concluir que a estimulação precoce exerce benefícios expressivos em bebês prematuros que possuem algum tipo de lesão cerebral, uma vez que gera melhoras significativas no desenvolvimento sensório-motor, cognitivo e afetivo desses bebês, com a potencialização da interação com o meio ambiente por meio de estímulos visuais, auditivos e táteis, bem como do incentivo à relação entre o prematuro e sua família. Nesse contexto, a estimulação precoce atua como um importante recurso para a promoção da saúde do recém-nascido pré-termo, pois essa, realizada juntamente com uma equipe multidisciplinar, interfere positivamente na sobrevida e no prognóstico desse indivíduo. É de grande relevância que a fisioterapia seja parte integrante dessa equipe, com a utilização de técnicas que estimulem a aquisição de habilidades funcionais pelas crianças que sofreram lesão no sistema nervoso ainda imaturo, buscando minimizar atrasos.

A partir da revisão de literatura feita, verifica-se que a realização da estimulação precoce traz inúmeros benefícios ao desenvolvimento de prematuros extremos, logo, os objetivos propostos foram alcançados. Entretanto, são necessários estudos mais aprofundados acerca dessa temática, em virtude da sua importantância para as áreas da Neuropediatria e da Neonatologia.

Palavras-chave: Estimulação precoce. Prematuros extremos. Neoplasticidade. 


\section{ANÁLISE DA TAXA DE OCUPAÇÃO DE LEITOS EM UMA UNIDADE DE CUIDADOS INTERMEDIÁRIOS E SEMI-INTENSIVOS NEONATAIS}

Taelyson Costa de Medeiros - Universidade Federal de Campina Grande, Cuité, Paraíba,

Brasil.

Mateus Fernandes da Silva - Universidade Federal de Campina Grande, Cuité,Paraíba, Brasil. Sabrina Mércia Belarmino Gomes - Universidade Federal de Campina Grande, Cuité, Paraíba, Brasil.

Thalita Oliveira de Melo - Universidade Federal de Campina Grande, Cuité, Paraíba, Brasil.

Larissa de Alcântara Santos - Universidade Federal de Campina Grande, Cuité, Paraíba,

Brasil.

Jaielison Yandro Pereira da Silva - Universidade Federal de Campina Grande, Cuité, Paraíba,

Brasil.

\section{Área Temática: Nutrição.}

E-mail: taelysoncosta@hotmail.com

\section{RESUMO}

A Unidade de Cuidados Intermediários e Semi-intensivos Neonatais é de grande importância para a manutenção da vida de bebês prematuros. Ela pode ser subdividida em UTIN e UCINCo, cada uma com suas particularidades assistências para tratar de forma terapêutica esse paciente. A nutrição é fundamental para a recuperação da saúde, e âmbito hospitalar o fornecimento de dietas é feito pelo lactário, o qual prepara, higieniza e distribui leite materno e fórmulas infantis. Como forma de manter controle são feitos registros. Em um lactário de um Hospital Universitário esses registros são feitos por meio de uma ferramenta eletrônica desenvolvida pelo setor de Nutrição e Dietética a qual fornece os dados diários de ocupação dos leitos da UTIN e UCINCo. Diante disso, este estudo tem como objetivo analisar a taxa de ocupação de leitos dessa unidade de cuidados, por meio de uma ferramenta eletrônica. Tratouse de pesquisa transversal quantitativa, descritiva e documental realizada durante os meses de novembro e dezembro de 2020, em um hospital universitário no interior do Rio Grande do Norte. Ao final do mês os dados da ocupação diária foram convertidos por meio de uma fórmula específica para obter-se a taxa de ocupação. Essa pesquisa foi submetida e aprovada por um Comitê de Ética em Pesquisa (CAAE: 38691920.0.0000.5568). Observou-se que a UTIN obteve maiores taxas com porcentagens de $72 \%$ e $79 \%$. Já a UCINCo apresentou uma taxa variada de $43 \%$ e $71 \%$. Esses dados podem estar relacionados com o perfil assistencial o qual cada setor é responsável. Além disso, demonstrou que não houve superlotação dos leitos. Portanto, conclui-se que é de suma importância analisar a taxa de ocupação desses leitos contribuindo para a gestão hospitalar com informações sobre a assistências prestada.

Palavras-chave: UTI neonatal. Recém-nascidos prematuros. Lactário. 
Durante a gestação podem acontecer algumas complicações maternas ou com o feto que acabam por antecipar o parto, gerando assim, o nascimento de bebês prematuros que vem se tornando cada vez mais comum. Esses pacientes apresentam imaturidade em muitos dos seus sistemas orgânicos e necessitam de cuidados específicos sendo, na maioria dos casos, transferidos para uma unidade especializada da instituição, destacando-se a Unidade de Cuidados Intermediários e Semi-intensivos Neonatais (UCIS) (BRASIL, 2012).

Uma UCIS presta assistência especializada para bebês prematuros podendo subdividirse em duas outras unidades as quais possuem suas especificidades assistências, sendo elas: Unidade de Terapia Intensiva Neonatal (UTIN), sendo o setor de maior especialização do cuidado aos recém-nascidos pré-termo (RNPT) e a Unidade de Cuidado Intermediário Neonatal Convencional (UCINCo), que é designada ao atendimento de bebês com médio risco e, que requeiram uma assistência contínua, porém, de menor complexidade (DUARTE; SENA; XAVIER, 2009; BRASIL, 2012).

Durante a permanência desses bebês há uma ocupação dos leitos destinados para cada uma dessas unidades. Sendo a superlotação um dos fatores que podem complicar a assistência prestada, logo, analisar a taxa de ocupação dos leitos é uma forma de auxiliar o processo de gestão hospitalar (VARELA et al., 2020).

Independente do setor ao qual esteja internado, esses pacientes necessitam de uma adequada alimentação e nutrição para recuperarem seu estado de saúde. Para tanto, quando é necessária a oferta de leite materno pasteurizado, suplementos lácteos ou dietas enterais, elas são preparadas pelo lactário. Essa é uma unidade hospitalar que mantém relação íntima com o serviço de nutrição e dietética da instituição que tem por finalidade preparar, higienizar e distribuir leite materno e fórmulas infantis modificadas em pó aos RNs (PIOVACARI; FIGUEIRA; POTENZA, 2009). Durante essa distribuição as profissionais que trabalham no lactário têm que registrar as informações para um melhor controle de produção e/ou desperdícios gerados.

Um lactário de um Hospital Universitário no interior do Rio Grande do Norte possui uma ferramenta eletrônica que otimiza esse serviço de registros, contribuindo para a produção de relatórios mensais sobre os funcionamentos das unidades. Um dos dados que pode ser obtido por meio dessa ferramenta é a ocupação diária dos leitos da UTIN e UCINCo. Por meio desses dados podem ser feitos cálculos para conhecer a taxa de ocupação da unidade, auxiliando assim, o processo de gestão hospitalar (VARELA et al., 2020). 


\section{OBJETIVOS}

Diante desse cenário, este estudo tem por finalidade analisar a taxa de ocupação de leitos em uma UTIN e UCINCo, por meio de uma ferramenta desenvolvida pelo setor de nutrição e dietética.

\section{METODOLOGIA}

Tratou-se de uma pesquisa transversal com natureza quantitativa, além de ser descritiva e com procedimentos documentais. A pesquisa foi realizada nos meses de novembro e dezembro de 2020 utilizando os registros de uma ferramenta eletrônica desenvolvida pelo setor de nutrição e dietética para o lactário de um hospital universitário no interior do Rio Grande do Norte o qual possuía uma UTIN e UCINCo, com cinco leitos cada.

As profissionais responsáveis pelo lactário registram em uma ferramenta eletrônica a ocupação dos leitos diariamente para os respectivos registros dietéticos de controle para o setor da Nutrição. Ao final do mês pode-se obter o panorama geral da quantidade de pacientes internados ao longo dos dias. Por meio de uma equação de acordo com Santos-Varela et al., (2020), obteve-se a taxa de ocupação da UTIN e UCINCo (Eq. 1)

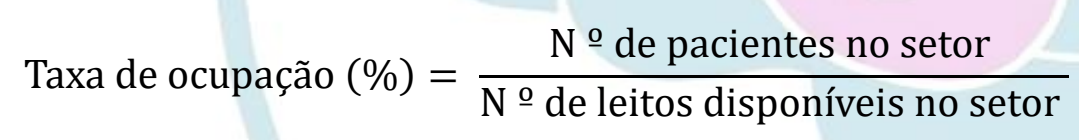

O projeto foi submetido e aprovado por um Comitê de Ética em Pesquisa sob o número CAAE: 38691920.0 .0000 .5568$.

\section{RESULTADOS E DISCUSSÃO}

Por meio da Tabela 1 é possível visualizar a taxa de ocupação de leitos da UTIN e UCINCo durante o mês de novembro e dezembro de 2020.

Tabela 1 - Taxa de ocupação da UTIN e UCINCo nos meses avaliados.

\begin{tabular}{lcccc}
\hline MESES & SETOR & LEITOS & f & \% \\
\hline \multirow{2}{*}{ Novembro } & UTIN & 5 & $4 \pm 1,19$ & $72 \%$ \\
& UCINCo & 5 & $2 \pm 0,78$ & $43 \%$ \\
\hline \multirow{2}{*}{ Dezembro } & UTIN & 5 & $4 \pm 1,00$ & $79 \%$
\end{tabular}




\begin{tabular}{lcccc} 
& UCINCo & 5 & $4 \pm 0,77$ & $71 \%$ \\
\hline \multirow{2}{*}{ TOTAL } & UTIN & 5 & $4 \pm 1,16$ & $88 \%$ \\
& UCINCo & 5 & $3 \pm 1,02$ & $64 \%$
\end{tabular}

Fonte: Dados da pesquisa (2021). UTIN, Unidade de Terapia Intensiva Neonatal; UCINCo, para Unidade de Cuidado Intermediário Neonatal Convencional .

Observou-se que nos meses de novembro a dezembro os índices da UTIN obtiveram uma maior taxa de ocupação com porcentagens de $72 \%$ e $79 \%$, respectivamente. Resultados distintos puderam ser vistos nesse mesmo período para a UCINCo a qual apresentou no mês de novembro uma taxa de $43 \%$ e em dezembro $71 \%$.

Diferindo desse resultado observa-se que no estudo de Varela et al. (2020) ao analisar a taxa de ocupação da UCINCo de um hospital materno-infantil de Marabá, Pará, percebeu-se para os meses de novembro e dezembro de 2018 uma taxa de 59\% e 39\%, respectivamente. Esses dados, assim como os da pesquisa apresentam uma taxa de ocupação de leitos inferior a $100 \%$, demonstrando assim, que não houve superlotação dos leitos.

Essa variância das taxas pode ser justificada devido o perfil de paciente que é característico para cada um desses setores. Na UTIN, os bebês necessitam de um cuidado mais especializado e prolongado utilizando em muitos casos equipamentos que são indispensáveis para o suporte à vida, ao passo que na UCINCo os bebês estão mais estáveis e não necessitam de tais equipamentos (ZULIAN et al., 2018). Outro fator que pode estar atrelado a essa variância é com relação a permanência desses pacientes, tendo em vista que na UCINCo esses bebês apresentam um menor tempo de permanência, permitindo assim, uma maior rotatividade da ocupação desses leitos, diferentemente da UTIN (DANTAS; BRANDÃO; BOGER, 2016).

\section{CONCLUSÃO}

Portanto, conclui-se que a taxa de ocupação das UTIN e UCINCo foi variável ao longo do período da pesquisa, além de mostrar que não houve superlotação. A análise desses dados permite observar a utilização desses leitos contribuindo para a gestão hospitalar com informações sobre a assistência prestada.

\section{REFERENCIAS}

DUARTE, E. D.; SENA, R. R.; XAVIER, C. C. Processo de trabalho na Unidade de Terapia Intensiva Neonatal: construção de uma atenção orientada pela integralidade. Revista da Escola de Enfermagem da USP, São Paulo, v. 43 n.3, p. 647-654, 2009. Disponível em: https://www.scielo.br/scielo.php?script=sci_arttext\&pid=S008062342009000300021. Acesso em: 13 maio 2021. 
SILVA-DANTAS, V. P.; BRANDÃO, T. C.; BOGER, M. E. Rotina fonoaudiológica na unidade de terapia intensiva neonatal de um hospital materno infantil. Revista de Medicina e Saúde de Brasília, Brasília. v. 6, n. 1, 2017. Disponível em: file:///C:/Users/taely/OneDrive/\%C3\%81rea\%20de\%20Trabalho/7636-37196-1-PB.pdf.

Acesso em: 25 maio 2021.

BRASIL. Ministério da Saúde (BR). Portaria No 930, de 10 de maio de 2012. Define as diretrizes e objetivos para a organização da atenção integral e humanizada ao recém-nascido grave ou potencialmente grave e os critérios de classificação e habilitação de leitos de Unidade Neonatal no âmbito do Sistema Único de Saúde (SUS). Diário Oficial da União, Brasília (DF), 2012.

SANTOS-VARELA, A. P. A.; YASOJIMA, E. Y.; CALDAS, I. F. R.; CASTRO, S. V.; TARTAGLIA, A. Estudo da taxa de ocupação em uma Unidade de Cuidados Intermediário Neonatal Convencional. Brazilian Journal of Development, Curtitiba, v. 6, n. 1, p. 2023 2030 , 2020. Disponível em: https://www.brazilianjournals.com/index.php/BRJD/article/view/6104. Acesso em: 14 maio 2020.

PIOVACARI, S. M. F.; FIGUEIRA, V. A. C. R.; POTENZA, A. L. S. Segurança alimentar: Lactário. Einstein Educação Continuada em Saúde, [s. l.], v. 7, n. 4, p. 216-218, 2009. Disponível em: http://apps.einstein.br/revista/arquivos/PDF/1511-EC_v7n4p216-8.pdf. Acesso: 19 maio 2021.

ZULIAN, A. C; LISBOA, D. D. A. J; BATISTA, J. S; LISBOA, R. R. Perfil dos pacientes internados na Unidade de Terapia Intensiva Neonatal. Jornal de Ciências da Saúde do Hospital Universitário da Universidade Federal do Piauí, [s. l.], v. 1, n. 3, p. 38-48, 2018. Disponível

file:///C:/Users/taely/OneDrive/\%C3\%81rea\%20de\%20Trabalho/perfil\%20epidemiologico\%2 Obebes.pdf. Acesso em: 25 maio 2021. 


\title{
ANÁLISE DA VARIAÇÃO DE FADIGA DURANTE O TRATAMENTO FISIOTERAPÊUTICO EM DISTROFIA MUSCULAR DE DUCHENNE: RELATO DE CASO
}

\author{
Graduadas: Pamela Cosme da Silva', Thailane Fiuza Mendes', Graziela Cristina da Silva', \\ Barbara Rocha Pereira Souza \\ Docentes: Fabiana Aparecida Vilaça', Andréa Abramo \\ 'Universidade Cruzeiro do Sul - Campus São Miguel Paulista, São Paulo, Brasil
}

\section{INTRODUÇÃO}

A distrofia muscular de Duchenne (DMD) trata-se de uma doença neuromuscular rara, progressiva, de alta morbidade e morte precoce. A história natural da doença tem padrão hereditário de origem genética relacionada ao dano no braço curto do cromossomo X (lócus Xp21) e ausência da proteína distrofina ${ }^{1}$. Afeta cerca de 1/3.500 meninos nascidos vivos que é o sexo alvo da doença ${ }^{2}$, tendendo o sexo feminino, por sua vez, ser portador assintomático, anormalidade acontece apenas em um dos cromossomos $\mathrm{X}$, por conseguinte será transmissora da doença ${ }^{3}$. O diagnóstico é realizado através de exames eletrofisiológicos e histológicos que demonstram altos níveis da enzima CK (creatinaquinase). Outra forma é a biópsia muscular, que serve para observar mudanças nas células musculares ${ }^{4}$.

As principais manifestações clínicas ainda ocorrem na infância entre a $3^{\circ}$ e $5^{\circ}$ idade $^{5}$ destacando-se o atraso de aprendizagem da marcha, quedas, tropeços frequentes e dificuldades de subir e descer escadas ${ }^{6}$. Outras manifestações detalhadas são a marcha na ponta dos pés que ocorre em consequência da contratura no tendão calcâneo e a pseudohipertrofia da panturrilha ${ }^{7}$. Uma particularidade das distrofias é a manobra de Gowers, caracterizada pela sequência do movimento, cuja indivíduo escala o próprio corpo para ficar em pé, devido à insuficiência da musculatura extensora proximal do quadril e joelho que torna difícil a realização da extensão voluntária do tronco ${ }^{2}$. Tais alterações no funcionamento do corpo e enfraquecimento progressivo ocorrem de forma gradual, bilateral e simétrica ${ }^{3}$, com início nos músculos da cintura pélvica, ascendendo para a cintura escapular até o acometimento da musculatura respiratória ${ }^{8}$.

O ponto central da doença é fadiga e a exaustão; sintomas comuns e representam um dos mais significativos elementos negativos para qualidade de vida da criança ${ }^{9}$. Em pacientes com DMD as limitações, especialmente à fraqueza muscular levam a restrições nos métodos de reabilitação, justamente pelo cuidado necessário para o paciente não fadigar, ocasionando 
dificuldade em graduar o cansaço, tal como o limite da exigência muscular durante o tratamento ${ }^{10}$. Com isso, o organismo desenvolve alterações metabólicas e fisiológicas para se adaptar a demanda energética para cada tipo de exercício, que pode ser observada a partir do aumento da frequência cardíaca (FC), frequência respiratória (FR) e da pressão arterial sistêmica (PA), indicando o nível de fadiga no decorrer das atividades executadas ${ }^{10}$. Assim, a modalidade, quantidade, intensidade do exercício e o acompanhamento da FC e FR são essenciais para monitorar o limite desses pacientes, e a progressão da patologia ${ }^{11}$.

\section{OBJETIVO}

Investigar, acompanhar e analisar durante um protocolo de tratamento de fisioterapia neuromotora, a variação de fadiga em uma criança com diagnóstico de DMD.

\section{MATERIAIS E MIÉTODO}

Participou voluntariamente do estudo um paciente já cadastrado na clínica escola do curso de Fisioterapia. A pesquisa prosseguiu no mesmo local, a partir de aplicação do Termo de Consentimento Livre e Esclarecido assinado pelos responsáveis e aceito pelo da Comissão Nacional de Ética em Pesquisa em Seres Humanos (CAAE 19184219.0.0000.8084).

Foi elaborado um protocolo de tratamento feito em etapas, aplicado em 9 sessões, com duração de 50 minutos uma vez por semana. Para avaliação e controle da fadiga, foi utilizado no início e final das sessões a Escala de Percepção Subjetiva de Esforço de Borg Modificada (BORG), foram aferidos a Saturação Periférica de Oxigênio (SpO2) e FC a cada uma das etapas do protocolo de tratamento, e também aferida da PA e a FR.

$1^{\text {a }}$ Etapa: constituiu o trabalho de flexibilidade muscular, para isso, foram realizados exercícios de alongamentos passivos nos seguintes grupos musculares: esternocleidomastóideo, trapézio, bíceps braquial, extensores de punho, supinador, peitorais, abdutores e adutores do ombro, eretores lombares, isquiotibiais, tríceps sural, iliopsoas, reto femoral, abdutores e adutores do quadril. Sendo realizado em uma série, mantida por 30 segundos para cada grupo muscular, com 30 segundos de descanso entre cervical, MMSS e MMII.

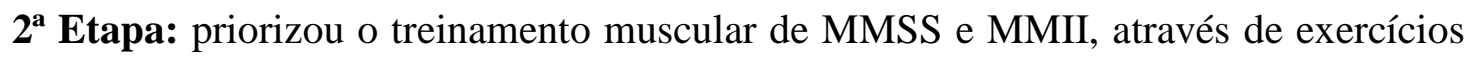
lúdicos, preconizando jogar uma bola de leite de tamanho médio, com ambos os MMSS e MMII em longo e médio alcance na posição sentada. A atividade foi realizada em 3 séries, forma crescente: 30 segundos, 45 segundos e 1 minuto respectivamente, com 30 segundos de descanso entre cada série. 


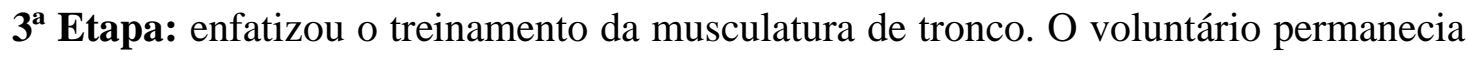
em decúbito dorsal, com uso de cunhas posicionado a 60 graus na região posterior, enquanto atirava uma bola de leite com ambas às mãos em um cesto, que tinha sua posição alterada entre a frente e as laterais. Essa atividade foi realizada em 3 séries, forma decrescente: 10 repetições e 1 minuto de descanso, 7 repetições e 40 segundos de repouso e 5 repetições.

A presente pesquisa trata-se de um estudo de caso. A análise dos dados foi realizada através de uma análise estatística descritiva, por meio de medidas de tendência central, pelo Programa Excell da Microsoft Office professional Plus 2016.

\section{RELATO DE CASO}

Menor R.L.S.V, sexo masculino, nascido a termo em 01 de fevereiro de 2012, com 8 anos de idade é natural e residente de São Paulo/SP. A anamnese revelou que aos dois anos de idade surgiram os primeiros sintomas da distrofia, com quedas frequentes e piora do quadro em curto prazo, conforme o relato materno. Sem histórico familiar, os pais buscaram ajuda médica. Após avaliação minuciosa foi solicitado exames laboratoriais, dentre eles, a dosagem de CK, que resultou níveis elevados da enzima. Com base nos critérios clínicos e laboratoriais constatou-se a DMD aos 3 anos de idade, que foi reafirmada por uma análise de DNA em 2017.

Em análise fisioterapêutica dos sintomas, a criança apresenta marcha livre do tipo anserina, pseudohipertrofia dos gastrocnêmios e solear, tornozelos em flexão plantar, retratilidade principalmente da musculatura de membros inferiores, acentuação da lordose lombar, escoliose em evolução, escápulas aladas e manobra de Gowers presente. Para a realização de atividades de vida diária mostrou-se independente para tarefas de alimentação e higiene pessoal e semidependente para o vestuário.

\section{RESULTADOS E DISCUSSÃO}

De nosso conhecimento, esse é o primeiro estudo que analisa a variação da fadiga durante a realização de um protocolo de atendimento neuromotor em uma criança com DMD.

Durante o repouso é normal que as variáveis fisiológicas de um indivíduo estejam dentro dos valores de referência, mas em alguns casos esses valores podem estar alterados, nosso estudo mostrou uma média da FC de 102,44 bpm no início das sessões, relativamente elevada em repouso, ponto também observado no estudo de Souza et al., os autores justificaram que a DMD gera uma repercussão no sistema nervoso autônomo, levando 
aumento da atividade simpática e/ou diminuição da atividade parassimpática com o agravamento da doença.

Marui et al. corroboraram verificando os mesmos efeitos fisiológicos causado pela própria patologia. Ao avaliar as variáveis pressóricas de 46 meninos com DMD, através do MAPA (Monitorização Ambulatorial da Pressão Arterial), no período de 24 horas em vigília e sono. Constaram que crianças de 6 a 8 anos apresentaram uma média alta da PAS e PAD e considerou que as pressões arteriais estavam elevadas não por influência do uso de corticóides, mas provavelmente pela deficiência da proteína distrofina, que levou a alterações na dilatação vascular.O dado que o estudo apontou sobre uma pesquisa realizada em camundongos com DMD reforçou os achados sobre ausência da distrofina, influenciando no controle neurovascular simpático. As médias das pressões em nosso relato foram PAS 124,44 mmHg e PAD 82,22 mmHg, também relativamente elevadas em uma criança em repouso.

Após o tratamento, ao final das sessões houve uma redução de 6,88 bpm na média da FC e de 4,44 mmHg na PAD, sendo as médias finais 95,56 bpm e 77,78 $\mathrm{mmHg}$ respectivamente. Essas reduções provavelmente ocorreram devido à modalidade do exercício de baixa intensidade empregado no protocolo. A equipe de pesquisa de Brum et al. estuda a 10 anos os efeitos do exercício sobre o sistema cardiovascular, e evidência que essa modalidade atua reduzindo a atividade nervosa simpática levando a vasodilatação dos vasos, diminuindo a resistência vascular periférica e com isso a PAD, também leva a queda da FC devido a diminuição do tônus vagal, colaborando com o nosso estudo e pode apontar que apesar da patologia alterar algumas respostas autônomas, o exercício de baixa intensidade é bem aceito e traz os resultados esperados quando também aplicado em pacientes com DMD.

A Escala de Borg Modificada também foi utilizada para acompanhar os níveis de fadiga e apresentou uma média maior no final da sessão, comparada ao início da sessão o que é esperado, no entanto, a média inicial já se encontrava um pouco elevada, influenciando o voluntário que não havia praticado nenhuma atividade física intensa. Martins et al., em sua revisão destacam que o uso de escalas em pediatria apresenta dificuldade, pois depende e exige da compreensão da criança, sendo algo complexo. Ressaltam que até o momento não há uma escala padrão ouro para avaliação da dispnéia e/ou percepção de esforço em crianças, porém a BORG ainda é uma das mais utilizadas nessa população, justificando o seu uso no presente estudo.

Gevaerd et al., aplicaram em um paciente de 17 anos diagnosticado com DMD, um protocolo de tratamento dividido em três etapas, composta por: alongamentos, exercícios respiratórios, movimentos ativos e ativo-assistido de MMSS e MMII. Nossa pesquisa também 
aplicou um protocolo com três etapas, contemplada com alongamentos e movimentos ativos de MMSS, MMII e em nosso caso também do tronco. O objetivo em utilizar um protocolo em etapas era poder controlar a fadiga, e isso foi possível durante todo o tratamento, permitindo observar a intensidade de cada exercício. A etapa relacionada aos MMSS demonstrou ser de maior intensidade, com média da FC de 103,22 bpm, sendo a mais elevada quando em comparação com as outras etapas. Miranda; Malaguti; Dal corso., em sua revisão, analisaram a disfunção muscular periférica em MMSS e MMII em DPOC, e constataram quando realizadas as três elevações básicas de MMSS houve aumento das variáveis VO2 (consumo de gás oxigênio) e VCO2 (consumo de gás carbônico), ventilação pulmonar, FR e FC. Sendo assim, atividades com os MMSS geram aumento do VCO2, isso por sua vez, tem alta ventilação com elevação do lactato. Dessa maneira, tais elementos confirmam com o que foi observado em nossa etapa de MMSS, através da FC.

Nesta pesquisa a FC aumentava ao longo das etapas propostas e de acordo com o nível de exigência do exercício, onde a $1^{\text {a }}$ etapa (alongamento) exibiu uma média de 93,11 bpm, a $2^{\mathrm{a}}$ em MMSS 103,22 bpm, e MMII 97 bpm, e a $3^{\mathrm{a}}$ etapa (tronco) 98,44 bpm. Também encontrado por Souza et al., que avaliaram o índice de gasto energético (IGE) através dos valores da FC durante o repouso e a marcha, e seus resultados demonstraram que o IGE aumentou conforme a progressão das etapas, onde era exigido maior esforço para a sua execução, sendo observado que os pacientes de maior idade apresentaram um maior gasto energético, mostrando que o aumento da FC indica o gasto energético e o seu monitoramento é válido para o controle da fadiga. Por fim, a literatura encontra-se escassa em relação a estudos que acompanham e analisam a fadiga em portadores de DMD, dificultando uma possível comparação com os resultados desse estudo.

\section{CONCLUSÃO}

Concluímos que o protocolo aplicado com exercícios de baixa intensidade permitiu controlar e acompanhar o nível de fadiga e a intensidade de cada exercício através de instrumentos de fácil utilização em um paciente com DMD, e que apesar da patologia levar a alterações no SNA, essa modalidade foi benéfica e atuou conforme o esperado, reduzindo a FC e a PAD.

Palavras-chave: Distrofia muscular, fadiga, distrofia muscular de Duchenne, distrofina, PhysicalTherapy. 
1.CAROMANO, F.A. Características do portador de distrofia muscular de Duchenne: Revisão. ArqCiencSaude Unipar 1999;3(3):211-218.

2.SANTOS, N.M et al. Perfil clínico e funcional dos pacientes com Distrofia Muscular de Duchenne assistidos na Associação Brasileira de Distrofia Muscular (ABDIM). RevNeurocienc, 2006; 14(1):015-022.

3.MARUI, F.R.R.H. et al. Comportamento de Variáveis Pressóricas em Crianças e Adolescentes com Distrofia Muscular de Duchenne. Arq. Bras. Cardiol., São Paulo, v. 110, n. 6, p. 551-557, June 2018. 


\section{ANÁLISE DO DESPERDÍCIO E CUSTOS GERADOS PELO USO DE FÓRMULA LÁCTEA PARA PREMATUROS EM UMA UNIDADE DE CUIDADOS INTENSIVOS E SEMI-INTENSIVOS POR MEIO DE REGISTROS DIETÉTICOS}

Mateus Fernandes da Silva - Universidade Federal de Campina Grande, Cuité, Paraíba,

Brasil.

Taelyson Costa de Medeiros - Universidade Federal de Campina Grande, Cuité, Paraíba,

Brasil.

Sabrina Mércia Belarmino Gomes - Universidade Federal de Campina Grande, Cuité, Paraíba, Brasil.

Raissa Mislaine Santos da Silva - Universidade Federal de Campina Grande, Cuité, Paraíba,

Brasil.

Larissa de Alcântara Santos - Universidade Federal de Campina Grande, Cuité, Paraíba,

Brasil.

Jaielison Yandro Pereira da Silva - Universidade Federal de Campina Grande, Cuité, Paraíba,

Brasil.

Área Temática: Nutrição.

E-mail: mateus.fnds@ hotmail.com

\section{RESUMO}

Fórmulas lácteas para prematuros são bastante usadas em unidades de cuidados intensivos e semi-intensivos a fim de assegurar uma melhor alimentação ao recém-nascido pré-termo em casos em que há a impossibilidade do uso de leite materno. Para tanto, torna-se necessária a adequada distribuição dessas fórmulas pelo lactário e seu uso nas enfermarias. A falta de comunicação entre as equipes, manejo e armazenamento inadequado, como também a falha na conferência do prazo de validade das formulações geram desperdício, o que representa um prejuízo na qualidade desse serviço. A análise dos custos com esse tipo de prejuízo pode fornecer informações de grande valia para a gestão hospitalar. Portanto, objetivou-se analisar os desperdícios e os custos gerados pelo uso de fórmulas lácteas para prematuros em uma unidade de cuidados intensivos e semi-intensivos por meio de registros dietéticos. Para tanto, os custos foram estimados utilizando o volume, a diluição, gramatura da fórmula em questão (lata), e da sua colher medida, além do seu preço, por meio de cálculos específicos. Ainda se analisou o índice de desperdício. Produziu-se $4.125 \mathrm{~L}$, sendo 56,2\% consumido e 43,8\% desperdiçado. O custo com a produção foi de $\mathrm{R} \$ 50,05$, sendo $\mathrm{R} \$ 28,15$ consumido, e $\mathrm{R} \$$ 21,90 desperdiçado. O índice de desperdício foi de 43\%, sendo classificado como péssimo. Portanto, conclui-se que é de grande importância analisar os custos com fórmulas infantis, principalmente seu desperdício, como forma de rever processos, contribuindo com a gestão hospitalar para um melhor uso de seus insumos.

Palavras-chave: UTI neonatal. Recém-nascidos prematuros. Fórmulas para lactentes. 


\section{INTRODUÇÃO}

A prematuridade é um problema de saúde pública que vem se tornando cada vez mais comum e para prestar a assistência necessária a esse tipo de paciente torna-se fundamental o encaminhamento para uma Unidade de Cuidados Intermediários e Semi-intensivos Neonatais (UCIS). Essa unidade possui um ambiente com tecnologias avançadas e profissionais qualificados que visam garantir uma melhor recuperação no quadro clínico desses bebês, contribuindo para melhorar sua condição de saúde (OLIVEIRA; SANINO, 2011).

A adequada alimentação para um recém-nascido pré-termo (RNPT) torna-se imprescindível para garantir sua recuperação. O leite materno é a primeira opção a ser utilizada, porém, em alguns casos seu uso é impossibilitado, optando-se por uma fórmula láctea (FL), mais especificadamente, uma fórmula láctea para prematuro (FLPT) (AZEVEDO, 2020).

A utilização dessa FL possui um custo elevado, principalmente, por atender demandas dietoterápicas especificas. Em âmbito hospitalar essa FL é processada pelo lactário, o qual faz parte do Serviço de Nutrição e Dietética cuja finalidade é preparar, higienizar e distribuir essas fórmulas (LINHARES, 2012). Além dessas etapas as profissionais do lactário também devem manter os registros de produção, dispensação e desperdício desse tipo de fórmula.

\section{OBJETIVOS}

Diante do exposto, este estudo tem por finalidade analisar o desperdício e os custos gerados pelo uso de FLPT utilizada em uma unidade de cuidados intensivos e semi-intensivos por meio de registros dietéticos.

\section{METODOLOGIA}

A pesquisa foi realizada com os registros dietéticos de uma ferramenta eletrônica disponível no lactário de um hospital universitário no interior do Rio Grande do Norte, sobre o uso de FLPT durante o mês de dezembro de 2020.

O volume produzido foi estimado com base na somatória do volume de todos os suplementos lácteos e dietas enterais preparadas e distribuídas pelo lactário. O volume 
desperdiçado foi considerado a somatória dos volumes dos desperdícios. O volume consumido foi estimado por meio da subtração do volume produzido pelo desperdiçado.

Os custos foram estimados utilizando o volume, a diluição, gramatura da colher medida e da lata da FLPT, além do seu preço (dado obtido pela gestão hospitalar com base na última licitação), conforme Equação 1.

$R \$ F L P T=\frac{\left(\frac{\text { volume }(m L)}{\text { diluição }(m L)} \times \text { colher medida }(g)\right) \times \text { Preço da FLPT }}{\text { Gramatura da lata de FLPT }}$

Ainda se calculou o índice de desperdício (ID) levando em consideração o volume total produzido dividido pelo volume desperdiçado, conforme a Equação 2. O desperdício foi classificado de acordo com Castro e Queiroz (1998) em "ótimo" quando inferior a 5\%; "bom” aquele percentual entre 5 e 10\%; "regular" entre 10 e $15 \%$ e "péssimo", acima de $15 \%$.

$$
\mathrm{ID}(\%)=\frac{\text { Volume total produzido }(\mathrm{mL})}{\text { Volume desperdiçado das enfermarias }(\mathrm{mL})} \times 100
$$

O projeto foi submetido e aprovado por um Comitê de Ética em Pesquisa sob o número CAAE: 38691920.0 .0000 .5568 .

\section{RESULTADOS E DISCUSSÃ̃}

Com base na pesquisa foram observados 206 registros sobre a utilização da FLPT sendo $83,5 \%$ sobre produção e distribuição e $16,5 \%$ de desperdício. O volume total produzido foi de $4.125 \mathrm{~L}$, sendo $56,2 \%$ consumido e $43,8 \%$ desperdiçado (Tabela 1 ).

Tabela 1 - Relação das frequências e volumes registrados com o uso da FLPT no mês de dezembro de 2020.

\begin{tabular}{cccc}
\hline \multirow{2}{*}{ RELAÇÃO DOS VOLUMES } & \multicolumn{2}{c}{ CARACTERÍSTICAS } \\
\cline { 2 - 3 } & \multirow{2}{*}{ Dezembro } & Frequência (\%) & Volume (\%) \\
\cline { 2 - 3 } & Volume produzido & $172(83,5 \%)$ & 4.125 L (100\%) \\
& Volume desperdiçado & - & $2.320 \mathrm{~L}(56,2 \%)$ \\
& Vonsumido & $34(16,5 \%)$ & $1.805 \mathrm{~L}(43,8 \%)$ \\
\hline
\end{tabular}

Fonte: Dados da pesquisa (2021). 
Para a produção dessa fórmula utilizou-se a diluição do fabricante, sendo $30 \mathrm{~mL}$ para cada colher medida. O valor da licitação da lata de 400g de FLPT foi de R \$26,00 e a colher medida da fórmula foi de 5,60 g. Com base nessas informações realizou-se a conversão para o custo institucional como visto na Tabela 2.

Tabela 2 - Custo institucional com o volume de produção, consumo e desperdício da FLPT durante o mês de dezembro de 2020.

\begin{tabular}{lccc}
\hline FÓRMULA & PRODUÇÃO & CONSUMO & DESPERDÍCIO \\
\hline FLPT & $\mathrm{R} \$ 50,05$ & $\mathrm{R} \$ 28,15$ & $\mathrm{R} \$ 21,90$ \\
\hline
\end{tabular}

Fonte: Dados da pesquisa (2021).

Observa-se que o custo com a produção foi de $\mathrm{R} \$ 50,05$, sendo $\mathrm{R} \$ 28,15$ consumido e $\mathrm{R} \$ 21,90$ desperdiçado. Na Tabela 3 observa-se que o ID foi de 43\%, sendo classificado como "péssimo".

Tabela 3 - Índice de desperdício da FLPT durante o mês de dezembro de 2020.

\begin{tabular}{|c|c|c|}
\hline FÓRMULA & ÍNDICE & CLASSIFICAÇÃOO \\
\hline FLPT & 0,43 & Péssimo \\
\hline
\end{tabular}

Fonte: Dados da pesquisa (2021).

Ressalta-se a importância dessas análises, pois o volume e o custo gasto com o desperdício foram próximos dos valores de consumo. Segundo Ferreira et al. (2021) o custo das fórmulas lácteas é elevado, principalmente, quando se tratam de fórmulas especializadas, a exemplo, para prematuros e/ou alérgicos. A internação de um bebê prematuro acarreta um custo relativamente considerável para a gestão hospitalar tendo em vista o nível de especialidade para suprir suas necessidades no que diz respeitos a equipamentos e demais insumos (AGUIAR, 2020).

Ferreira et al. (2021) e Azevedo (2020) apresentam que um dos maiores motivos para os desperdícios de fórmulas lácteas nessas unidades trata-se de falhas de comunicação entre a equipe e o lactário, que poderia ser modificado por meio da criação de um diálogo mais ativo. (FERREIRA et al. 2021; OLIVEIRA; OLIVEIRA; PEREIRA, 2017). 
Portanto, conclui-se que é de grande importância analisar os custos com fórmulas infantis, principalmente seu desperdício, como forma de rever processos, contribuindo com a gestão hospitalar para um melhor uso de seus insumos.

\section{REFERÊNCIAS}

AGUIAR, A.A. Os efeitos da prematuridade na gestão financeira do sistema de saúde do exército. 2020. 20 f. Trabalho de conclusão de curso (Curso de aperfeiçoamento Militar/Curso de aperfeiçoamento de oficiais médicos) - Escola de Saúde do Exército, [s. l.], 2020 .

AZEVEDO, S. Gestão da qualidade do serviço de lactário hospitalar de um instituto nacional de saúde: proposição de indicadores. 2020. 135 f. Dissertação (Mestrado em Nutrição Clínica) - Universidade Federal do Rio de Janeiro, Rio de Janeiro, 2020.

CASTRO, F. A. F.; QUEIROZ, V. M. V. Cardápios: planejamento, elaboração e etiqueta. Viçosa: Universidade Federal de Viçosa; 1998. 97 p.

FERREIRA, L. C. et al. Análise do percentual de desperdício do leite humano e de fórmulas infantis em serviço de neonatologia. Saúde Coletiva, Barueri, v. 11, n. 61, p. 4898-4905, 2021.

LINHARES, I. W. Avaliação das condições higiênico-sanitárias no preparo de fórmulas infantis em lactário hospitalar. 2012. 117 f. Dissertação (Mestrado em Ciência dos Alimentos) - Faculdade de Farmácia, Universidade Federal de Minas Gerais, Belo Horizonte, 2012.

OLIVEIRA, D. A.; OLIVEIRA, J. L.; PEREIRA, K. N. Análise dos principais fatores de desperdício em uma Unidade de Alimentação e Nutrição-UAN. South American Journal of Basic Education, Technical and Technological, v. 4, n. 2, p. 3, 2017.

OLIVEIRA, L. T.; SANINO, G. E. A humanização da equipe de enfermagem em Unidade de Terapia Intensiva Neonatal: concepção, aplicabilidade e interferência na assistência humanizada. Revista da Sociedade Brasileira de Enfermeiros Pediatras, v. 11, n. 2, p. 7583, 2011. 


\section{ASSISTÊNCIA DO ENFERMEIRO NA HIPOTERMIA TERAPÊUTICA PARA NEUROPROTEÇÃO DE NEONATOS COM ENCEFALOPATIA HIPÓXICO- ISQUÊMICA: REVISÃO INTEGRATIVA}

Nadia Maia Pereira - Universidade Estadual do Piauí - UESPI, Parnaíba, Piauí, Brasil. Diêgo Afonso Cardoso Macêdo de Sousa - Universidade Estadual do Piauí - UESPI, Parnaíba, Piauí, Brasil.

\section{Área Temática: Enfermagem}

E-mail do autor para correspondência: nadiamaia25@hotmail.com

\section{RESUMO}

A Hipotermia Terapêutica é um tratamento que reduz a mortalidade e os danos neurológicos de neonatos com Encefalopatia Hipóxico-Isquêmica e consiste em resfriar o recém-nascido a uma temperatura entre $32^{\circ} \mathrm{C}$ e $34^{\circ} \mathrm{C}$. Este trabalho objetivou identificar os cuidados prestados pelo Enfermeiro na Hipotermia Terapêutica para neuroproteção de neonatos com Encefalopatia Hipóxico-Isquêmica. Trata-se de uma revisão integrativa da literatura, cujos estudos foram selecionados através da busca eletrônica nas bases de dados e bibliotecas Scopus, CINAHL, BVS-BIREME, SciELO e Web of Science via Portal de Periódicos CAPES, BDENF e MEDLINE via PUBMED, utilizando-se descritores selecionados a partir do MeSH e do DeCs, e cruzados através do operador booleano AND. Após a aplicação dos critérios de inclusão e exclusão, foram selecionados dois artigos para esta revisão. Após análise dos resultados encontrados, observou-se que o enfermeiro tem um importante papel na atenção às funções cardiovascular, respiratória, renal e gastrointestinal e às condições dermatológicas e no monitoramento do bebê durante a fase de reaquecimento. É imprescindível que o neonato que preenche os critérios para essa terapia seja identificado precocemente. Futuras pesquisas são necessárias para se esclarecer melhor o papel do enfermeiro na hipotermia terapêutica e a sua segurança e eficácia como neuroproteção para neonatos com Encefalopatia Hipóxico-Isquêmica leve.

Palavras-chave: Papel do Enfermeiro. Hipotermia Induzida. Encefalopatia por Hipóxia. Recém-Nascido. 
A Hipotermia Terapêutica (HT) é o cuidado padrão para recém-nascidos (RNs) com Encefalopatia Hipóxico-Isquêmica (EHI) moderada ou severa. Consiste em reduzir a temperatura cerebral dos neonatos a um intervalo de $32^{\circ} \mathrm{C}$ e $34^{\circ} \mathrm{C}$ entre seis e setenta e duas horas após o nascimento, seguido de reaquecimento gradual ao longo de quatro horas até que se obtenha uma temperatura axilar de $36,5^{\circ} \mathrm{C}$ e central (esofágica ou retal) de aproximadamente $37^{\circ} \mathrm{C}$ (ANDRADE et al., 2011; MERRIL, 2012).

É executada através de dois métodos: o primeiro é realizado através do resfriamento de corpo inteiro, em que o neonato é colocado em um colchão térmico; e o segundo através de resfriamento seletivo de cabeça, realizado por meio de um capacete (ANDRADE et al., 2011).

A EHI constitui a consequência mais grave da asfixia perinatal e ocorre em cerca de $33 \%$ dos RNs que a apresentam. Cerca de 15 a 20\% dos neonatos afetados morrem no período pós-natal e $25 \%$ dos sobreviventes desenvolvem deficiências graves na infância, como disfunções sensoriais, motoras e cognitivas; com alto ônus individual, familiar e social (GLUCKMAN et al., 2005; AUSTIN, 2018).

Segundo a Sociedade Brasileira de Pediatria (2020) os materiais necessários para instituir a Hipotermia Terapêutica são: berço com material que suporte a fase de reaquecimento; colchão térmico ou capacete de resfriamento; termômetro esofágico ou retal e monitor multiparamétrico. A adoção da HT em países de alta renda é um dos avanços mais significativos do cuidado neonatal nos últimos 20 anos por sua importância na redução da morbimortalidade neonatal. No entanto, nos países em desenvolvimento, como o Brasil, onde a EHI é mais incidente, a HT não é amplamente utilizada, mesmo com a simplicidade relativa da instituição da terapia (AUSTIN, 2018).

\section{OBJETIVOS}

Identificar os cuidados prestados pelo Enfermeiro na Hipotermia Terapêutica para neuroproteção de neonatos com Encefalopatia Hipóxico-Isquêmica através da análise de produções científicas.

\section{METODOLOGIA}

Trata-se de uma revisão integrativa de literatura, construída segundo Mendes; Silveira e Galvão (2008). Para a realização da pesquisa foram utilizados os descritores controlados: "Hypothermia, Induced", "Hypoxia-Ischemia, Brain", "Infant, Newborn”, "Nurse's role" e suas traduções para o português: "Hipotermia Induzida", "Encefalopatia HipóxicoIsquêmica", "Neonato" e "Papel do Enfermeiro", selecionados a partir do MeSH e do DeCs, 
respectivamente. O cruzamento dos descritores foi realizado através do operador booleano AND.

A busca foi realizada no mês de fevereiro de 2021, nas seguintes bases de dados e bibliotecas: Scopus, CINAHL, BVS-BIREME, Scielo, Web of Science, estas via Portal de Periódicos CAPES; BDENF, e MEDLINE via PUBMED.

Foram incluídos artigos disponíveis na íntegra, publicados em português, inglês ou espanhol, nos anos de 2005 a 2020. Foram excluídas revisões de literatura e artigos repetidos e/ou que após a leitura do título e resumo não responderam à questão da pesquisa. A amostra inicial constituiu-se de 84 artigos. Após a aplicação dos critérios de inclusão e exclusão préestabelecidos restaram dois artigos que foram selecionados para esta revisão.

Em seguida, foi observado se havia similaridade entre os resultados encontrados e foram encontradas respostas para a questão norteadora e para os demais objetivos deste estudo. Foi observado o conhecimento científico produzido até o momento acerca do tema deste trabalho e foram identificadas lacunas do conhecimento que puderam direcionar futuras pesquisas.

\section{RESULTADOS E DISCUSSÃO}

Apesar da busca em diversas fontes de informação e da pesquisa por artigos dos últimos 15 anos, somente dois estudos responderam à questão de pesquisa do presente trabalho. O artigo intitulado "Hipotermia Induzida para Neonatos com Encefalopatia Hipóxico-isquêmica" foi publicado em 2007 no Journal of Obstetric, Gynecologic, and Neonatal Nursing, escrito por enfermeiras da Carolina do Norte. O artigo "Hipotermia Terapêutica para tratar Encefalopatia Hipóxico-Isquêmica em Neonatos: Implicações para Enfermeiros" foi publicado no ano de 2012 na revista Nursing for Women's Health, escrito por uma enfermeira neonatologista, no Canadá.

Com base nas pesquisas publicadas até o momento, a HT é reservada para os neonatos a termo ou que se aproximam do termo, com histórico de um evento perinatal agudo, que apresentem na gasometria arterial de sangue do cordão ou colhida na primeira hora de vida $\mathrm{pH}<7,0$ ou déficit de base $\leq-15$ ou Apgar $<5$ no décimo minuto de nascimento e que exibem sinais de EHI moderada ou grave (SHANKARAN et al., 2005).

Os enfermeiros têm fundamental participação na identificação dos bebês em risco de desenvolver EHI, além de acompanhar e relatar mudanças no estado do paciente. O enfermeiro também é responsável pelo monitoramento cuidadoso dos sinais vitais do neonato. 
Deve-se também realizar a gasometria arterial de rotina e verificar a glicemia capilar (LONG; BRANDON, 2007; GRAÇA et al., 2012; MARGOTTO; ZACONETA, 2015).

Para os bebês em uso de ventilação assistida, também é função do enfermeiro manter a saturação do neonato entre $92 \%$ e $98 \%$ e realizar a aspiração de secreções que podem estar mais espessas devido à hipotermia (GRAÇA et al., 2012; MARGOTTO; ZACONETA, 2015).

O enfermeiro também deve realizar um balanço hídrico rigoroso. Se o bebê apresentar oligúria por mais de 8 horas, deverão ser administrados volume e diurético, conforme prescrição médica. O enfermeiro deve propiciar uma ambientação da UTIN de modo que minimize os estímulos ao bebê e atentar para as lesões na pele do RN que podem surgir devido ao resfriamento e falta de movimentação por conta da sedação (LONG; BRANDON, 2007; MERRIL, 2012).

É importante que os enfermeiros avaliem e manejem a dor, realizem os cuidados com a nutrição parenteral e acompanhe os sinais vitais do bebê durante a fase de reaquecimento para evitar uma elevação excessivamente rápida da temperatura e hipotensão (LONG; BRANDON, 2007; MERRIL, 2012; GRAÇA et al., 2012; MARGOTTO; ZACONETA, 2015).

\section{CONCLUSÃO}

A HT é apontada como o cuidado padrão para neonatos com EHI moderada e grave pela sua eficácia em reduzir a mortalidade e as sequelas neurológicas nos bebês, no entanto, é imprescindível que o neonato que preenche os critérios para essa terapia seja identificado precocemente e que os profissionais, sobretudo, os enfermeiros estejam devidamente capacitados para realizarem seus cuidados durante a terapia.

São diversas as funções do enfermeiro durante este tratamento que vão desde a identificação dos bebês em risco de desenvolver a EHI e a atenção às funções cardiovascular, respiratória, renal e gastrointestinal e às condições dermatológicas até ao monitoramento durante a fase de reaquecimento. A execução responsável e baseada em evidências científicas dos cuidados de enfermagem repercute na redução dos riscos desse tratamento para o bebê e otimiza a sua efetividade. É necessário que futuras pesquisas se aprofundem no papel do enfermeiro frente à HT haja vista que poucos são os estudos publicados com essa temática.

REFERENCIAS

ANDRADE, A. H. V. et al. Atualização terapêutica: hipotermia terapêutica. Einstein: Educ. Contin. Saúde. n. 3 pt 2, v. 9, p.159-61, 2011. Disponível em: 
<http://apps.einstein.br/revista/arquivos/PDF/2214-EC_v9n3_159-161.pdf>. Acesso em: 12 dez. 2019.

AUSTIN, T. Hipotermia terapêutica para encefalopatia hipóxico-isquêmica: desafios durante a transferência e perspectivas globais. J Pediatr. v. 94, n. 3, p. 221-223, 2018.

GLUCKMAN, P. D. et al. Selective head cooling with mild systemic hypothermia after neonatal encephalopathy: multicenter randomized trial. Lancet. v. 365. n. 9460. p. 663-670, 2005.

GRAÇA, A. M. et al. Hipotermia induzida no tratamento da encefalopatia hipóxico-isquêmica neonatal: consenso nacional. 2012.

LONG; M.; BRANDON, D. H. Induced Hypothermia for Neonates With Hypoxic-Ischemic Encephalopathy. JOGNN Clinical Issues. v. 36, n. 3, Jun, 2007.

MARGOTTO, P. R.; ZACONETA, C. A. Protocolo para hipotermia terapêutica. Brasília: Hospital Materno Infantil de Brasília, 2015.

MENDES, K. D. S.; SILVEIRA, R. C. C. P.; GALVÃO, C. M. Revisão integrativa: método de pesquisa para a incorporação de evidências na saúde e na enfermagem. Texto \& Contexto Enfermagem. v. 17, n. 4, p. 758-764, Out-Dez, 2008.

MERRIL, L. Therapeutic Hypothermia to treat Hypoxic Ischemic Encephalopathy in Newborns: Implications for nurses. Nursing for Women's Health. v. 16. 2012.

SHANKARAN, S. et al. Whole-body hypothermia for neonates with hypoxic-ischemic encephalopathy. N Engl J Med. v. 353. p. 1574-1584, 2005. 


\section{ATUAÇÃO INTERPROFISSIONAL DOS CUIDADOS ÀS CRIANÇAS COM AUTISMO: UMA REVISÃO LITERÁRIA}

Maria Eduarda Wanderley de Barros Silva - Universidade Federal de Campina Grande, Cuité, Paraíba, Brasil.

Larissa de Alcântara Santos - Universidade Federal de Campina Grande, Cuité, Paraíba,

Brasil.

Nayane Gabriela Ferreira Macêdo e Silva - Universidade Federal de Campina Grande, Cuité, Paraíba, Brasil.

Sabrina Mércia Belarmino Gomes - Universidade Federal de Campina Grande, Cuité, Paraíba, Brasil.

Thalita Oliveira de Melo - Universidade Federal de Campina Grande, Cuité, Paraíba, Brasil

Aréa Temática: Multiprofissional.

E-mail do autor para correspondência: eduarda.wanderley@outlook.com

\section{RESUMO}

O Transtorno do Espectro Autista (TEA) é uma condição de saúde caracterizada pelo déficit no comportamento e comunicação social, sendo considerada uma pessoa com deficiência que possui acesso as diretrizes que versam sobre ações e políticas de atendimento, participação na comunidade, atenção integral às necessidades de saúde, inserção no mercado de trabalho e outros direitos, como a inclusão no sistema regular de ensino. Objetivou identificar a atuação interprofissional dos cuidados às crianças com autismo. Trata-se de um estudo de natureza bibliográfica realizada no primeiro semestre de 2021, através da Scientific Electronic Library Online (SCIELO), utilizando-se descritores pré-estabelecidos pelo Descritores em Ciências da Saúde (DECs) "Transtorno Autístico", “Assistência à Saúde” e "Equipe de Assistência ao Paciente”. Os artigos que compuseram a amostra foram submetidos aos seguintes critérios de inclusão: I) ser indexado; II) estar nos idiomas português ou inglês; III) publicado entre os períodos de 2016 a 2021; IV) ser do tipo original ou de revisão. Dessa forma, existe a necessidade do compartilhamento e da troca de informações e conhecimentos entre os profissionais de saúde e familiares com a finalidade de interagir sobre medos, dúvidas, situações difíceis, diagnóstico, participação em programas ou grupos de intervenção, comparação de experiências pessoais ou vivenciadas por outros pais fazendo com que se tenha a intervenção interprofissional e benefícios dos pais nessa vivência com a criança. $\mathrm{O}$ 
TEA necessita ser discutido no ambiente profissional com intuito de envolver a equipe interdisciplinar e juntamente os familiares envolvidos nos cuidados da criança.

Palavras-chave: Transtorno Autístico. Assistência à Saúde. Equipe de Assistência ao Paciente.

\section{INTRODUÇÃO}

O Transtorno do Espectro do Autismo (TEA), sendo considerado um transtorno neurológico caracterizado por comprometimento no déficit de comportamento e comunicação social desde o nascimento ou começo da infância tendo como características a falta de interação social, isolamento social e a dificuldade de manter relações (ANJOS et al., 2021). O cuidado interpessoal possui como conceito a noção do trabalho em equipe com discussões e diálogos dos papéis profissionais, sendo uma proposta de trabalho em conjunto com as especificidades de cada paciente com a finalidade de proporcionar qualidade no cuidado ao paciente.

Historicamente o autismo é considerado como um distúrbio, doença ou deficiência, isto encontra-se em controvérsia pela comunidade dos autistas que discorda desse ponto de vista, afirmando que o autismo é uma forma natural da diversidade humana afirmando que não existem cérebros ou mentes normais, mas uma contrução cultural do que a sociedade considera como normal e a incompreensão de várias variantes neurológicas sendo o caso do autismo (ANJOS et al., 2021).

Dessa forma, o autismo deve ser considerado como um espectro de condições multidiversas, podendo apresentar vários tipos de comorbidades que aumentam sua complexidade essas condições pode colocar as pessoas no espectro autista (AS) em uma posição de desvantagem ou deficiência social (CHÁVEZ et al., 2020). Assim, se tem a relevância de possuir uma equipe interdisciplinar qualificada com estratégias de intervenções com finalidade de estabelecer um laço de confiança e segurança com a criança pra que ela se sinta segura e desenvolva a comunicação e o seu convívio social.

\section{OBJETIVOS}

- Objetivos Gerais:

Identificar a atuação interprofissional dos cuidados às crianças com autismo. 
- Objetivos Específicos:

Analisar as ações que a equipe interprofissional de saúde executa acerca dos cuidados as crianças com autismo.

\section{MÉTODO}

Trata-se de uma pesquisa bibliográfica de caráter descritivo, realizada através de fontes secundárias contidas em bancos de dados indexados através da Scientific Electronic Library Online (SCIELO). Utilizando-se descritores pré-estabelecidos pelo Descritores em Ciências da Saúde (DECs) "Transtorno Autístico", "Assistência à Saúde" e "Equipe de Assistência ao Paciente", realizada no primeiro semestre de 2021. A amostra total foi de 5 artigos.

Os artigos que compuseram a amostra foram submetidos aos seguintes critérios de inclusão: I) ser indexado; II) estar nos idiomas português ou inglês; III) publicado entre os períodos de 2016 a 2021; IV) ser do tipo original ou de revisão.

\section{RESULTADOS}

O TEA, faz com que o indivíduo possua sua comunicação prejudicada, atividades e interesses repetitivos e tenha comportamento agressivo gerando com isso a falta de interação e dificuldade de manter relações sociais com outras crianças e com sua própria família se isolando e vivendo no seu mundo. De acordo com os resultados verificou-se que os pais possuem dificuldades de lidar e gerenciar problemas comportamentais das crianças autistas (MARANHÃO et al., 2019).

Dessa forma, se tem a necessidade do compartilhamento e troca entre os profissionais de saúde e familiares com a finalidade de interagir sobre medos, dúvidas, situações difíceis, diagnóstico, participar de programas ou grupos de intervenção, comparação de experiências pessoais ou vivenciadas por outros pais fazendo com que se tenha a intervenção interprofissional e benefícios dos pais nessa vivênccia com a criança (ANJOS et al., 2021).

O Autismo Infantil se tornou um problema para o Brasil devido a falta de um dignóstico eficiente, pois não possui profissionais adequadamente qualificados para acompanhar esses pacientes. Assim, desde o surgimento da doença foi relatado que vem acontecendo a evolução dos conceitos de doença, pois com os conhecimentos ao longo dos 
anos é relatado que nem sempre é manifestado os mesmos sinais e sintomas e muitas vezes não tendo a mesma intensidade quando comparado anteriormente (SOUZA et al., 2017).

Em outro estudo foi relatado que é inconteste a necessidade de serviços especializados que sejam capazes de promover e articular a integração apropriada do primeiro nível de atenção com níveis secundários e terciários, além do apropriado balanço de disciplinas profissionais que são necessárias para servir as necessidades da saúde das crianças autistas. Com a criação do Serviço de Atenção ao Transtorno do Espectro do Autismo (SATEA), se tem a prerrogativa de atuar na formação, desenvolvimento e educação permanente de profissionais de saúde, desenvolvendo ações integradas de ensino, pesquisa e extensão centradas nas concepções de responsabilidade social, equidade, qualidade e eficiência, para gerar evidências científicas, desenvolver estratégias e promover parcerias capazes de fortalecer e auxiliar o Sistema Único de Saúde (SUS) (MARANHÃO et al., 2019).

\section{CONCLUSÃO}

Diante do exposto, fica evidente que o TEA necessita ser discutido com intuito de envolver a equipe interdisciplinar e demais envolvidos nos cuidados da criança. Apesar de todos estarem cientes de que a criança portadora de autismo apresenta significativos problemas de interação social, a equipe deve garantir o vínculo com a família e os cuidadores durante todas as etapas do cuidado, não excluindo nenhum profissional, tão pouco colocando todas as responsabilidades sobre apenas um. É importante que a equipe interprofissional auxilie e acompanhe a criança, desde o diagnóstico até as fases do desenvolvimento, observando e minimizando os sintomas, estimulando as relações sociais, a linguagem, a coordenação motora, bem como a família em cada situação vivida, observando a estrutura familiar, base desta criança.

\section{REFERÊNCIAS}

ANJOS, B.B.; MORAIS, N.A. As experiências de famílias com filhos autistas: uma revisão integrativa da literatura. Cienc. Psicol. Montevideo, v. 15, n. 1, 2021. Available from: <http://www.scielo.edu.uy/scielo.php?script=sci_arttext\&pid=S16884221202100010120 $3 \& \operatorname{lng}=\mathrm{es} \& \mathrm{nrm}=\mathrm{iso}>$. Access on 24 Apr. 2021.

CHAVÉZ, C.L. et al. La determinación social del autismo en población infantil ecuatoriana. Rev. Cienc. Salud, Bogotá, v.18, p. 4-30, 2020. Available from: 
<http://www.scielo.org.co/scielo.php?script=sci_arttext\&pid=S169272732020000400004\&ln $\mathrm{g}=\mathrm{en} \& \mathrm{nrm}=\mathrm{iso}>$. Access on 24 Apr. 2021.

MARANHÃO, S.; LISBOA, L.; REIS, C. (2019). Educação e trabalho interprofissional na atenção ao transtorno do espectro do autismo: uma necessidade para a integralidade do cuidado no SUS. Revista Contexto \& Amp Saúde, v. 37, p. 59-68, 2019. Disponível em: https://doi.org/10.21527/2176-7114.2019.37.59-68. Acesso em 24 Abr. 2021.

SOUSA, A. M. B.; SOUSA, C.S. (2017). Produções científicas sobre os cuidados de enfermagem às crianças com Transtorno do Espectro Autista (TEA). Revista Científica Multidisciplinar Núcleo do Conhecimento, v. 2, p. 387-406, 2017. Dsiponível em: https://www.revistas.unijui.edu.br/index.php/contextoesaude/article/view/8116. Acesso em 24 Abr. 2021. 


\title{
BENEFÍCIOS DO MÉTODO CANGURU NO CONTEXTO DA INTERNAÇÃO EM UNIDADES DE TERAPIA INTENSIVA NEONATAL: REVISÃO INTEGRATIVA
}

\author{
Lívia Sayuri Félix Mendes - Centro Universitário INTA - UNINTA, Sobral, Ceará, Brasil. \\ José Marcos Fernandes Mascarenhas - Christus Faculdade do Piauí - CHRISFAPI, Piripiri, \\ Piauí, Brasil.
}

Maria Dhescyca Ingrid Silva Arruda - Faculdade São Francisco da Paraíba - FASP,

Cajazeiras, Paraíba, Brasil.

Jessica Maria Santos Dias - Faculdade UNINASSAU, Teresina, Piauí, Brasil.

Thaina Safira Souza da Costa - Instituto Dexter, Parnaíba, Piauí, Brasil.

Área Temática: Outros.

E-mail do autor para correspondência: livya.mendessp@gmail.com

\section{RESUMO}

O Método Canguru é uma técnica criada na Colômbia, em 1979, e consiste no cuidado pele a pele entre um recém-nascido e sua mãe, ou profissional de saúde responsável. A técnica possui inúmeros benefícios de utilização, inclusive quando aplicada com bebês internados em Unidades de Terapia Intensiva Neonatal (UTIN). Dessa forma, o presente estudo objetivou identificar na literatura científica os principais benefícios da utilização do Método Canguru no contexto da internação na UTIN. Os inúmeros benefícios descritos englobam aspectos anatômicos, fisiológicos e emocionais para o recém-nascido e sua família, comprovando a necessidade de aplicação da técnica como um recurso de assistência multiprofissional aos neonatos.

Palavras-chaves: Método Canguru. Recém-Nascido Prematuro. Unidades de Terapia Intensiva Neonatal.

\section{INTRODUÇÃO}

O Método Canguru é uma técnica desenvolvida em 1979, na Colômbia, e consiste em um tipo de assistência neonatal caracterizada pelo contato pele a pele entre a mãe e o bebê, voltada para o atendimento do recém-nascido prematuro ou com baixo peso (BRASIL, 2017). Atualmente, com princípios difundidos por todo o mundo, já se sabe que o Método pode trazer inúmeros benefícios para os neonatos, incluindo aqueles internados em Unidades de Terapia Intensiva Neonatal (UTIN). 
Segundo Vanin et al. (2020), os neonatos que necessitam de internação na UTIN costumam apresentar peculiaridades anatômicas e fisiológicas específicas, com alta probabilidade de desenvolver disfunções respiratórias e atraso no desenvolvimento neuropsicomotor. Assim, no contexto da internação na UTIN, o Método Canguru integra um conjunto de práticas multiprofissionais, que visam principalmente evitar as complicações decorrentes da prematuridade e minimizar o período de internação hospitalar (MEDEIROS, 2016).

Dessa forma, considerando o alto índice de prematuridade no Brasil e a necessidade de internação destes neonatos em Unidades de Terapia Intensiva, bem como as diversas complicações relacionadas ao prolongamento do tempo de internação na UTIN, é essencial o desenvolvimento de estudos sobre a temática, que sintetizem os benefícios da realização do mesmo, afim de subsidiar uma prática assistencialista de qualidade.

\section{OBJETIVOS}

Este estudo objetivou identificar na literatura científica os benefícios da utilização do Método Canguru no contexto da internação em Unidades de Terapia Intensiva Neonatal.

\section{METODOLOGIA}

Trata-se de uma revisão integrativa da literatura, realizada no período de março a junho de 2021, com base na pergunta norteadora: Quais são os benefícios da utilização do Método Canguru no contexto da internação em Unidades de Terapia Intensiva Neonatal?

Para as buscas dos dados considerou-se como bases de dados a Literatura LatinoAmericana em Ciências da Saúde (LILACS), Medical Literature Analysis and Retrieval System Online (MEDLINE) via Pubmed, e Base de Dados de Enfermagem (BDENF). Os descritores controlados considerados para operacionalização das buscas foram, segundo os Descritores em Ciências da Saúde (DeCS): "Método Canguru", "Recém-Nascido Prematuro", "Unidade de Terapia Intensiva Neonatal". O operador booleano utilizado foi o AND.

Incluíram-se artigos primários, publicados entre os anos de 2016 a 2021, nos idiomas português ou inglês, que contemplavam o objetivo proposto e estavam disponíveis gratuitamente na íntegra, e excluíram-se estudos secundários, literatura cinzenta, e artigos repetidos nas bases de dados. A amostra inicial foi de 54 estudos, e após a leitura de títulos, 
resumos e texto na íntegra, foram identificados 21 artigos que atendiam aos critérios de inclusão e respondiam à pergunta norteadora, compondo a amostra final.

Por tratar-se de um estudo que envolve dados secundários não houve necessidade de apreciação pelo Comitê de Ética em Pesquisa.

\section{RESULTADOS E DISCUSSÃO}

Com base nos resultados considerados para esta revisão, identificou-se diversos estudos que investigavam os benefícios da utilização do Método Canguru no contexto da internação em Unidades de Terapia Intensiva. Tais estudos, realizados em diversos países, foram unânimes ao demonstrar a disseminação da técnica por todo o mundo, comprovando que o Método pode ser utilizado de forma benéfica em diversos contextos sociais e culturais. A Figura 01 ilustra o posicionamento segundo o Método Canguru.

Figura 01: Posicionamento segundo o Método Canguru.

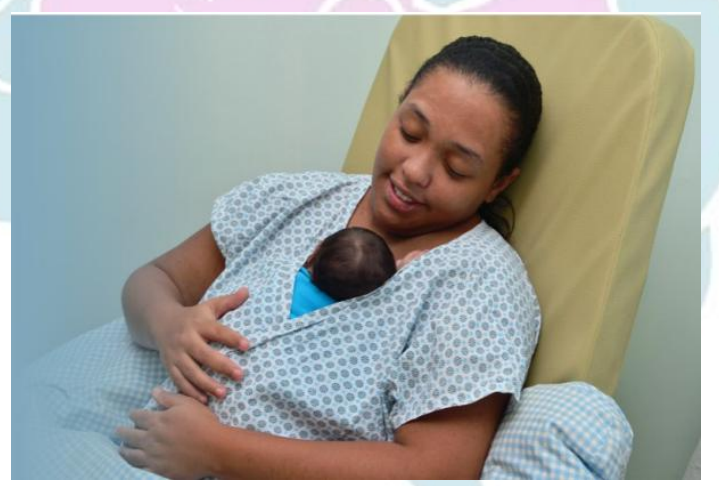

FONTE: BRASIL (2017).

Segundo Abreu, Duarte e Dittz (2020), o Método Canguru proporciona tanto benefícios clínicos para o bebê, quanto para a humanização e apego mãe-bebê. Os autores identificaram que tais benefícios incluem ganho de peso, crescimento e desenvolvimento adequado do bebê e desenvolvimento da confiança dos pais ao lidar com a fragilidade dos bebês prematuros, logo após o nascimento.

Apesar de, em sua maioria, ser desenvolvido no binômio mãe-bebê, o estudo de Benoit et al. (2016) indica que benefícios semelhantes também são encontrados quando a técnica é desenvolvida pelos profissionais do serviço, como os enfermeiros. A pesquisa que envolveu 40 enfermeiros comprovou que a técnica é eficaz no alívio da dor de bebês prematuros 
internados na UTIN, quando a mãe, por algum motivo, não pode estar presente, ou durante o desenvolvimento de técnicas específicas.

Já para Yue et al. (2020), mesmo com os inúmeros benefícios, não é possível deixar de enfatizar os desafios para a realização da técnica, que incluem barreiras culturais como a preocupação com a prática tradicional de confinamento pós-parto, ansiedade e culpa associadas a ter um bebê prematuro.

Apesar do desenvolvimento do estudo nas províncias chinesas, os autores acreditam que resultados semelhantes devem ocorrer nos demais continentes, o que foi comprovado nos estudos de Lewis et al. (2019), realizado nos Estados Unidos, e no de Yismaw, Galelay e Sisay (2019), realizado no noroeste da Etiópia.

Os autores ressaltam ainda diversos fatores que podem estar relacionados a não realização do Método Canguru na UTIN, envolvendo fatores mentais, emocionais, físicos e estruturais, como como acomodações caras, transporte não confiável, falta de creches e políticas inadequadas de licença maternidade que limitam a frequência e a duração da aplicação da técnica e a capacidade dos pais de fornecer cuidados (YUE et al., 2020).

Já para Campbell et al. (2019), tais dificuldades são superadas pelos inúmeros benefícios da utilização do Método Canguru, que foram semelhantes aos benefícios já relatados e aos descritos por Vittner et al. (2019), Eliades (2018) e Dantas et al. (2018).

O estudo de Yao et al. (2021), encontrou resultados positivos no uso da técnica também com relação ao desenvolvimento dos bebês prematuros, considerando as variáveis perímetro cefálico, crescimento corporal, aumento do peso e ingestão de leite, além de menores incidências de pneumonia e sepse neonatal, e redução do período de permanência hospitalar, quando comparado ao grupo controle, que não utilizava o Método Canguru. Variáveis semelhantes foram estudadas por Ozdel e Sari (2019), constando que a técnica apresenta melhores resultados do que a utilização da posição prona, nas mesmas condições.

Além disso, Forde et al. (2020), concluiu que a utilização do Método Canguru é capaz de reduzir o estresse oxidativo causado pela internação de prematuros na UTIN, através de um biomarcador não invasivo chamado alantoína, que, segundo os autores, está diretamente relacionado à manutenção da homeostase dos recém-nascidos, considerando temperatura abdominal, frequência cardíaca, saturação de oxigênio, índice de perfusão e conservação de energia em bebês prematuros.

Apenas o estudo de Alves et al. (2020), indica a realização do método durante a amamentação. Os demais estudos não foram claros com relação ao momento ao que se deve iniciar a utilização do Método Canguru na UTIN, por quanto tempo, ou a partir de que 
momento os benefícios supracitados poderão ser observados consistentemente, podendo ser sugestivos de pesquisas futuras.

\section{CONCLUSÃO}

Com base nos estudos analisados, pode-se observar que os bebês internados em Unidades de Terapia Intensiva Neonatal, que são mantidos em Posição Canguru durante o período de internação tendem a apresentar melhor evolução clínica e de desenvolvimento, considerando, por exemplo, parâmetros como menor frequência cardíaca e melhores níveis de conforto e melhor alimentação.

Além disso, foi determinado que o método Canguru, realizado pelas mães ou por profissionais de saúde, reduz a resposta à dor, aumenta a duração do sono, reduz o tempo de permanência no hospital, facilita a amamentação, reduz o risco de hipotermia, diminui o nível de ansiedade da mãe ao iniciar a relação com o bebê, e melhora o crescimento e desenvolvimento do recém-nascido.

Portanto, por ser um método financeiramente acessível e de fácil aplicação, recomenda-se, que os profissionais de saúde da UTIN favoreçam a realização do posicionamento Canguru como um importante recurso para minimizar os danos causados pela internação e pela permanência prolongada no ambiente hospitalar.

\section{REFERÊNCIAS}

ABREU, M. Q.S.; DUARTE, E. D.; DITTZ, E. S. Construção do apego entre o binômio mãe e bebê pré-termo mediado pelo posicionamento canguru. Revista de Enfermagem do Centro-Oeste Mineiro, v.10, n.1, 2020.

BENOIT, B.; CAMPBELL-YEO, M.; JOHNSTON, C.; LATIMER, M.; CADDELL, K.; ORR, T. Utilização do método canguru pela enfermeira como uma intervenção para dor processual em bebês prematuros. Advances in Neonatal Care, v. 16, n.3, 2016.

BRASIL. MINISTÉRIO DA SAÚDE. Ação Humanizada ao recém-nascido: Método Canguru. 3 ed. Brasília: Ministério da Saúde, 2017. Disponível em: https://bvsms.saude.gov.br/bvs/publicacoes/atencao_humanizada_metodo_canguru_manual_3 ed.pdf. Acesso em: 31 mai 2021. 


\title{
EFEITOS DA MUSICOTERAPIA NA REDUÇÃO DA SINTOMATOLOGIA DOLOROSA EM NEONATOS: REVISÃO INTEGRATIVA
}

\author{
Vivia Rhavena Pimentel Costa- Universidade Estadual do Piauí, Teresina, Piauí, Brasil \\ Abimael de Carvalho- Universidade Estadual do Piauí, Teresina, Piauí, Brasil \\ Ana Paula de Carvalho Souza- Universidade Estadual do Piauí, Teresina, Piauí, Brasil \\ Ramires dos Santos Moraes- Centro Universitário UniIFacid, Teresina, Piauí, Brasil \\ Janaina de Moraes Silva- Universidade Estadual do Piauí, Teresina, Piauí, Brasil.
}

Área Temática: Multiprofissional.

E-mail do autor para correspondência: viviarhavena@outlook.com

\section{RESUMO}

A UTIN constitui-se como um ambiente paradoxal, uma vez que ao mesmo tempo em que diminui a mortalidade dos recém-nascidos, também os expõe a vários estímulos que geram estresse, desconforto e dor. Diante do exposto, o objetivo do presente estudo foi verificar os efeitos da música na redução da sintomatologia dolorosa em neonatos, por meio de uma revisão integrativa realizada nas bases Lilacs, Scielo e Pubmed. Incluiu-se ensaios clínicos randomizados e estudos descritivos, condizentes ao objetivo proposto, publicados nos últimos 10 anos, nos idiomas português e inglês. Por sua vez, foram excluídos todos os artigos não disponíveis na íntegra, teses, revisões e guias de prática clínica. Foram identificados 12 estudos, contudo, foram 5 considerados relevantes para a composição da revisão integrativa. Por meio da análise dos estudos selecionados, observa-se que a utilização da música na unidade de terapia intensiva neonatal durante a realização de procedimentos apresenta benefícios na redução da dor em neonatos.

Palavras-chave: Música. Neonato. Dor.

\section{INTRODUÇÃO}

Conforme MELO et al. (2020) os neonatos internados em Unidade de Terapia Intensiva Neonatal (UTIN) estão sujeitos a cerca de 50 a 130 procedimentos por dia. Esses procedimentos incluem intubação e aspiração traqueal, punções repetidas; remoção de eletrodos e esparadrapos; cateterismos e sondagens; troca de curativos; mudanças bruscas de decúbito e manuseio excessivo. Assim a UTIN constitui-se como um ambiente paradoxal, uma vez que ao mesmo tempo em que diminui a mortalidade dos recém-nascidos, também os expõe a vários estímulos que geram estresse, desconforto e dor. 
A exposição frequente e repetida do neonato à dor pode causar prejuízos a curto, médio e longo prazo. Em curto prazo, essa exposição pode gerar irritabilidade, déficit de atenção e orientação, recusa alimentar, modificação no padrão de sono, além de influenciar na relação mãe e filho. A longo prazo, o RN pode apresentar aumento da sensibilidade à dor, devido ao aumento das ramificações nervosas na região agredida repetidamente e à diminuição do limiar de sensação dolorosa.

Apesar das escassas opções terapêuticas de analgesia para o RN e levando em consideração as questões éticas e humanitárias, a dor do neonato deve ser reconhecida, avaliada e tratada a fim diminuir o sofrimento e possibilitar uma assistência mais humanizada a esse paciente. Nessa direção, a musicoterapia e a estimulação musical no ambiente da UTIN vêm se destacando nas últimas décadas por revelar benefícios no que tange a redução da dor em neonatos.

Definida como o uso terapêutico da música ou de atividades musicais no tratamento de doenças somáticas e mentais, a musicoterapia vem acumulando evidências científicas de sua efetividade no manejo da dor, da ansiedade e do estresse emocional, entre outras condições (SILVA et al., 2013).

\section{OBJETIVOS}

Diante do exposto, o objetivo do presente estudo foi verificar os efeitos da musicoterapia na redução da sintomatologia dolorosa em neonatos em unidade de terapia intensiva neonatal.

\section{METODOLOGIA}

O estudo consiste em uma revisão integrativa da literatura. Conforme Sousa, Silva e Carvalho (2010), a revisão integrativa consiste na mais ampla abordagem metodológica referente às revisões, por permitir a inclusão de estudos experimentais e não-experimentais para uma compreensão completa do fenômeno analisado, além de incorporar um vasto leque de propósitos: definição de conceitos, revisão de teorias e evidências e análise de problemas metodológicos de um tópico particular.

O percurso metodológico para a elaboração dessa revisão seguiu as seguintes etapas: elaboração da pergunta norteadora, busca ou amostragem na literatura, definindo critérios de 
inclusão e exclusão, coleta de dados, análise crítica dos estudos incluídos, discussão dos resultados e síntese do conhecimento, com apresentação da revisão integrativa.

A problemática surgiu a partir da seguinte questão norteadora: Quais os efeitos da musicoterapia na sintomatologia dolorosa em neonatos submetidos a procedimentos em unidade de terapia intensiva neonatal? A operacionalização da pesquisa ocorreu no período compreendido entre os meses de maio e junho de 2021. Como bancos de dados, utilizou-se: LILACS (Literatura Latino-Americana em Ciências da Saúde), Scielo e Pubmed. Os termos de busca foram selecionados por meio dos Descritores em Ciências da Saúde (Decs), com a combinação dos operadores booleanos "Música (Song)" AND "Neonato (Neonate)" AND "Dor (Pain)".

Incluiu-se ensaios clínicos randomizados e estudos descritivos, condizentes ao objetivo proposto, publicados nos últimos 10 anos, nos idiomas português e inglês. Por sua vez, optou-se em excluir-se todos os artigos não disponíveis na íntegra, teses, revisões de literatura e guias de prática clínica. Os estudos encontrados em mais de uma base de dados foram contabilizados uma única vez.

Ao todo foram identificados 12 estudos. Após a contabilização dos artigos duplicados e mediante a leitura de títulos e resumos, restaram 8. Posteriormente, após a realização da leitura na íntegra destes estudos, foram 4 considerados relevantes para a composição da revisão integrativa. Quanto ao ano de publicação, todas as referências encontradas foram publicadas nos últimos cinco anos em língua portuguesa.

\section{RESULTADOS E DISCUSSÃO}

Os estudos são unânimes ao apontar que a constância de procedimentos dolorosos aos quais os neonatos são submetidos quando inseridos em unidade de terapia intensiva neonatal, podem vir a ocasionar efeitos indesejáveis como dificuldade no desenvolvimento neurológico, aumento da irritabilidade, inquietação e alterações fisiológicas. Verificou-se também que a música produz diversos efeitos nesses indivíduos, dentre eles se pode destacar a melhora em componentes como frequência cardíaca e respiratória. É importante destacar que esses benefícios, por sua vez, conseguem produzir redução significativa na percepção da dor uma vez que o neonato consegue ficar mais calmo. Atrelado a esses resultados, os estudos também demonstraram redução nas expressões faciais durante os procedimentos dolorosos em consonância com a utilização da música, tendo como consequência a redução do choro.

Outro ponto a ser destacado consiste no tipo de música usada durante as intervenções relatadas nos estudos. Em dois deles foi utilizada a música de ninar cantada pela mãe, onde tal 
procedimento proporcionou benefícios significativos que resultaram no alívio do quadro álgico. Por sua vez, outro estudo relatou o uso da música de ninar de forma gravada. Destacase que em comparação com as demais formas, esta mostra-se menos efetiva. Esse mesmo estudo destacou a importância do uso de canções que a mãe costumava ouvir durante o processo de gestação.

O estudo de Silva et al. (2013) teve como objetivo avaliar o efeito da música clássica nas respostas fisiológicas de recém-nascidos pré-termo hospitalizados. Para tanto, 12 recém-nascidos pré-termo, com idade gestacional $\leq 36$ semanas, em respiração espontânea foram submetidos a sessões de musicoterapia durante 15 minutos duas vezes ao dia, nos períodos matutino e vespertino, por três dias consecutivos, como desfecho, observou-se a diminuição da frequência cardíaca imediatamente após a segunda sessão de musicoterapia (t pareado; $p=0,002$ ) e o aumento ao final da terceira sessão, em relação ao início (t pareado; $p=0,005$ ). A frequência respiratória diminuiu após a musicoterapia na quarta e quinta sessões ( $\mathrm{t}$ pareado; $\mathrm{p}=0,01$ e 0,03, respectivamente). Todos esses ganhos contribuíram para a minimização da dor nesses neonatos.

Destaca-se que apesar de avanços, é preciso destacar que o manejo da sensação dolorosa nos cuidados ao neonato precisa ganhar mais espaço no dia a dia dos profissionais de saúde que trabalham na UTIN pois, grande parte desses profissionais, ainda demonstra dificuldade em avaliar e lidar com a dor no recém-nascido devido às falhas nos conhecimentos básicos sobre a experiência dolorosa nesses pacientes, observando-se certo distanciamento entre o conhecimento teórico e a prática na avaliação da dor, na maioria dos serviços neonatais.

\section{CONSIDERAÇÕES FINAIS}

Por meio da análise dos estudos selecionados, observa-se que a utilização da música na unidade de terapia intensiva neonatal durante a realização de procedimentos apresenta benefícios na redução da dor em neonatos. Além disso, verificou-se efeitos significativos em 
parâmetros hemodinâmicos, tais como frequência cardíaca (FC), pressão arterial sistêmica (PA) e temperatura corporal (TC), além de promover a regularização do ritmo respiratório, relaxamento muscular e melhora do sono. Ressalta-se, ainda, a importância e necessidade de estudos subsequentes sobre essa temática, assim como o desenvolvimento de protocolos de cuidados ou intervenções junto ao neonato em situações de enfrentamento da dor.

\section{REFERENCIAS}

CARDOSO MVLM; MELO GM. Música e glicose 25\% em prematuros no pré-procedimento da punção arterial: ênfase na mímica facial. Rev. Eletr. Enf, v. 16, 2016.

PALAZZI, A.; MESCHINI, R.; PICCININI, C. A. Intervenção musicoterápica para mãe-bebê pré-termo: Uma proposta de intervenção na uti neonatal. Psicol. estud., v. 24, e41123, 2019 SOUZA, M. T.; SILVA, M. D.; CARVALHO, R. Revisão integrativa: o que é e como fazer? Einstein. 2010; 8(1 Pt 1):102-6.

SILVA, C. M et al. Respostas fisiológicas de recém-nascidos pré-termo submetidos à musicoterapia clássica. Rev Paul Pediatr, v.31, n. 1, p. 30-36, 2013. 


\section{INDICADORES DA QUALIDADE EM TERAPIA NUTRICIONAL ENTERAL NA NEONATOLOGIA: UMA REVISÃO INTEGRATIVA DA LITERATURA}

Sabrina Mércia Belarmino Gomes - Universidade Federal de Campina Grande, Cuité, Paraíba,

Brasil.

Larissa de Alcântara Santos - Universidade Federal de Campina Grande, Cuité, Paraíba,

Brasil.

Thalita Oliveira de Melo - Universidade Federal de Campina Grande, Cuité, Paraíba, Brasil.

Nayane Gabriela Ferreira Macêdo e Silva - Universidade Federal de Campina Grande, Cuité, Paraíba, Brasil.

Maria Eduarda Wanderley de Barros Silva - Universidade Federal de Campina Grande, Cuité, Paraíba, Brasil.

Ana Paula de Mendonça Falcone - Universidade Federal de Campina Grande, Cuité, Paraíba,

Brasil.

Área Temática: Multiprofissional.

E-mail: sabrinamercia3279@gmail.com

\section{RESUMO}

A introdução da nutrição enteral (NE) em bebês prematuros em Unidades de Terapia Intensiva Neonatal (UTIN) se demonstra como peça importante no tratamento para esses recém-nascidos $(\mathrm{RN})$, interferindo positivamente no desenvolvimento, crescimento e evolução do quadro clínico. Para tanto, a NE fornece maior ingestão de nutrientes, acelera o crescimento e ganho de peso, podendo diminuir a estadia do neonato na UTIN. É responsabilidade do nutricionista a prescrição e formulação da conduta dietoterápica e acompanhamento individualizado do quadro clínico, enquanto o profissional enfermeiro com formação em neonatologia irá administrar e garantir exames radiológicos que assegurem a localização correta do cateter. É aconselhável que a nutrição enteral mínima seja administrada o mais rápido possível, tendo seu avanço individualizado de acordo com as necessidades do neonato.

Palavras-Chave: Terapia intensiva neonatal. Pré-termo. Alimentação artificial.

\section{INTRODUÇÃO}

A literatura aponta a etiologia da prematuridade como multifatorial, sendo assim, importante que haja um acompanhamento pré-natal desde o início da descoberta da gravidez para que essas causas possam ser identificadas e acompanhadas ainda de forma inicial, 
possibilitando um maior tempo de estadia intrauterina. Recém-nascidos (RN) a termo, são aqueles que completaram 38-40 semanas intrauterinas e apresentam maturidade fisiológica compatível com a vida. Já os RN prematuros ou pré-termo, são bebês que não chegaram a completar 37 semanas gestacionais, tendo seu estado fisiológico ainda imaturo, necessitando de internação na UTIN para que intervenções sejam aplicadas garantindo a homeostasia fisiológica do RN (CAMPOS et al., 2020).

Dentre essas intervenções, existe a necessidade da introdução da nutrição enteral, que segundo (BOZZETTI; TAGLIABUE, 2017), deve ser aplicada principalmente a bebês prematuros com muito baixo peso (peso inferior a $1.500 \mathrm{~g}$ ) ou extremo baixo peso $(1.000 \mathrm{~g})$ admitidos na UTIN, devido à falta de habilidade de coordenar a sucção, deglutição e respiração ocasionados pela prematuridade, impossibilitando a nutrição oral. Por isso, é importante a administração da alimentação via sonda para neonatos com peso inferior a $1.500 \mathrm{~g}$ para assim obter uma evolução saudável do quadro clínico do recém-nascido, bem como um bom desenvolvimento após a alta da UTIN.

Visto isso, podemos ter diversos tipos de sonda para via de alimentação e, segundo (NASCIMENTO; SANTOS; SILVA, 2019), os tipos de sonda classificam-se de acordo com o local de inserção, como: orogástrico, quando for inserido pela cavidade oral e o nasogástrico quando a administração ocorrer por uma das narinas. Para nutrir o prematuro, se dá preferência pela inserção da sonda pela boca, até que a parte periférica da sonda alcance a região superior do estômago.

Ademais, pela necessidade de existir a implantação da sonda de forma adequada, se faz necessária a participação de uma equipe multiprofissional para o acompanhamento e garantia da rápida evolução da saúde do neonato, além de haver maior cooperação e discussão de possíveis terapias complementares que possam ser abordadas. De acordo com NASCIMENTO et al. (2019), esse manejo deve ser realizado pelo enfermeiro, pois é ele o responsável pela administração do cateter e por garantir exames radiográficos que assegurem a localização correta da sonda, evitando complicações na adaptação à vida extra uterina, enquanto o nutricionista elabora fórmulas artificiais, prescrição dietética, volume e gotejamento para a alimentação do RN, além de acompanhar o desenvolvimento do estado nutricional.

\section{OBJETIVOS}


Apontar os benefícios trazidos pela nutrição enteral em neonatos prematuros de acordo com os achados da literatura.

\section{MÉTODO}

Foi realizada uma pesquisa integrativa da literatura nas bases de dados: Scielo, PubMed e Google Scholar, usando os descritores "enteral nutrition" e "nutrition in neonatology" cruzados pelo operador booleano "AND". Nesta pesquisa foram selecionados 20 artigos, e, após utilizar os seguintes critérios para a seleção: relevância do tema, periódico publicado e ano de publicação, restaram 5, que se encontram nos idiomas inglês e espanhol.

\section{RESULTADOS E DISCUSSÃO}

É comum que esses recém-nascidos pré-termo necessitem de cuidados intensivos e, consequentemente, triagem nutricional que considerará seu estado fisiológico e nutricional atual, devido a importância do agravo à saúde causado pela prematuridade e pelos estresses fisiológicos e metabólicos que aumentam a necessidade de nutrientes do neonato. A literatura retrata que bebês prematuros ou bebês a termo com muito baixo peso ou extremo baixo peso ao nascer têm poucas reservas de nutrientes e, segundo WALSH et al. (2020), estão sujeitos a agravos à saúde, que podem ser tratados e controlados através de condutas dietoterápicas adequadas, como no caso da NE.

No que concerne a terapia nutricional nos neonatos se deve ao estado de prematuridade, pois apresentam órgãos e sistemas ainda pouco desenvolvidos. Visto isso, o sistema digestório e o trato gasto intestinal (TGI) podem se apresentar comprometidos dependendo do nível de prematuridade, tendo em vista que esse sistema termina de se maturar nas últimas semanas de gestação (CAMPOS et al., 2020). Além disso, reflexos motores como os de sucção, deglutição e respiração ainda não estão aptos, causando impossibilidade da nutrição oral. Para tanto, a nutrição enteral surge como uma solução para esse quadro, trazendo meios para aumentar o aporte calórico do RN, fazendo com que haja o aumento de peso e auxílio necessário para as demandas energéticas envolvidas na maturação dos órgãos e sistemas desse RN.

Com isso, a terapia nutricional se faz importante mesmo que seja introduzida minimamente, como descreve a nutrição trófica, pois se apresenta como uma alimentação de 
baixo volume e baixo aporte calórico, que irá atuar como fator auxiliador para o avanço da maturidade gastrointestinal, metabólica e fisiológica. Sendo recomendada nos primeiros dias de vida do RN, antes da administração da nutrição enteral plena (KIM, 2016).

\section{ESCOLHA DA NUTRIÇÃO ENTERAL}

O leite humano é a forma preferível para a alimentação do RN, sabendo que confere proteção contra sepse e outras infecções, além de melhorar o desenvolvimento neurológico, tendo seus efeitos comprovados até os 2 anos e 5 meses de idade corrigida. Devido a falta de maturidade para coordenar a sucção do leite materno através da amamentação, a terapia nutricional surge como forma alternativa para essa administração do leite materno através da nutrição enteral.

Dessa forma, há uma grande importância na estimulação da lactação para que possibilite a extração imediata após o parto. Na ausência de leite materno, pode ser usado o leite pasteurizado doado para utilizar como elemento dietoterápico via sonda para o RN, junto a fortificantes multinutrientes (tanto no leite materno ou no leite humano pasteurizado doado). Essas formulas contém proteína do soro do leite, polímeros de glicose, triglicerídeos de cadeia média, cálcio e fosforo. Mesmo sabendo disso, a administração da nutrição enteral em neonatos pode ser feita também através de fórmulas para prematuros, quando não há possibilidade de usar o leite humano (KIM, 2016).

\section{CONSIDERAÇÕES FINAIS}

O nascimento precoce e o baixo peso ao nascer são um dos principais fatores associados à mortalidade perinatal e/ou a danos imediatos ou tardios ao RN. Neste cenário, para atingir a maturação fisiológica necessária para boas condições de alta do paciente prematuro, a nutrição enteral aparece como importante fator benéfico, que otimiza a maturação dos órgãos e sistemas do neonato internado em UTIN, pois, apesar de invasiva, se torna fundamental para a garantia da saúde do bebê pré-termo na adaptação extrauterina.

\section{REFERÊNCIAS}

BOZZETTI, V.; TAGLIABUE, P. E. Enteral nutrition for preterm infants: by bolus or continuous? An update. La Pediatria Medica e Chirurgica [internet], v.39,2, n. 159, 2017. Disponível em: http://www.pediatrmedchir.org/index.php/pmc/article/view/159/164\#citations. Acesso em: 19 abr. 2021. 
CAMPOS, J. O.; SANTANA, M. S.; OLIVEIRA, T. L. P. S.; ROCHA, C. S. A.; DA SILVA, A. R. Avaliação do estado nutricional de recém-nascidos pré-termo em unidade de terapia intensiva neonatal. Brazilian Journal of Development, v. 6, n. 10, p. 80007-80028, 2020. Disponível

https://www.brazilianjournals.com/index.php/BRJD/article/view/18542/14928. Acesso em: 19 abr. 2021.

KIM, M. J. Enteral nutrition for optimal growth in preterm infants. Korean journal of pediatrics, $\quad$ v. $59, \quad$ n. $12, \quad$ p. 466, 2016. Disponível em: https://www.ncbi.nlm.nih.gov/pmc/articles/PMC5300910/\#: :text=Minimal\%20enteral\%20n utrition $\% 20$ should $\% 20$ begin,feeding $\% 20$ practices $\% 20$ to $\% 20$ improve $\% 20$ growth. Acesso em: 19 abr. 2021.

NASCIMENTO, J.; SANTOS, I. M. M.; SILVA, L. J. Cuidados com recén nacidos alimentados por sonda gástrica: conceptos y prácticas. Texto contexto - enferm, Florianópolis, $\quad$ v. 28, e20170242, 2019. Disponível em: https://www.scielo.br/scielo.php?script=sci_arttext\&pid=S0104-07072019000100504. Acesso em: 17 abr. 2021.

WALSH. V.; BROWN, J. V. E.; COPPERTHWAITE, B. R.; ODDIE, S. J.; MCGUIRE, W. Early full enteral feeding for preterm or low birth weight infants. Database of Systematic reviews, n. 12, 2020. Disponível em: https://pubmed.ncbi.nlm.nih.gov/33368149/. Acesso em: 17 abr. 2021 


\section{MARCADORES INFLAMATÓRIOS E TERAPIA NUTRICIONAL NA SEPSE NEONATAL: UMA REVISÃO DA LITERATURA}

Larissa de Alcântara Santos - Universidade Federal de Campina Grande, Cuité, Paraíba,

Brasil.

Sabrina Mércia Belarmino Gomes - Universidade Federal de Campina Grande, Cuité, Paraíba,

Brasil.

Thalita Oliveira de Melo - Universidade Federal de Campina Grande, Cuité, Paraíba, Brasil.

Taelyson Costa de Medeiros - Universidade Federal de Campina Grande, Cuité, Paraíba,

Brasil.

Mateus Fernandes da Silva - Universidade Federal de Campina Grande, Cuité, Paraíba, Brasil.

Ana Paula de Mendonça Falcone - Universidade Federal de Campina Grande, Cuité, Paraíba,

Brasil.

Área temática: Multiprofissional.

E-mail: larissasantos1918@gmail.com

\section{RESUMO}

A sepse neonatal ou Infecção Primária da Corrente Sanguínea (IPCS) caracteriza-se por uma síndrome complexa, ocasionada por uma resposta inflamatória sistêmica descontrolada, associada a um foco infeccioso que pode determinar disfunção ou falência de um ou mais órgãos ou mesmo a morte do recém-nascido. Definido assim, como uma das principais causas de morbimortalidade neonatal, particularmente em recém-nascidos prematuros devido a imaturidade do sistema imunológico. Sendo essencial o diagnóstico precoce através de exames laboratoriais e avaliação clínica de sinais, para que haja um diagnóstico precoce e uma consequentemente conduta terapêutica nestes pacientes, através de um aporte nutricional adequado, bem como o uso de antimicrobianos, além de entender e investigar os possíveis fatores que acarretaram a gênese da sepse neonatal e implementar medidas preventivas, sendo um dos melhores recursos para a precaução desta patologia.

Palavras-chave: Análise Clínica. Nutrição. Recém-nascido. Sepse.

\section{INTRODUÇÃO}

De origem infecciosa, e caracterizada por manifestações múltiplas, podendo acarretar uma disfunção ou falência de um ou mais órgãos e até mesmo a morte, a sepse neonatal é uma das principais causas de morbimortalidade entre os recém-nascidos. Pode se desenvolver de 
forma precoce, quando diagnosticada nas primeiras 48 horas de vida do recém-nascido $(\mathrm{RN})$ na presença de fator de risco perinatal para a infecção. E na forma tardia, onde o diagnóstico é feito após as primeiras 48 horas e a incidência está relacionada ao ambiente de cuidado, notadamente na Unidade de Terapia Intensiva Neonatal (UTIN) (SANTOS et al., 2014).

Para tanto, a nutrição possui um papel importante para a prevenção e tratamento da sepse neonatal em bebês admitidos em UTIN através de uma nutrição artificial que pode ser de forma enteral ou parenteral. A terapia nutricional destaca-se por diminuir as perdas de nutrientes essenciais para a maturação do sistema imunológico, gastrointestinal e formação completa da fisiologia, na qual o leite humano, ofertado de forma precoce na nutrição enteral pode diminuir os riscos de infecção (FREITAS et al., 2011).

A literatura recomenda que a nutrição enteral (NE) seja mínima e utilizada de forma precoce, pretendendo acelerar a recuperação e o desenvolvimento do trato intestinal, promovendo a redução das infecções. Já a nutrição parenteral (NP) é indicada em contextos nos quais as necessidades metabólicas e nutricionais não são saciadas com a nutrição enteral, sendo considerada de extrema importância nas primeiras 24 horas de vida e necessária em casos de sepse, ofertando imunonutrientes como glutamina, arginina, selênio, probióticos e antioxidantes, apresentando uma importante melhora do estado nutricional e uma diminuição da mortalidade neonatal (FREITAS et al., 2011).

O enfermeiro, frente ao recém-nascido com essa enfermidade, é, muitas vezes, o profissional que observa os primeiros sinais e sintomas da infecção, tornando-o importante para o diagnóstico e intervenção precoce, ao advogar em nome da criança e garantir a oportuna complementação diagnóstica e antibioticoterapia empírica (SANTOS et al., 2014). Além da assistência do nutricionista que pode contribuir na avaliação do estado nutricional, prescrição de exames bioquímicos que possam auxiliar na conduta dietoterápica e consequente acompanhamento nutritivo, para posteriores avanços no quadro clínico.

Segundo Moreira et al. (2004) os sinais clínicos como dificuldade respiratória, apneia, letargia, icterícia sem causa definida, vômitos, diarreia, petéquias e outros, geram um grau de desconfiança maior sobre uma possível infecção, fazendo parte do diagnóstico precoce. Além da utilização de exames laboratoriais como forma complementar ao diagnóstico, sendo eles a hemocultura (cultura de sangue), exame de líquor, urocultura e cultura de aspirado traqueal como exames para isolamento do microrganismo. E como testes hematológicos o leucograma, plaquetas, velocidade de hemossedimentação (VHS) e por fim os testes imunológicos como a proteína C-reativa (PCR), citocinas e procalcitoninas (SILVEIRA; PROCIANOY, 2012). 
Expor as principais características da sepse neonatal, e promover uma análise acerca do diagnóstico clínico e laboratorial como chaves para uma prevenção adequada sobre essa patologia, além de elencar a importância da terapia nutricional, e o auxílio de uma equipe multiprofissional como meios para uma conduta terapêutica sobre a mesma.

\section{Método}

Foi realizado um levantamento bibliográfico, usando as bases de dados SCientific Eletrônica Library Online (SciELO) e Google Acadêmico, sendo utilizado como descritores: "because neonatal", "nutrition" e "inflammatory markers and neonatal sepsis", cruzados pelo operador booleano "AND”. Foram selecionados 15 artigos, e após utilizar os seguintes critérios para a seleção dos artigos: relevância do tema, abranger os marcadores inflamatórios da sepse neonatal e a influência da nutrição acerca da mesma, bem como a participação de uma equipe multiprofissional, em especial médicos, enfermeiros e nutricionistas, restaram quatro artigos que correspondem aos anos de 2004 a 2014 por se tratar de um tema pouco discutido e publicado, e encontram-se nos idiomas inglês e português.

\section{RESULTADOS E DISCUSSÃO}

Moreira et al. (2004) trazem que no diagnóstico laboratorial, o teste mais apropriado para determinar de forma mais clara a sepse neonatal é a hemocultura, entretanto sua praticidade é discutível, posto que seu resultado requer dias, e não horas. A cultura de líquor é indispensável nos recém-nascidos com diagnóstico provável de sepse, pois se o resultado da hemocultura for positivo ou se apresentar algum sinal clínico de sepse, a avaliação do líquor se torna obrigatória e imediata. A urocultura e cultura de aspirado traqueal só são necessários de acordo com o quadro que o neonato se encontra, pois não são empregados na rotina de investigação de sepse neonatal precoce.

Os testes hematológicos como leucograma, são muito limitados para o diagnóstico de sepse neonatal, porém a neutropenia é prognosticador da gravidade da sepse neonatal porque representa uma depleção da reserva medular de neutrófilos (SILVEIRA; PROCIANOY, 2012). Já em relação às plaquetas, a trombocitopenia é encontrada em até 50\% dos recém- 
nascidos com sepse, e apresenta valor limitado no diagnóstico inicial de sepse, e sua diminuição está relacionada com sepse tardia. Já a velocidade de hemossedimentação (VHS) é um teste diagnóstico pouco sensível e específico, pois pode apresentar falso-positivos por conta de hemólise e coagulação intravascular disseminada.

Ademais, aos marcadores bioquímicos, nos testes imunológicos, segundo Silveira e colaboradores (2012) apontam que a proteína C-reativa (PCR) tem sido um marcador útil para sepse neonatal em muitos estudos devido a sua elevação, entretanto ela não é um método adequado para o diagnóstico de sepse neonatal precoce por apresentar um aumento mais tardio, na evolução do processo inflamatório. As citocinas, por sua vez, têm sido estudadas como marcadores incontestáveis da infecção neonatal, particularmente interleucina-6 (IL-6), fator de necrose tumoral- $\alpha$ (TNF- $\alpha$ ) e interleucina-1 $\beta$ (IL-1 $\beta)$. Contudo, a procalcitonina é caracterizada como um pró-hormônio normalmente produzido na tireoide que em recémnascidos com sepse tem se mostrado em níveis elevados.

Baseado nestas condições apresentadas nos pacientes hematológicos, podem ser feitas intervenções nutricionais buscando a melhora do quadro clínico do paciente, entre estas intervenções podemos citar a suplementação da glutamina que apresenta função na manutenção do trofismo da mucosa intestinal e da barreira mucosa, além do papel na regulação da resposta inflamatória mediada pelo intestino, ademais, a atuação da arginina possui atuação como substrato para a síntese de óxido nítrico tecidual. Já o selênio, possui papel na imunocompetência e sua suplementação pode estar associada com benefícios na redução da incidência de sepse (FREITAS et al., 2011).

Segundo Freitas et al. (2011), o emprego de probióticos, por via enteral apresenta uma redução da mortalidade neonatal, sendo seu uso contínuo e rotineiro. Já os antioxidantes por fazerem parte de diferentes etapas da resposta imune, como a produção de citocinas, resposta mediada por células, produção de imunoglobulinas e função fagocitária, podem auxiliar na resposta anti-infecciosa. Visto isso, a nutrição enteral e parenteral é essencial no tratamento precoce, sendo a enteral utilizando leite humano, que ajudará na maturação e prevenção da atrofia do trato gastrointestinal (FREITAS et al., 2011).

\section{CONSIDERAÇÕES FINAIS}

Entende-se, portanto, que a avaliação dos sinais clínicos e marcadores bioquímicos são considerados fatores essenciais como marcadores inflamatórios no diagnóstico preliminar da sepse neonatal. Bem como um aporte nutricional adequado com o intuito de promover uma maturação do sistema fisiológico, auxiliando no ganho de peso do recém-nascido, e 
diminuindo os impactos gerados pela sepse neonatal, somando com o uso de antimicrobianos, diminuindo assim o número de casos de morte de recém-nascidos que desenvolveram a sepse neonatal e consequentemente, menor estadia na UTIN e no ambiente hospitalar.

\section{Referências}

FREITAS, B. et al. Terapia nutricional e sepse neonatal. Revista Brasileira de Terapia Intensiva, v. 23, n. 4, p. 492-498, 2011. DOI:https://doi.org/10.1590/S0103507X2011000400015. Disponível em: https://www.scielo.br/scielo.php?script=sci_arttext\&pid=S0103-507X2011000400015. Acesso em: 05 de maio de 2021.

MOREIRA, M.; LOPES, J.; CARVALHO, M. Sepse neonatal. O recém-nascido de alto risco: teoria e prática do cuidar [online]. Rio de Janeiro: Editora FIOCRUZ, p.564, 2004. Disponível em http://books.scielo.org/id/wcgvd. Acesso em: 05 de maio de 2021.

SANTOS, A. et al. Diagnósticos de enfermagem de recém-nascidos com sepse em uma Unidade de Terapia Intensiva Neonatal. Revista Latino-Americana de Enfermagem, v. 22, n. 2, p. 255-261, 2014. DOI:https://doi.org/10.1590/0104-1169.3101.2410. Disponível em: https://www.scielo.br/scielo.php?script=sci_arttext\&lng=pt\&tlng=pt\&pid=S010411692014000200255. Acesso em: 05 de maio de 2021.

SILVEIRA, R.; PROCIANOY, R. Uma revisão atual sobre sepse neonatal. Boletim Científico de Pediatria-Vol, v. 1, n. 1, 2012. Disponível em:https://www.sprs.com.br/sprs2013/bancoimg/131210152124bcped_12_01_06.pdf. Acesso em: 05 de maio de 2021. 


\title{
MÉTODO MÃE CANGURU - OS BENEFÍCIOS DE UM CUIDADO HUMANIZADO AO PRÉ-TERMO: UMA REVISÃO DA LITERATURA
}

\author{
Samara Elisy Miranda Matos ${ }^{1}$; Andressa Ferreira Andrade ${ }^{1}$; Natália De Fátima Gonçalves \\ Amâncio ${ }^{2}$ \\ ${ }^{1}$ Acadêmicos do Curso de Medicina do Centro Universitário de Patos de Minas; \\ ${ }^{2}$ Docente do Curso de Medicina do Centro Universitário de Patos de Minas. \\ Centro Universitário de Patos de Minas (UNIPAM), Patos de Minas- MG.
}

Aréa Temática: Multiprofissional.

E-mail do autor para correspondência: samaraelisy@ gmail.com

Introdução: O Método Mãe Canguru é uma forma de assistência neonatal que consiste no contato pele a pele precoce entre mãe e o recém-nascido pré termode forma crescente, visando à formação e o fortalecimento de vínculo entre os pais e o recém-nascido. Objetivos: Verificar na literatura evidências científicas em relação aos benefícios da assistência neonatal humanizada baseada na aplicação do Método Mãe Canguru. Metodologia: Trata-se de uma revisão integrativa de literatura realizado através das bases de dados SCIELO, MEDLINE e LILACS. Resultados e Discussão: Mãe e bebê são beneficiados com o método e a formação dos laços. O contato pele a pele precoce entre mãe e bebê auxilia no controle fisiológico, controle da temperatura corporal, regulação do estado comportamental, contribui para o aumento do vínculo família/mãe e filho, e para o desenvolvimento neurocomportamental e psicoafetivo do recém- nascido. Conclusão: $O$ método mãe canguru apresenta-se como uma técnica viável, acessível e promissora na redução da mortalidade e das consequências negativas de um parto prematuro.

Palavras-chave: Maternidade Hospitalar. Pré-Termo. Humanização da Assistência.

\section{INTRODUÇÃO}

O Método Mãe Canguru (MMC), também conhecido como "Contato Pele a Pele" foi desenvolvido na década de 1970 pelos neonatologistas Rey e Martinez, médicos do Instituto Médico Infantil (IMI) de Bogotá, Colômbia (SANTOS e FILHO, 2016). É uma forma de assistência neonatal que consiste no contato pele a pele precoce entre mãe e o recém-nascido 
pré-termo (RNPT) de baixo peso, de forma crescente, visando a formação e o fortalecimento de vínculo entre os pais e o recém-nascido (ZIRPOLI, et al.,2019).

Muitas vezes ao nascer, devido às suas condições, o RNPT demanda cuidados por um período longo pela equipe de saúde, o que pode postergar o contato corporal, a comunicação e os cuidados pele a pele com os pais, prejudicando a formação de laços afetivos e o desenvolvimento neuropsicomotor, uma vez que uma ligação segura com os pais tem sido considerada como um fator biológico protetor, amenizando os efeitos adversos do estresse. Dessa forma, o MMC tem sido proposto como uma alternativa ao cuidado neonatal convencional, visando amenizar os impactos negativos de um parto antecipado e de uma internação tão precoce. (BRASIL, 2017)

\section{OBJETIVOS}

Verificar na literatura nacional publicada nos últimos anos evidências científicas em relação aos benefícios da assistência neonatal humanizada baseada na aplicação do Método Mãe Canguru para os recém-nascidos pré-termo de baixo peso.

\section{METODOLOGIA}

Este estudo trata-se de uma revisão integrativa de literatura. O estudo foi realizado através das bases de dados SCIELO, MEDLINE e LILACS. A partir da combinação dos descritores maternidade hospitalar, pré-termo e humanização da assistência. Os dados foram levantados para a produção do artigo no mês de junho de 2021. Foram estabelecidos como critérios de inclusão: produções em português e textos completos publicados entre 2016 a 2021. E, como critérios de exclusão: textos que não se adaptaram com a temática pesquisada, e publicações de data anterior aos últimos 5 anos. Foram analisados 223 estudos e com uma leitura minuciosa 4 artigos foram selecionados para estruturar essa revisão.

\section{RESULTADOS E DISCUSSÃO}

As evidências expressas nos artigos incluídos na revisão encontram-se no Quadro 1.

Quadro 1- Síntese dos artigos referentes aos benefícios do Método Mãe Canguru

\begin{tabular}{|l|l|}
\hline Estudo & Achados Principais \\
\hline
\end{tabular}




\begin{tabular}{|c|c|}
\hline BILOTTI, et al., 2016 & $\begin{array}{l}\text { O MMC favorece o controle térmico, } \\
\text { reduz a ocorrência de choro, favorece } \\
\text { o controle eficiente da frequência } \\
\text { respiratória e oxigenação, favorece a } \\
\text { estimulação sensorial adequada do } \\
\text { recém-nascido e proporciona } \\
\text { crescimento adequado. }\end{array}$ \\
\hline LOTTO, LINHARES, 2018 & $\begin{array}{l}\text { O Método Canguru pode ser definido } \\
\text { como uma intervenção naturalística } \\
\text { eficaz no alívio da dor do recém- } \\
\text { nascido. }\end{array}$ \\
\hline SANTOS, FILHO, 2016 & $\begin{array}{l}\text { A revisão evidenciou que o Método } \\
\text { Mãe Canguru (MMC) é eficaz na } \\
\text { redução da dor e estresse do recém- } \\
\text { nascido de baixo peso submetido a } \\
\text { procedimentos dolorosos, diminuição } \\
\text { do tempo de internação, diminuição } \\
\text { dos custos de recursos humanos e de } \\
\text { materiais, aumento da prevalência ao } \\
\text { aleitamento exclusivo, aumento da } \\
\text { atividade motora e regulação dos } \\
\text { parâmetros fisiológicos. }\end{array}$ \\
\hline ZIRPOLI, et al., 2019 & $\begin{array}{l}\text { O contato pele a pele e promove } \\
\text { estabilidade térmica, estimula } \\
\text { aleitamento materno e aumenta } \\
\text { vínculo entre mãe e filho. }\end{array}$ \\
\hline
\end{tabular}

Em todo o mundo, nascem anualmente 20 milhões de bebês prematuros e de baixo peso (menores de 2,5kg). Destes, um terço morre antes de completar um ano de vida. O MMC é considerado a forma mais adequada de atenção a esses indivíduos, e visa reverter essa realidade. Consiste em uma assistência prestada ao RNPT de baixo peso, onde o mesmo é posicionado em decúbito ventral, na posição vertical contra o peito da mãe. (ZIRPOLI, et al., 
2019). É uma intervenção considerada viável, disponível e preferida para diminuir a taxa de morbimortalidade neonatal. (LOTTO, LINHARES, 2018).

Mãe e bebê são beneficiados com o método e a formação dos laços. O contato pele a pele precoce entre mãe e bebê, gradual e progressivo auxilia no controle fisiológico, controle da temperatura corporal e regulação do estado comportamental. (SANTOS, FILHO, 2016). Além disso, o aumento do vínculo família/mãe e filho leva a melhora da qualidade do desenvolvimento neurocomportamental e psicoafetivo do RNPT, reduz a ocorrência de choro, favorece o controle eficiente da glicemia capilar, da frequência respiratória e oxigenação, permite uma estimulação sensorial adequada, reduz o risco de infecção hospitalar e diminui o tempo de internação.( BILOTTI, et at., 2016)

Estudos apontam que o MMC é efetivo também para alívio de dor, aumentando a frequência do sono tranquilo dos bebês (LOTTO, LINHARES, 2018). Já na amamentação, o método melhora a sua incidência e duração, auxilia positivamente no processo de sucção e atua como um facilitador do aleitamento materno exclusivo (BILOTTI, et al.,2016).

Os achados da presente revisão comprovam a efetividade do MMC no desenvolvimento e redução da mortalidade do RNPT. Diante de inúmeros benefícios proporcionados pelo MMC observa-se a necessidade da transferência de conhecimentos científicos do contato pele a pele para a prática, como preconizado pelo Ministério da Saúde.

Quanto às limitações da presente revisão, pode-se citar a restrição do critério temporal e o fato de só terem sido usados artigos nacionais. Destaca-se a necessidade de novos estudos que avaliem as consequências em longo prazo desse método no desenvolvimento dos RNPT. Assim, espera-se que haja expansão da aplicação desse método que vai além das necessidades fisiológicas.

\section{CONCLUSÃO}

Os estudos selecionados mostraram a presença de diversos fatores que evidenciam os benefícios do MMC para o desenvolvimento neurocomportamental e psico-afetivo do recémnascido pré-termo de baixo peso, a formação de vínculos sólidos entre pais e filhos e a redução da morbimortalidade neonatal. Assim, considerando o grande número de prematuros nascidos no mundo e a elevada mortalidade desse grupo, o MMC apresenta-se como uma 
técnica viável, acessível e promissora na redução dessa estatística e das consequências negativas de um parto prematuro.

\section{REFERÊNCIAS}

BILOTTI, C.C, et al. Método mãe canguru para recém-nascido de baixo peso: revisão de literatura. Revista Saúde e Pesquisa, v. 9, n. 3, p. 587-595, set./dez. 2016

BRASIL. Ministério da Saúde. Atenção humanizada ao recém-nascido: Método Canguru: manual. Brasília, DF, 2017.

LOTTO, C.R; LINHARES, M.B.M. Contato "Pele a Pele" na Prevenção de Dor em Bebês Prematuros: Revisão Sistemática da Literatura. Trends Psychol. vol.26 no.4 Ribeirão Preto. 2018

SANTOS, M.H; FILHO, F.M.A. Benefícios do método mãe canguru em recém-nascidos pré-termo ou baixo peso: uma revisão da literatura. Universitas: Ciências da Saúde, Brasília, v. 14 , n. 1 , p. $67-76$, jan./jun. 2016

ZIRPOLI, D.B, et al. Benefícios do Método Canguru: Uma Revisão Integrativa . Rev Fund Care Online, 2019.11(n. esp):547-554 


\section{O POTENCIAL DA INTERVENÇÃO NUTRICIONAL SOBRE O AUTISMO EM}

\section{CRIANÇAS}

Nayane Gabriela Ferreira Macêdo e Silva - Universidade Federal de Campina Grande, Cuité, Paraíba, Brasil.

Thalita Oliveira de Melo - Universidade Federal de Campina Grande, Cuité, Paraíba, Brasil. Sabrina Mércia Belarmino Gomes - Universidade Federal de Campina Grande, Cuité, Paraíba, Brasil.

Larissa de Alcântara Santos - Universidade Federal de Campina Grande, Cuité, Paraíba,

Brasil.

Maria Eduarda Wanderley de Barros Silva - Universidade Federal de Campina Grande, Cuité, Paraíba, Brasil.

Ana Paula de Mendonça Falcone - Universidade Federal de Campina Grande, Cuité, Paraíba,

Brasil.

Área Temática: Multiprofissional.

E-mail:ng758723@gmail.com

\section{RESUMO}

O autismo é um distúrbio do neurodesenvolvimento, ao qual representa grandes prejuízos na comunicação, convívio social, e interação, sobretudo, em crianças. Como parte do manejo clínico, a nutrição é considerada uma estratégia terapêutica de grande essencialidade no acompanhamento de crianças autistas. Este trabalho trata-se de uma revisão da literatura, feita a partir de artigos científicos obtidos através da base de dados PUBMED, utilizando os descritores "autism", "nutrition", "children" intercalados entre si, através do operador booleano "AND", presente durante as combinações. Foi visto que hábitos alimentares desse público se encontram muitas vezes limitados, o que por consequência pode afetar o estado nutricional e também os processos fisiológicos do organismo parcial ou integralmente dependentes de diversos nutrientes, além de sintomas comumente encontrados no distúrbio autista parecem ser mitigados a partir da suplementação de vitaminas, minerais e outros. Em síntese, os sintomas que acompanham o distúrbio autista em crianças, podem ser mitigados através de diversos nutrientes, e dessa forma definir uma maior qualidade de vida para este público.

Palavras-Chave: Autismo. Nutrição. Manifestações clínicas.

\section{INTRODUÇÃO}

Integralizando um prejuízo principalmente no conjunto de reações que configuram o comportamento, o autismo tem por característica principal, distúrbios sobre as interações sociais, além de sua alta expressividade em comportamentos repetitivos, gerando dificuldades na comunicação. Na esfera pediátrica, acaba por necessitar de uma atenção diferenciada 
expressa de forma a visar um melhor manejo de pacientes pediátricos portadores deste transtorno, já que nesta fase a aplicabilidade de estratégias coadjuvantes ao manejo clínico pertinente, amplia de forma significativa uma melhora sobre o neurodesenvolvimento, refletindo em avanços no futuro, e garantindo uma melhor qualidade de vida e convívio social (ADAMS, 2015).

A partir do enlace com estratégias que possam delimitar uma melhora na qualidade de vida deste público, a nutrição se apresenta como forma terapêutica visando a melhora dos sintomas, e também do estado nutricional e metabólico das crianças portadoras, onde será refletida em condições metabólicas normais, já que é sabido que os hábitos alimentares adequados muitas vezes são comprometidos em detrimento de uma alimentação comumente mais auto restritiva e limitada presente nos portadores deste distúrbio. Dessa forma, a nutrição enquanto parte de uma totalidade essencial para melhora no neurodesenvolvimento, é de extrema importância em diversas reações do organismo, sendo os nutrientes protagonistas em reações enzimáticas como cofatores, além de estarem envolvidos na síntese de neurotransmissores (ADAMS et al., 2011).

Em consonância aos sintomas resultantes do prejuízo no neurodesenvolvimento, achados clínicos correspondentes ao eixo nutricional são necessários de análise e também de intervenções. Sintomas gastrointestinais, como: diarreia, constipação, e síndrome do intestino irritável parecem derivar de um certo grau de disbiose microbiana, presente em crianças com autismo, além da diminuição na concentração de vitaminas, minerais, e aminoácidos, e o aumento de biomarcadores do estresse oxidativo são sugestivos de um estado nutricional afetado dentro deste quadro (ADAMS et al., 2011).

\section{OBJETIVO}

Tendo em vista, a essencialidade da atenção neuropediátrica em conjunto com a atenção multidisciplinar, este trabalho tem como objetivo analisar o potencial da intervenção nutricional sobre crianças portadoras do autismo.

\section{METODOLOGIA}

Trata-se de uma revisão integrativa da literatura científica, feita a partir de artigos científicos obtidos através da base eletrônica de dados PUBMED, no idioma inglês, utilizando os Descritores em Ciências da Saúde (DeCS): “autism”, “nutrition”, “children” intercalados entre si, através do operador booleano "AND", presente durante as combinações. Foram 
selecionados artigos que se encontravam dentro dos critérios de inclusão, sendo eles, aqueles que dispunham da temática interessada, estudos que abordassem o autismo na faixa etária infantil, e que apresentassem as condições nutricionais deste público, assim como, excluídos aqueles que se encontravam em duplicata e não apresentavam informações pertinentes para a construção desta pesquisa. Os estudos selecionados são concordantes aos últimos 9 anos, e correspondem ao idioma inglês.

\section{RESULTADOS E DISCUSSÃO}

Sabendo que a nutrição possui a capacidade de mitigar os sintomas presentes no autismo, é possível pontuar, que o mesmo desencadeia um desequilíbrio sobre as defesas antioxidantes, gerando o estresse oxidativo, tal perspectiva possui origem da recorrente alimentação restrita deste público, o que acaba representando menor ingestão de nutrientes essenciais para a homeostase antioxidante. Desse modo, reações enzimáticas, e processos fisiológicos parcialmente dependentes dos mais variados nutrientes, acabam sendo afetadas podendo gerar um desequilíbrio nutricional, afetando diretamente o estado nutricional pediátrico autista e os processos fisiológicos normais. Sobretudo, é visto que moléculas importantes na homeostase antioxidante são importantes na fisiologia e metabolismo normal do organismo, tais como: biotina, glutationa, Dinucleótido de Nicotinamida e Adenina (NADH), Nicotinamida Adenina Dinucleótido Fosfato (NADPH), sulfato plasmático, Sadenosilmetionina (SAM), adenosina trifosfato plasmática (ATP), e triptofano, e que se encontram em menores concentrações nestes portadores, além disso, achados que corroboram o estado de metilação prejudicada e aumentos consideráveis na concentração de biomarcadores do estresse oxidativo parecem estar respectivamente diminuídos e comumente presentes em portadores autistas, principalmente em crianças. Com isso, a suplementação de vitaminas e minerais tem melhorado os parâmetros acima, além de apresentar efeitos positivos sobre a hiperatividade. É possível ressaltar que a presença de maiores variações genéticas, podem prejudicar a oferta de cofatores de minerais e vitaminas, já que se apresentam com maiores necessidades, assim, lançando prejuízos no diâmetro comportador dos processos enzimáticos dependentes destes, além de terem papel importante na síntese de neurotransmissores e seus percussores podendo estes serem prejudicados (ADAMS, 2015).

Sintomas gastrointestinais como: constipação, síndrome do intestino irritável e diarreia, são presentes em portadores autistas pediátricos, com isso, o uso da suplementação com o prebiótico a base de um galactooligossacarídeo (B-GOS) que desempenha um efeito similar à fibras, proporcionou mudanças positivas a saúde de crianças autistas, em razão da 
reação imunomoduladora sobre o intestino e na microbiota, ocasionando o aumento no número de bactérias benéficas como a bifidobacterium spp, redução nos problemas gastrointestinais, e escores menores de comportamento social associados a uma dieta restritiva, além de mudanças positivas com o aumento de 1 hora em relação ao tempo de sono das crianças. (GRIMALDI et al., 2018). Além disso, a suplementação de vitamina D junto à ácidos graxos poli-insaturados de cadeia longa, ômega-3, também parecem melhorar os sintomas do comportamento, já que levou a melhoras importantes no neurodesenvolvimento, além de apresentar regulação positiva sobre a resposta inflamatória (MAZAHERY et al., 2019).

Na literatura há análises que evidenciam um perfil funcional dos ácidos graxos poliinsaturados de cadeia longa, como o ácido docosahexaenoico (DHA) e ácido eicosapentaenoico (EPA) mediante a estrutura cerebral, assim como também, o respaldo de forma significativa no encargo correspondente a função cerebral melhorada, o que tem apresentado melhora em transtornos do neurodesenvolvimento. A melhora deve-se principalmente em sua funcionalidade nas membranas celulares, tratando de um efeito potencial, já que a formação contínua de axônios por parte dos neurônios, assim como as extensões dendríticas, acompanhadas a estruturas de membranas celulares. Com isso, a suplementação de omega-3, representante da família dos ácidos graxos poli-insaturados, parece melhorar de forma significativa comportamentos de externalização presentes em crianças com autismo. Em contrapartida, alguns estudos não apontam melhoras estatisticamente consideráveis por parte dessa suplementação, configurando um manejo de caráter ambíguo e de efeitos inconclusivos (MANKAD et al., 2015).

\section{CONCLUSÃO}

A nutrição possui parte essencial na melhoria dos sintomas e quadros clínicos que levam a prejuízos mediante ao transtorno autista. De mesmo modo, é possível concluir sua atuação sobre a faixa etária infantil portadora, apresentando os nutrientes atuantes na melhora de sintomas, que geralmente encontram-se presentes nesse distúrbio e em especial na população pediátrica. Dentre os sintomas presentes, os gastrointestinais, do comportamento e interação social e também bioquímicos, que abrange as alterações sobre os marcadores de estresse oxidativo, foram melhorados a partir da suplementação dos nutrientes já citados ao longo da pesquisa. No entanto, apesar das evidências expostas, ainda são presentes vieses que tornam estes respaldos ainda inconcisos, necessitando de estudos maiores e mais aprofundados. Contudo, uma nutrição adequada e que abranja o máximo de diversidades 
nutricionais, podem representar para este público um melhor estado nutricional, permeando alterações contribuintes aos parâmetros de desenvolvimento e consequentemente qualidade de vida.

\section{REFERENCIAS}

ADAMS, J. B., et al. Effect of a vitamin/mineral supplement on children and adults with autism. BMC pediatrics, Arizona, v. 11, n. 1, p. 1-30, 2011.

ADAMS, J. B. Vitamin/mineral supplements for children and adults with autism. Vitam Miner, Arizona, v. 3, n. 127, p. 2376-1318.100012, 2015.

GRIMALDI, R., et al. A prebiotic intervention study in children with autism spectrum disorders (ASDs). Microbiome, United Kingdom, v. 6, n. 1, p. 1-13, 2018.

MANKAD, D., et al. A randomized, placebo controlled trial of omega-3 fatty acids in the treatment of young children with autism. Molecular autism, Toronto, v. 6, n. 1, p. 1-11, 2015 .

MAZAHERY, H., et al. A randomised-controlled trial of vitamin d and omega-3 long chain polyunsaturated fatty acids in the treatment of core symptoms of autism spectrum disorder in children. Journal of autism and developmental disorders, New Zealand, v. 49, n. 5, p. 1778-1794, 2019. 


\title{
OS EFEITOS DA MUSICOTERAPIA NA SAÚDE DE RECÉM NASCIDOS PREMATUROS INTERNADOS EM UNIDADES DE TERAPIA INTENSIVA
}

\author{
${ }^{1}$ Ana Paula de Carvalho Souza- Universidade Estadual do Piauí, Teresina, Piauí, Brasil. \\ ${ }^{2}$ Abimael de Carvalho- Universidade Estadual do Piauí, Teresina, Piauí, Brasil. \\ ${ }^{3}$ Vivia Rhavena Pimentel Costa- Universidade Estadual do Piauí, Teresina, Piauí, Brasil. \\ ${ }^{4}$ Janaína de Moraes Silva- Fisioterapeuta e PhD em Ciências Biomédicas pela \\ Universidade Federal do Piauí, Teresina, Piauí, Brasil.
}

Área Temática: Multiprofissional

E-mail do autor para correspondência: anapaula.cvlh@gmail.com

\section{RESUMO}

Os recém nascidos (RN) internados em unidades de terapia intensiva neonatal (UTIN) estão expostos a vários estímulos dolorosos e negativos responsáveis por causarem tensões fisiológicas e estresses psicológicos. A musicoterapia pode aliviar os estímulos dolorosos dos recém nascidos, fornecendo estímulos auditivos que reduzem a percepção da dor, diminuindo ou até mesmo evitando a necessidade de usar agentes farmacológicos. O objetivo do estudo foi identificar na literatura científica os efeitos da musicoterapia na saúde de recém nascidos prematuros internados em unidades de terapia intensiva neonatal. Revisão bibliográfica de literatura através das bases de dados BVS, PubMed e periódicos CAPES, por meio dos descritores Infant, Newborn AND Music Therapy. De um total de 1.387 estudos foram selecionados cinco. Uma intervenção com musicoterapia mostrou ter efeitos positivos na saúde de recém nascidos prematuros internados em unidades de terapia intensiva, principalmente na diminuição do estresse e da resposta à dor, estabilidade dos parâmetros fisiológicos e cardiorrespiratórios e melhora das conectividades funcionais do cérebro.

Palavras- Chaves: Recém Nascido Prematuro; Unidade de Terapia Intensiva; Musicoterapia.

\section{INTRODUÇÃO}

Os recém nascidos $(\mathrm{RN})$ internados em unidades de terapia intensiva neonatal (UTIN) estão expostos a vários estímulos dolorosos e negativos como aplicações invasivas, ruídos, luzes e ao isolamento na incubadora, e muitas vezes são impedidos de experimentar o usual contato com a mãe. Esse conjunto de fatores são responsáveis por causarem tensões fisiológicas e estresses psicológicos (SILBERSTEIN; LITMANOVITZ, 2016). Estes estímulos podem desencadear uma resposta caracterizada por alterações tanto em parâmetros fisiológicos como em parâmetros comportamentais (BALDA; GUINSBURG, 2018). 
A musicoterapia e a estimulação através da música foram técnicas que se disseminaram muito nas UTIs neonatais nas últimas décadas, visto que a audição é uma das habilidades mais precocemente desenvolvidas no feto (MCMAHON; WINTERMARK; LAHAV, 2012). A musicoterapia pode aliviar os estímulos dolorosos dos recém nascidos a termo e prematuros, fornecendo estímulos auditivos que reduzem a percepção da dor, diminuindo ou até mesmo evitando a necessidade de usar agentes farmacológicos (BO; CALLAGHAN, 2000; HARTLING et al., 2009; JOYCE; KECK; GERKENSMEYER, 2001; LAI et al., 2006; ROBB; BURNS; CARPENTER, 2011).

A música pode ser considerada uma ferramenta importante no cuidado de recém nascidos em UTI neonatais, podendo diminuir o estresse, apoiando o desenvolvimento cognitivo e da fala, influenciando positivamente também nos parâmetros fisiológicos, tais como frequência cardíaca, pressão arterial sistêmica e temperatura corporal, além disso, regulariza o ritmo respiratório, relaxa a musculatura e melhora o sono (AMINI et al. 2013; AYD; LD, 2014; GARUNKSTIENE et al., 2014; LOEWY et al., 2013; STANDLEY, 2002).

\section{OBJETIVO}

Identificar na literatura científica os efeitos da musicoterapia na saúde de recém nascidos prematuros internados em unidades de terapia intensiva neonatal.

\section{MÉTODOS}

Trata-se de uma revisão bibliográfica de literatura realizada durante os meses de abril a julho de 2021, através do banco de dados Biblioteca Virtual em Saúde (BVS), da base de dados PubMed e dos periódicos CAPES, utilizando por meio dos Descritores de Ciências da Saúde (DECS) os descritores “Infant, Newborn AND Music Therapy”. Tendo como pergunta norteadora, quais os efeitos da musicoterapia na saúde de recém nascidos prematuros internados em unidades de terapia intensiva?. Foram incluídos estudos controlados, em qualquer idioma, entre 2016 e 2021, em sua forma completa e disponíveis nas bases de dados. Foram excluídos artigos de revisão, em andamento, e os que a população de estudo não fossem RNs prematuros internados em UTI ou que não tivessem como intervenção a musicoterapia. 
Inicialmente encontrou-se um total de 1.387 estudos, após a aplicação dos critérios de inclusão e exclusão restaram 306, após a leitura de título seguida por resumo resultou em um total de cinco estudos para esta revisão. A amostra dos estudos contou com um total de 376 recém nascidos prematuros internados em unidades de terapia intensiva neonatal, com idade gestacional entre 24 e 36 semanas.

Foram utilizadas como intervenção a musicoterapia através de discos com músicas clássicas e de ninar, gravações de mães cantando canções de ninar, rimas infantis, música de flauta clássica indiana instrumental e música ao vivo com uso de violoncelo. Os estudos analisados compararam a musicoterapia sozinha ou associada com o toque terapêutico, com outra intervenção ou com um grupo controle. Eles investigaram os efeitos da musicoterapia na resposta à dor, no estresse, parâmetros cardiorrespiratórios e fisiológicos, e nas conectividades do cérebro.

Os estudos encontraram resultados que demonstraram que a musicoterapia como intervenção para prematuros em UTI, tem efeitos na diminuição da resposta à dor, melhora nas concentrações de $\beta$-endorfina, mas não na concentração de cortisol no sangue, melhora na estabilidade cardiorrespiratória, na manutenção dos parâmetros fisiológicos, reduzindo o estresse, e garantindo um efeito benéfico nas conectividades funcionais do cérebro.

O estudo de Qiu et al. (2017) não especificou o tempo de execução da musicoterapia, já nos outros estudos o tempo variou de 15 a 45 minutos. Em relação à quantidade de sessões, a maioria dos estudos não explicitaram na sua metodologia, os que a fizeram, contaram com poucas sessões de no máximo três vezes por semana. A respeito da quantidade de decibéis das músicas executadas, apenas três estudos citaram essa medida de intensidade sonora, que correspondeu a variação de 35 a 65 decibéis.

Os estudos de Qiu et al. (2017) e Shukla et al. (2018) utilizaram a musicoterapia associada ao toque terapêutico e ao método canguru respectivamente, como intervenção para estímulos dolorosos, que segundo Prasopkittikun e Tilokskulchai (2003) também ajuda a reduzir a dor em neonatos, o que pode ter influenciado em seus resultados com efeitos positivos. Os autores também utilizaram o uso de vídeos das expressões dos neonatos e da escala de Perfil de Dor em Bebês Prematuros para avaliar a influência da intervenção na dor dos RNs. 
Uma intervenção com musicoterapia mostrou ter efeitos positivos na saúde de recém nascidos prematuros internados em unidades de terapia intensiva, principalmente na diminuição do estresse e da resposta à dor, estabilidade dos parâmetros fisiológicos e cardiorrespiratórios e melhora das conectividades funcionais do cérebro.

\section{REFERÊNCIAS BIBLIOGRÁFICAS}

AMINI, E. et al., Efeito da canção de ninar e da música clássica na estabilidade fisiológica de bebês prematuros hospitalizados: um ensaio randomizado. J Neonatal Perinatal Med 2013; 6: 295-301.

BALDA, R. C. X; GUINSBURG, R. A. Linguagem da dor no recém nascido. Documento científico do departamento de neonatologia da Sociedade Brasileira de Pediatria, São Paulo, 2018.

GARUNKSTIENE, R. et al., Ensaio controlado de canções de ninar ao vivo versus gravadas em bebês prematuros. Nordic J Music Ther v. 23, p. 71-88, 2014.

PRASOPKITTIKUN, T; TILOKSKULCHAI, F. Manejo da dor causada por picada no calcanhar em neonatos: uma análise da pesquisa realizada na Tailândia. J Perinat Neonatal Nurs. v. 17, p. 304-12, 2003.

SILBERSTEIN, D; LITMANOVITZ, I. Cuidado do desenvolvimento na unidade de terapia intensiva neonatal de acordo com o programa de avaliação e cuidado individualizado do desenvolvimento do recém-nascido (NIDCAP). Harefuah v. 155, p. 27-31, 2016. 


\section{PAPEL DO LEITE HUMANO NA ENTEROCOLITE NECROSANTE EM BEBÊS PREMATUROS: UMA REVISÃO INTEGRATIVA}

Larissa de Alcântara Santos - Universidade Federal de Campina Grande, Cuité, Paraíba,

Brasil.

Sabrina Mércia Belarmino Gomes - Universidade Federal de Campina Grande, Cuité, Paraíba,

Brasil.

Thalita Oliveira de Melo - Universidade Federal de Campina Grande, Cuité, Paraíba, Brasil. Maria Eduarda Wanderley de Barros Silva - Universidade Federal de Campina Grande, Cuité, Paraíba, Brasil.

Nayane Gabriela Ferreira Macêdo e Silva - Universidade Federal de Campina Grande, Cuité, Paraíba, Brasil.

Tamires Alcântara Dourado Gomes Machado - Universidade Federal de Campina Grande, Cuité, Paraíba, Brasil.

Área temática: Multiprofissional.

E-mail: larissasantos1918@gmail.com

\section{RESUMO}

A enterocolite necrosante (NEC) é uma doença gastrointestinal multifatorial comum em bebês prematuros, relacionada principalmente com baixo peso ao nascer, intestino imaturo, disbiose enteral, resposta imune desregulada e outras comorbidades. Sendo por essas razões, fatores contribuintes para a morbidade e mortalidade neonatal. Para tanto, o aporte nutricional precoce adequado tem se mostrado imprescindível no que se diz respeito ao tratamento de recém-nascidos acometidos por essa enfermidade. A alimentação enteral que consiste na alimentação artificial para aqueles que estão impedidos de se alimentar de forma convencional, como no caso dos recém-nascidos prematuros que ainda não conseguem deglutir e praticar o ato da sucção, ofertando leite humano que possui em sua composição nutrientes essenciais, se apresenta vantajosa no que se diz respeito ao manejo adequado do tratamento de NEC, seguindo a linha de alimentação estabelecida pelas diretrizes, delimitando o uso alongado de antibióticos e medicamentos de alto risco, que possam trazer problemas futuros a estes indivíduos.

Palavras-chave: Enterocolite necrosante. Leite humano. Recém-nascido.

\section{INTRODUÇÃO}

Recém-nascidos (RN) a termo são caracterizados por bebês que completaram 38-40 semanas de vida intrauterina e possuem maturidade fisiológica adequada para a vida. Já o RN 
prematuro é caracterizado por aqueles, que por causas maternas ou do próprio feto, não conseguem completar 37 semanas de vida intrauterina, tendo sua fisiologia ainda imatura e suscetível ao desenvolvimento de problemas futuros e comorbidades (CHANDRAN et al., 2020).

A enterocolite necrosante (NEC) é uma patogênese de característica multifatorial. Com maior prevalência em bebês com menor idade gestacional, por apresentarem uma maior imaturidade intestinal, peristaltismo reduzido, fina camada da mucosa, imaturidade das células epiteliais, maior incidência de apoptose dos enterócitos, disbiose microbiana, baixo peso ao nascer, estresse oxidativo e resposta imune desregulada, que podem causar inflamação intestinal e necrose, além de serem expostos a lesões constantes na mucosa devido a insultos perinatais como hipóxia, hipotermia e alimentação de fórmulas (ACETI et al., 2018) caracterizando-se, como fatores cruciais para o início de uma cascata inflamatória que pode culminar no desenvolvimento de NEC em recém-nascidos.

Apesar dos avanços na assistência perinatal e neonatal, a NEC continua sendo uma das principais causas de morbidade e mortalidade em $\mathrm{RN}$ prematuros, com taxas de mortalidade chegando a aproximadamente 30\% (ACETI et al., 2018).

Segundo, Sinclair e colaboradores (2020) as diretrizes alimentares padronizadas de manejo de fluidos e nutricionais, têm sido associadas a um menor risco de NEC em bebês com baixo peso ao nascer e a introdução a nutrição precoce tem sido utilizada com excelentes resultados diminuindo a mortalidade. Dessa forma, é bem reconhecido que o aporte nutricional de leite humano através da dieta enteral tem se mostrado benéfico para bebês prematuros, apresentando principalmente efeitos na redução do risco de NEC e aumento nos resultados de neurodesenvolvimento.

\section{OBJETIVOS}

Apontar e discutir os benefícios da terapia nutricional precoce de leite humano em bebês prematuros que desenvolveram enterocolite necrosante.

\section{MÍ́TODOS}

Trata-se de uma revisão integrativa que abrangeu informações publicadas nas plataformas digitais: Pubmed, National Center for Biotechnology Information (NCBI) e 
Sociedade Americana de Nutrição Parenteral e Enteral (ASPEN), utilizando os descritores "necrotizing enterocolitis" e "nutrition”, cruzados pelo operador booleano "AND”. Foram utilizados os seguintes critérios para a seleção dos respectivos artigos: periódico publicado, relevância do tema e ano de publicação. Os achados correspondem aos últimos sete anos e encontram-se no idioma inglês.

Inicialmente a pesquisa deu-se pela busca dos descritores, e em seguida foram utilizadas as palavras-chave e sinônimos como forma de facilitar a busca. Por essa razão, optou-se por uma revisão integrativa da literatura, buscando nos artigos o tema proposto em questão e a sua significância.

\section{RESULTADOS E DISCUSSÃO}

É sabido que a amamentação traz inúmeros benefícios para o recém-nascido, tendo em vista sua composição rica em nutrientes e anticorpos que irão auxiliar o bebê no processo de recuperação da NEC. Aceti et al. (2018), apontam que o leite humano é conhecido por ser um melhor catador de radicais livres do que a fórmula infantil, contribuindo de forma significativa para a diminuição do nível global de estresse oxidativo em bebês prematuros.

O leite humano fornece oligossacarídeos que podem exercer uma série de efeitos benéficos sobre o intestino do $\mathrm{RN}$, bem como, ácidos graxos poli-insaturados, eritropoietina, fator de crescimento epidérmico, acetil-hidrolase e componentes que alteram a flora bacteriana, alterando a camada do muco, diminuindo o epitélio e a permeabilidade, aumentando o peristaltismo (motilidade), que por consequência reduz o pH gástrico melhorando a função de barreira protegendo contra NEC (SCHANLER; ABRAMS; KIM, 2017).

Fatores como o uso de leite materno, adjunto da suplementação de probióticos, otimização da osmolaridade da alimentação com leite de fórmula para prematuros, uso de antibióticos de longo prazo e bloqueadores do receptor $\mathrm{H} 2$, podem em conjunto causar efeitos prejudiciais sobre o meio microbiano intestinal, aumentando o risco de NEC (CHANDRAN et al., 2020). A utilização exclusiva do leite humano evitando suplementação com outras substâncias é aconselhável, afim de diminuir o uso de antibióticos que podem causar danos futuros ao recém-nascido e reduzir os seus dias de internação na Unidade de Terapia Intensiva Neonatal (UTIN).

Segundo Aceti et al. (2018), a alimentação enteral, têm impacto negativo sobre o risco de NEC, entretanto este risco é reduzido quando os bebês prematuros são alimentados com 
uma dieta exclusivamente baseada em leite humano em comparação com dietas que contêm produtos ou substâncias derivados de bovinos encontrados em leites de fórmula.

RN prematuros que sobrevivem a NEC, especialmente NEC cirúrgica, estão em risco aumentado de déficits neurocognitivos. Ainda assim, a administração de colostro por via enteral não fornece apenas terapia imunológica por meio de sua interação com tecido linfoide orofaríngeo e intestinal, mas também inibe citocinas pró-inflamatórias e aumentam os fatores de proteção imunológica nesses bebês imunológicamente frágeis (CHANDRAN et al., 2020).

\section{CONSIDERAÇÕES FINAIS}

Depreende-se, portanto, que a utilização do leite humano de forma exclusiva como alternativa nutricional na prevenção e no manejo do tratamento de enterocolite necrosante, apresenta inúmeros benefícios que podem facilitar o processo de recuperação do bebê prematuro e a sua estadia na UTIN, além da redução do estresse oxidativo, diminuição do uso de antibióticos, fortalecimento da microbiota intestinal e sistema imunológico. Em contrapartida, a utilização de leites artificiais como os de fórmulas que contém derivados bovinos, pode apresentar danos a esse recém-nascido, como o aumento da cascata inflamatória, redução da homeostase intestinal, aumento da permeabilidade intestinal e um efeito tóxico direto para as células epiteliais intestinais. Ficando clara a evidência de que o leite humano continua sendo extremamente importante como única e exclusiva forma de alimentação, independente de apresentar enfermidades ou não, enfatizando assim a relevância do uso do leite humano na primeira fase da vida.

\section{REFERÊNCIAS}

ACETI, A. et al. Oxidative stress and necrotizing enterocolitis: pathogenetic mechanisms, opportunities for intervention, and role of human milk. Oxidative medicine and cellular longevity, v. 2018, 2018. DOI: https://doi.org/10.1155/2018/7397659. Disponível em: https://www.hindawi.com/journals/omcl/2018/7397659/. Acesso em: 20 abr. 2021.

CHANDRAN, S. et al. Evidence Based Practices Reduce Necrotizing Enterocolitis and Improve Nutritional Outcomes in Very Low Birth Weight Infants. Journal of Parenteral and Enteral Nutrition, 2020. DOI: https://doi.org/10.1002/jpen.2058. Disponível em: https://aspenjournals.onlinelibrary.wiley.com/doi/abs/10.1002/jpen.2058. Acesso em: 20 abr. 2021.

SCHANLER, R. J.; ABRAMS, S. A.; KIM, M. S. Prevention of necrotizing enterocolitis in newtons. UpToDate, Abrams SA Oct 07 2015, 2017. Disponível em: 
file://C:/Users/maga/Downloads/Preven\%C3\%A7\%C3\%A3o\%20da\%20enterocolite\%20necr osante\%20em\%20recem-nascidos.pdf. Acesso em: 20 de abr. 2021.

SINCLAIR, T. J. et al. Progressive metabolic dysfunction and nutritional variability precedes necrotizing enterocolitis. Nutrients, $\quad$ v. $12, \quad$ n. $5, \quad$ p. $1275,2020$. DOI:https://doi.org/10.3390/nu12051275. Disponível em: https://www.mdpi.com/20726643/12/5/1275/htm. Acesso em: 20 abr. 2021 


\title{
QUESTÕES ATUAIS NO TRATAMENTO FARMACOLÓGICO DO TRANSTORNO DO DÉFICIT DE ATENÇÃO E HIPERATIVIDADE EM CRIANÇAS
}

\author{
Victória Freitas de Souza Moura - Centro Universitário UniFacid, Teresina, Piauí, Brasil. \\ Luana Mendes Carvalho Bomfim - Centro Universitário UniFacid, Teresina, Piauí, Brasil. \\ Josenil Bezerra Nascimento Neto - Cirurgião Geral da Associação Piauiense de Combate ao
}

Câncer.

Aréa Temática: Medicina.

E-mail do autor para correspondência: victoriafreitasdesousamoura@ hotmail.com

\section{RESUMO}

A dificuldade de aprendizagem associada a um comportamento hiperativo tem sido uma das principais queixas relatadas nas unidades escolares. O Transtorno do Déficit de Atenção e Hiperatividade associa-se a um prejuízo funcional em diversas áreas, no entanto, existem tratamentos eficazes para ajudar a gerenciar a desatenção, hiperatividade e sintomas de impulsividade. O objetivo deste estudo foi realizar um levantamento bibliográfico sobre a importância do tratamento farmacológico, sobretudo dos psicoestimulantes e do tratamento não farmacológico na redução dos sintomas de TDAH em jovens de 6 a 17 anos com diagnósticos já estabelecidos, através dos bancos Embase®, PsycINFO® e o Banco de Dados Cochrane de Revisões Sistemáticas (CDSR). Dos artigos analisados a maioria tece críticas à prescrição indiscriminada dos psicoestimulantes. As drogas estimulantes, quando usadas com supervisão, geralmente são consideradas bastante seguras. Estimulantes não fazem a criança sentir-se dopada, embora algumas crianças relatem que se sentem diferentes ou engraçadas. Terapias não farmacológicas, isoladamente ou em combinação com medicação gestão, poderiam potencialmente abordar os principais sintomas do TDAH ou os prejuízos de longo prazo que estão associados ao transtorno. Garantir o diagnóstico adequado e evitar erros de diagnóstico é uma preocupação fundamental para a prática clínica.

Palavras-chave: Criança. Metilfenidato. TDAH. Terapia medicamentosa.

\section{INTRODUÇÃO}


Muitas crianças têm alguma desatenção ou atividade motora sem foco $\mathrm{e}$ impulsividade, mas para crianças com transtorno de déficit de atenção / hiperatividade (TDAH), essa desatenção, hiperatividade e impulsividade parecem ser mais graves, ocorrem com mais frequência e geralmente comprometem a capacidade de uma criança em casa e na escola. (COELHO et al, 2010).

O Transtorno do Déficit de Atenção e Hiperatividade é considerado um distúrbio cerebral caracterizado por desatenção e/ou hiperatividade e impulsividade. Mais especificamente, a desatenção sugere que uma criança pode apresentar dificuldade de realizar tarefas com foco sustentado e persistência, enquanto a hiperatividade sugere que a criança está em constante movimento em situações que tal atividade é inadequada, com uma tendência a incomodar e falar excessivamente. Uma criança que é impulsiva geralmente requer recompensas ou gratificação e age antes de pensar, o que coloca a criança em risco de prejuízo. (COELHO et al, 2010).

O TDAH é mais comumente diagnosticado em crianças em idade escolar, afetando aproximadamente 5 a $7 \%$ da população estudantil, embora também possa ser diagnosticado em pessoas de todas as faixas etárias. Em uma sala de aula média de 30 crianças, pesquisas sugerem que pelo menos um terá TDAH. Trata-se um distúrbio crônico, impactando um indivíduo ao longo de sua vida, embora a gravidade dos sintomas tem tendência a diminuir com a idade. (WALKUP et al, 2014).

De fato, algumas crianças com esse transtorno podem ter um déficit de linguagem não diagnosticada ou uma desordem que complica sua condição. Tratamentos eficazes estão disponíveis para ajudar a gerenciar a desatenção, hiperatividade, sintomas de impulsividade e podem melhorar a capacidade de uma pessoa em casa, na escola e em outros lugares. $\mathrm{O}$ tratamento pode incluir medicamentos, terapia comportamental ou a combinação dos dois. Neste estudo, o tratamento medicamentoso será enfatizado, o que inclui estimulantes como metilfenidato e anfetamina; não estimulantes, tais como atomoxetina; antidepressivos tricíclicos; e agonistas alfa. (WALKUP et al, 2014).

\section{OBJETIVO}

Avaliar a importância do tratamento farmacológico, sobretudo dos psicoestimulantes e do tratamento não farmacológico na redução dos sintomas de TDAH nas amplas categorias de hiperatividade, impulsividade e desatenção em jovens de 6 a 17 anos. 
Para identificar a literatura publicada relevante, pesquisamos Sistema Online de Busca e Análise de Literatura Médica- MEDLINE® (via PubMed), Excerpta Medica DatabaseEmbase ${ }^{\circ}$, American Psychological Association- PsycINFO® e o Banco de Dados Cochrane de Revisões Sistemáticas (CDSR), limitando a pesquisa a estudos conduzidos em crianças de até 17 anos de idade nos idiomas português e inglês e publicados a partir de janeiro 01 de novembro de 2009 à 7 de novembro de 2016. Essas bases de dados foram selecionadas com base em opiniões de especialistas internos de que eles identificariam a maior parte da literatura relevante sobre esse tópico e após revisões sistemáticas relacionadas anteriormente.

Foram utilizados em inglês os descritores "ADDH', "child", 'drug therapy', ''methylphenidate'. Desta busca foram encontrados 65 artigos, posteriormente submetidos aos critérios de exclusão. Os critérios de exclusão foram: artigos duplicados, disponibilizados na forma de resumo, que não abordavam diretamente a proposta estudada e que não atendiam aos demais critérios de inclusão. Após os critérios de seleção restaram 9 artigos que foram submetidos à leitura minuciosa para a coleta de dados.

\section{RESULTADOS E DISCUSSÃO}

Abordagens farmacológicas são comuns com alguma controvérsia. Os medicamentos para o TDAH são agrupados em duas categorias principais: estimulante e não estimulante. Medicamentos estimulantes, como metilfenidato e anfetaminas, são tratamentos altamente eficazes para o TDAH e estão disponíveis há décadas. As anfetaminas foram prescritas por mais de 70 anos; metilfenidato há mais de 50 anos, e ambos os tipos de medicação têm sido muito bem estudados. (PRINGSHEIM et al, 2011).

É importante trabalhar a prescrição com o médico para encontrar a medicação e a dosagem corretas. Para muitas pessoas, os estimulantes reduzem drasticamente hiperatividade e impulsividade e melhoraram sua capacidade de concentração, trabalho e aprendizagem. Os medicamentos também podem melhorar coordenação física, como a necessária na escrita e nos esportes. (MULAS et al, 2002).

As drogas estimulantes, quando usadas com supervisão, geralmente são consideradas bastante seguras. Estimulantes não fazem a criança sentir-se dopada, embora algumas crianças 
relatem que se sentem diferentes ou engraçadas. Tais mudanças são geralmente muito menores. (MULAS et al, 2002).

Embora alguns pais se preocupem com o fato de seu filho tornar-se dependente da medicação, até hoje não há evidência convincente de que os medicamentos estimulantes, quando usados no tratamento do TDAH, causem abuso ou dependência. Uma revisão de todos os estudos de longo prazo sobre medicação estimulante e abuso de substâncias, realizado por pesquisadores no Hospital Geral de Massachusetts e na Harvard Medical School, descobriu que adolescentes com TDAH que permaneceram em sua medicação durante a adolescência tiveram uma menor probabilidade de uso de substâncias ou abuso do que os adolescentes com TDAH que não estavam tomando medicamentos. (WALKUP et al, 2014).

As drogas estimulantes vêm em formas de longo e curto prazo. Os mais novos estimulantes de liberação prolongada podem ser tomados antes da escola e são de longa duração para que a criança não precise ir para a enfermaria da escola todos os dias para medicação. O médico pode discutir com os pais as necessidades da criança e decidir quais substâncias utilizar e se a criança precisa tomar o medicamento apenas durante o horário escolar ou à noite e fins de semana também. Se a criança não apresentar melhora dos sintomas, tomando uma medicação por uma semana, o médico pode tentar ajustar a dosagem. Se ainda não houver melhora, a criança pode mudar para outro medicamento. (DELGADO et al, 2014).

A única medicação não estimulante aprovada pelo Food and Drug Administration (FDA), a atomoxetina (Strattera), também tem demonstrado ser um tratamento eficaz para o TDAH. Alguns pais preferem a atomoxetina não estimulante (Strattera) por causa de suas preocupações com o uso da medicação estimulante. Além disso, a atomoxetina (Strattera) pode ser uma boa alternativa para crianças que não respondem bem à medicação estimulante ou tem outras condições junto com seu TDAH. (MULAS et al, 2002).

Os estimulantes são frequentemente usados com a expectativa de que as crianças sejam capazes de atender melhor a aspectos críticos de seu ambiente, e esse resultado é visto em $75 \%$ ou mais das crianças que estão tomando a medicação. Um estudo de tratamento comparando o uso de medicação isolada à medicação mais intervenção comportamental indicou que o uso de medicação era quase tão efetivo quanto à medicação e intervenções comportamentais. No momento, no entanto, a qualidade da evidência disponível sugere que não pode-se dizer com certeza se tomar metilfenidato, por exemplo, irá melhorar a vida de crianças e adolescentes com TDAH. (MULAS et al, 2002). 
Metilfenidato, o medicamento estimulante mais utilizado, está associado a vários eventos adversos não graves, como problemas com sono e diminuição do apetite. Embora a evidência não sugira um risco aumentado de eventos adversos sérios, são necessários estudos para avaliar o risco de eventos adversos graves em crianças que tomam metilfenidato durante um longo período de tempo. Além disso, restam limitações na eficácia da medicação devido a problemas persistentes com a falta de efeitos positivos generalizados em áreas mais amplas da vida, incluindo desempenho acadêmico, função executiva, motivação e auto-regulação. (OTASOWIE et al, 2014).

Cerca de uma em cada dez crianças não é beneficiada por um medicamento estimulante. Outros tipos de medicamento podem ser usados se os estimulantes não funcionarem ou se o TDAH ocorrer com outro transtorno. Antidepressivos e outros medicamentos podem ajudar a controlar a depressão que acompanha ou ansiedade. Para crianças com TDAH e distúrbios de linguagem devem incorporar intervenção linguística, se os alunos quiserem compreender a estrutura e as regras do discurso e conversa. (FONTANA et al, 2007).

\section{CONCLUSÃO OU CONSIDERAÇÕES FINAIS}

Os psicoestimulantes podem ser eficazes na redução da distração, melhorando a atenção sustentada, reduzindo comportamentos impulsivos e melhorando o nível de atividade. Terapias não farmacológicas (terapia comportamental, psicoterapia, intervenções psicossociais e intervenções de medicina complementar e alternativa), isoladamente ou em combinação com medicação gestão, poderiam potencialmente abordar os principais sintomas do TDAH ou os prejuízos de longo prazo que estão associados ao transtorno. Entender o papel das terapias não farmacológicas pode ser um desafio, pois engloba uma ampla gama de abordagens para o cuidado, desde intervenções comportamentais altamente estruturadas até medicamentos complementares. Apesar da crescente pesquisa sobre o tratamento para o TDAH e a conscientização sobre o curso da doença, questões importantes permanecem sobre o diagnóstico e o manejo do TDAH. Garantir o diagnóstico adequado e evitar erros de diagnóstico é uma preocupação fundamental para a prática clínica. Para o tratamento, as perguntas-chave incluem como melhor adequar a terapia aos indivíduos com base em suas características (por exemplo, idade, sexo, sintomas de TDAH, condições de comorbidade, terapia anterior e atual) e como monitorar de forma eficiente e eficaz os indivíduos com TDAH ao longo do tempo. (DELGADO et al, 2014). 
Podem existir diferenças clínicas entre o tratamento farmacológico e não farmacológico utilizado para o tratamento do TDAH. Incertezas sobre terapias e o equilíbrio entre benefícios, custos e danos potenciais devem ser considerados antes do início do tratamento. Há uma necessidade urgente de estudos significativos de alta qualidade sobre os múltiplos tratamentos para o TDAH em crianças e adolescentes. (PRINGSHEIM et al, 2011).

\section{REFERÊNCIAS}

COELHO, Liana et al. Transtorno do déficit de atenção e hiperatividade (TDAH) na criança: aspectos neurobiológicos, diagnóstico e conduta terapêutica. Acta medica portuguesa, v. 23, n. 4, p. 689-696, 2010.

DELGADO, Luna et al. Tratamiento del trastorno por déficit de atención e hiperactividad (TDAH). Implicaciones para enfermería. Revista de enfermeria, Barcelona, v. 37, n. 9, p. 30-34, 2014.

FONTANA, Rosiane et al. Prevalência de TDAH em quatro escolas públicas brasileiras. Arquivos de neuro-psiquiatria, v. 65, n. 1, p. 134-137, 2007. https://doi.org/10.1590/S0004$\underline{282 X 2007000100027}$

MULAS, F et al. Efectos de los psicoestimulantes en el desempeño cognitivo y conductual de los niños con un déficit de atención con hiperactividad subtipo combinado. Revista de neurologia, [s.1], v. 35, n. 1, p. 17-24, 2002.

OTASOWIE, John et al. Tricyclic antidepressants for attention deficit hyperactivity disorder (ADHD) in children and adolescents. Cochrane Database Of Systematic Reviews, [s.1.], p.1-22, 19 set. 2014. Wiley.

PRINGSHEIM, Tamara; STEEVES, Thomas. Pharmacological treatment for Attention Deficit Hyperactivity Disorder (ADHD) in children with comorbid tic disorders. Cochrane Database Of Systematic Reviews, [s.1.], p.1-35, 13 abr. 2011. Wiley. http://dx.doi.org/10.1002/14651858.cd007990.pub2.

STURMAN, Nancy et al. Methylphenidate for children and adolescents with autism spectrum disorder. Cochrane Database Of Systematic Reviews, [s.1.], p.1-38, 21 nov. 2017. Wiley. http://dx.doi.org/10.1002/14651858.cd011144.pub2.

WALKUP, John T.; STOSSEL, Lauren; RENDLEMAN, Rebecca. Beyond Rising Rates: Personalized Medicine and Public Health Approaches to the Diagnosis and Treatment of Attention-Deficit/Hyperactivity Disorder. Journal Of The American Academy Of Child \& Adolescent Psychiatry, [s.1.], v. 53, n. 1, p.14-16, jan. 2014. Elsevier BV. http://dx.doi.org/10.1016/j.jaac.2013.10.008.

WEIBEL, S et al. "Practical considerations for the evaluation and management of Attention Deficit Hyperactivity Disorder (ADHD) in adults." L'Encephale, [s.1.], v. 46, n. 1, p. 30-40, 2020. http://dx.doi.org/10.1016/j.encep.2019.06.005 


\section{REALIZAÇÃO DE UMA ATIVIDADE EDUCATIVA SOBRE AUTO-ORDENHA DE LEITE MATERNO EM MÃES ACOMPANHANTES DE BEBÊS INTERNADOS EM UNIDADES DE TERAPIA INTENSIVA NEONATAL: RELATO DE EXPERIÊNCIA}

Sabrina Mércia Belarmino Gomes - Universidade Federal de Campina Grande, Cuité, Paraíba,

Brasil.

Larissa de Alcântara Santos - Universidade Federal de Campina Grande, Cuité, Paraíba,

Brasil.

Thalita Oliveira de Melo - Universidade Federal de Campina Grande, Cuité, Paraíba, Brasil.

Taelyson Costa de Medeiros - Universidade Federal de Campina Grande, Cuité, Paraíba,

Brasil.

Mateus Fernandes da Silva - Universidade Federal de Campina Grande, Cuité, Paraíba, Brasil.

Jaielison Yandro Pereira da Silva - Universidade Federal de Campina Grande, Cuité, Paraíba,

Brasil.

Área Temática: Multiprofissional.

E-mail: sabrinamercia3279@gmail.com

\section{RESUMO}

O aleitamento materno deve ser incentivado em recém-nascidos pelos benefícios inerentes a essa prática. No entanto, alguns bebês acabam apresentando complicações ao longo da gestação, e nascem de forma prematura, sendo necessário, o encaminhamento para uma unidade de terapia intensiva neonatal. Nessa unidade, esses bebês necessitam de uma adequada alimentação e nutrição para garantir sua recuperação, trazendo destaque para o leite materno. Nesse contexto, o profissional de nutrição pode desempenhar um papel fundamental no auxílio das mães, como, por exemplo, o incentivo à extração de leite materno por meio da auto-ordenha. Diante disso, objetivou-se descrever a experiência do profissional de nutrição na realização de uma atividade educativa junto com mães acompanhantes de bebês internados em uma unidade de terapia intensiva neonatal sobre a técnicas de auto-ordenha de leite materno. Para tanto, realizou-se uma atividade educativa conduzida por um nutricionista sobre os passos para a realização da técnica, além da elaboração e um material didático, no formato de cartilha, que foi entregue às mães. Observa-se que atividades como essa promovem o fortalecimento de vínculos, além de esclarecer dúvidas sobre o procedimento. O uso de materiais didáticos vem como uma estratégia para a fixação do conteúdo repassado. Portanto, sugere-se que mais atividades como essa sejam realizadas, não apenas pelo nutricionista, mas pelos demais membros da equipe como forma de promover a educação em saúde.

Palavras-chave: Lactância. Leite materno. Pré-termo. UTIN. 
A amamentação promove diversos benefícios para o recém-nascido $(\mathrm{RN})$, tendo em vista sua composição de nutrientes e compostos imunológicos que contribuem para a maturação dos sistemas orgânicos, além de promover o crescimento e desenvolvimento adequados. No entanto, ressalta-se que alguns bebês acabam apresentando complicações ao longo da gestação, e acabam nascendo de forma prematura. A prematuridade é uma condição multifatorial, a qual, contribui para que o bebê nasça antes do tempo previsto. Dessa forma, muitos desses recém-nascidos pré-termo (RNPT) não apresentam maturidade fisiológica e motora adequadas para se manterem estáveis, sendo necessário o encaminhamento para a Unidade de Terapia Intensiva Neonatal (UTIN).

A UTIN trata-se de uma área destinada à cuidados intensivos para RNs em estado grave ou em risco de morte, que necessitam de atenção especializada de uma equipe multiprofissional que disponham de recursos necessários para diagnóstico e tratamento (BEZERRA SEGUNDO et al., 2018). Neste quadro, destaca-se o nutricionista, profissional que contribuí com a promoção da autonomia da genitora por meio de informações, entre elas, sobre o aleitamento materno (AM) tanto na teoria quanto na prática. É importante que haja a conscientização da importância do AM para essas mães, pois, promove benefícios tanto para o bebê, no auxílio adequado para alimentação e nutrição, contribuindo na melhora do quadro e reduzindo o seu período de internação, quanto para elas, contribuindo para alívio da mama evitando intercorrências clínicas maternas como o ingurgitamento mamário ou mastite (LIMA et al., 2020; PEREIRA et al., 2018).

A separação do binômio mãe-bebê é um dos fatores que estão ligados a complicações maternas na lactação, e na ausência da sucção ao seio, devem-se ser realizadas orientações para manter o estímulo da produção láctea até que a amamentação seja reestabelecida, a exemplo, o repasse da técnica de auto-ordenha para a extração do leite materno.

\section{OBJETIVOS}

Diante do exposto, este estudo tem por objetivo descrever a experiência do profissional de nutrição na realização de uma atividade educativa junto com mães acompanhantes de bebês internados na UTIN sobre a técnica de auto-ordenha de leite materno. 
Trata-se de um estudo descritivo, qualitativo, do tipo relato de experiência, realizado em um Hospital Universitário Amigo da Criança no interior do Rio Grande do Norte, por meio de uma atividade educativa realizada em uma sala de apoio da UTIN, no mês de dezembro de 2020. Foram convidadas a participar da atividade mães de bebês internados do referido setor hospitalar. Todas as mães que decidiram participar da atividade permaneceram sentadas em cadeiras separadas, utilizando máscaras e com a disponibilidade de álcool gel para higienização das mãos.

A temática abordada foi a "importância da técnica de auto-ordenha para extração do leite materno". Assim, foram realizadas orientações verbais sobre "higienização das mamas", "paramentação", "massagens", "extração manual” e "armazenamento do LM”, além de alguns questionamentos feitos durante essas orientações como forma de estimular a participação. Por fim, foi entregue uma cartilha, elaborada pelo nutricionista, como material de apoio. O material contemplava os assuntos abordados de forma oral, sendo acompanhados de figuras ilustrativas. A atividade educativa foi conduzida nutricionista responsável pela UTIN, e apresentou uma duração média de 20 minutos.

\section{RESULTADOS E DISCUSSÃO}

Participaram da atividade quatro mães, as quais demonstraram bastante interesse e participação na discussão, mostrando que a auto-ordenha mesmo que seja um assunto e uma prática, bem comum, às vezes é feito de forma automática e pouco se é falado sobre o real benefício para as mães. Elas são orientadas à realização de auto-ordenha para que seja efetivada a alimentação enteral do bebê ou para armazenar o leite para ser utilizado em sua ausência (BEZERRA et al., 2017).

Por isso, torna-se necessária a intervenção e o diálogo com essas mães, a fim de esclarecer as dúvidas, promover o cuidado a esse momento delicado, além de fortalecer vínculos. Foram levantados questionamentos sobre a experiência com a realização da autoordenha e as mães relataram a realização tanto com o auxílio dos profissionais de saúde quanto sozinhas, à medida que ganhavam mais segurança e autonomia na realização dessa prática.

Apesar de ser um método qualitativo, sem coleta de dados ou questionários a posteriori, foi possível observar que, durante a atividade educativa, as mães conseguiram elucidar suas dúvidas sobre as técnicas corretas de pega e de auto-ordenha do leite materno. 
Para tanto, as cartilhas, bem como a experiência em grupo, se mostraram como pontos chaves para o sucesso da partilha de conhecimento, que se deu não só do profissional para com as mães, como também entre elas mesmas.

Em alguns momentos, elas conseguiam tirar as próprias dúvidas que surgiam entre si, de modo que as mães que já tinham experiência com outros filhos conseguissem ajudar nessa partilha, fazendo com que os profissionais de saúde envolvidos sentissem maior facilidade em repassar o assunto, além de sentir que todas estavam confortáveis e interessadas na discussão e no material fornecido.

A distribuição de materiais educativos, no formato de cartilhas, pode ser considerada como uma ação estratégica, pois auxilia no processo de educação em saúde com essas mães, otimizando o entendimento do assunto, além da possibilidade de consulta em momentos posteriores. Na elaboração de um material educativo deve-se conhecer público que receberá esse material para que possa ser mais bem aproveitado. Conforme Melo et al. (2020), alguns critérios a serem considerados na elaboração desse tipo de material são: 1) a facilidade da leitura; 2) clareza e 3) aparência didática do conteúdo.

\section{CONCLUSÃO}

Portanto, conclui-se que é de grande importância a realização de práticas educativas como forma de reforçar assuntos e estimular algumas e diante desse contexto colocar as mães no papel de protagonistas na melhora dos seus bebês. Além disso, contribuí para a troca de experiências tanto entre mães e profissionais quanto de mãe para mãe, deste modo, fortalecendo vínculos. Ressalta-se que não apenas o nutricionista pode ser responsável por essas práticas, mas também, os demais profissionais que compõe essa equipe.

A elaboração e entrega de uma cartilha pode ser considerada como uma ótima estratégia no sentido de reforçar assuntos tanto para as mães que já possuíam certo nível de experiência, quanto para as recém-chegadas ao setor, contribuindo para a aprendizagem, independentemente, do nível de conhecimento. Portanto, sugere-se que mais atividades como essa sejam realizadas como forma de promover a educação em saúde.

\section{REFERÊNCIAS}

BEZERRA SEGUNDO, W. G. et al. A importância das unidades de terapia intensiva neonatal (UTIN) e de cuidados intermediários neonatal (UCIN) para o recém-nascidos 
prematuros. Revista de Ciências da Saúde Nova Esperança, João Pessoa, v. 16, n. 2, p. 8590, 2018. Disponível em: 10.17695/issn.2317-7160.v16n2a2018p85-90. Acesso em: 17 maio 2021.

BEZERRA, M. J. et al. Percepção de mães de recém-nascidos prematuros hospitalizados acerca da amamentação. Revista Baiana de Enfermagem, Bahia, v. 31, n. 2, 2017. Disponível em: doi 10.18471/rbe.v31i2.17246. Acesso em: 26 abr. 2021.

LIMA, S. P. et al. Proteção, promoção e apoio a amamentação: fortalecendo a iniciativa hospital amigo da criança. Revista de Extensão da UNIVASF, Petrolina, v. 8, n. 1, p. 155165, 2020. Disponível em:

https://www.periodicos.univasf.edu.br/index.php/extramuros/article/view/1046/766. Acesso em: 26 abr. 2021.

MELLO, N. C. et al. Construção e validação de cartilha educativa para dispositivos móveis sobre aleitamento materno. Texto \& Contexto-Enfermagem, Florianópolis, v. 29, 2020. Disponível em: http://dx.doi.org/10.1590/1980-265x-tce-2018-0492. Acesso em: 20 maio 2021.

PEREIRA, M. C. R. et al. O significado da realização da auto-ordenha do leite para as mães dos recém-nascidos prematuros. Revista Gaúcha de Enfermagem, Porto Alegre, v. 39, 2018. Disponível em: https://doi.org/10.1590/1983-1447.2018.2017-0245. Acesso em: 26 abr. 2021. 


\title{
RELATO DE EXPERIÊNCIA DA PARTICIPAÇÃO DE DISCENTES DE FISIOTERAPIA EM UM GRUPO DE ESTUDOS E EXTENSÃO DE FISIOTERAPIA EM NEONATOLOGIA
}

\author{
Abimael de Carvalho- Universidade Estadual do Piauí, Teresina, Piauí, Brasil. \\ Thayson Brito Leal- Centro Universitário UniFacid, Teresina, Piauí, Brasil. \\ Avylon Luan Silva Sousa- Centro Universitário UniFacid, Teresina, Piauí, Brasil. \\ Ana Paula de Carvalho Souza- Universidade Estadual do Piauí, Teresina, Piauí, Brasil. \\ Ramires dos Santos Moraes- Centro universitário UniFacid, Teresina, Piauí, Brasil. \\ Janaina de Moraes Silva - Universidade Estadual do Piauí, Teresina, Piauí, Brasil.
}

Área Temática: Multiprofissional.

E-mail do autor para correspondência: abimaeldecarvalho123@gmail.com.

Este estudo consiste em um relato de experiência com caráter descritivo, tendo como base a vivência de acadêmicos de fisioterapia como membros de um projeto de pesquisa e extensão denominado 'Grupo de Estudos e Extensão de Fisioterapia em Neonatologia, cujo objetivo era aliar teoria e prática para desenvolver o raciocínio crítico, o pensamento científico e habilitar os seus participantes a atuarem no campo da neonatologia. Através dos relatos dos discentes que participaram do projeto, foi possível perceber que a inserção dos mesmos nas ações propostas, contribuiu positivamente para o seu processo de formação acadêmica na área de neonatologia.

Palavras-chave: Fisioterapia. Extensão universitária. Neonatos.

\section{INTRODUÇÃO}

As Diretrizes Curriculares Nacionais do Curso de Graduação em Fisioterapia (DCNs/Fisioterapia) apontam que os conteúdos essenciais para o curso de graduação, devem estar relacionados com todo o processo saúde/doença do cidadão, da família e da comunidade, articulados à realidade epidemiológica e profissional, dessa forma, proporcionando a integralidade das ações do cuidar, quer nas alterações patológicas ou cinético funcionais ou nas repercussões psíquicas e orgânicas, cabendo ao profissional entender que as pessoas são dotadas de subjetividades e que o corpo não se dissocia da mente (BISPO JÚNIOR, 2009).

As DCNs/Fisioterapia apontam ainda que a atuação do profissional deve ser multiprofissional, interdisciplinar e transdisciplinar, uma vez que o fisioterapeuta possui perfil 
para atuar em centros de reabilitação, clínicas especializadas e hospitais, utilizando, tanto seus conhecimentos práticos quanto teóricos.

Contudo, mesmo diante de avanços, a organização curricular de Fisioterapia, comumente, vem direcionando sua abordagem para determinados problemas de saúde voltados para o estudo de doenças que deixam sequelas reabilitáveis. Dessa maneira, essa estrutura não favorece ao acadêmico de Fisioterapia uma aproximação maior com a realidade social da população mais carente, bem como com o conhecimento concreto acerca do enfrentamento de problemas. Logo, mudanças recentes nos projetos políticos pedagógicos dos cursos, revelam maior preocupação com a formação de seus futuros profissionais (MAIA, 2016).

Dessa forma, com o objetivo de reinventar a formação acadêmica em Fisioterapia e na busca de promover uma maior aproximação desta com os indivíduos envolvidos no processo do cuidado, se faz cada vez mais necessária a implementação de projetos de extensão universitária na grade curricular.

Trilhando esse caminho, o Plano Nacional, documento definido a partir do Fórum de Pró-Reitores de Extensão das Universidades, assinala a concepção da extensão como prática acadêmica que interliga a universidade, nas suas atividades de ensino e de pesquisa, com as demandas da maioria da população, sendo uma prática que possibilita a formação do profissional cidadão e se credencia, junto à sociedade, como espaço privilegiado de produção de conhecimento significativo para a superação das desigualdades sociais existentes (CARDOSO et al., 2015).

Nesse contexto, o Grupo de Estudos e Extensão de Fisioterapia em Neonatologia, foi fundado no ano de 2019 por acadêmicos e docentes do curso de fisioterapia da Universidade Estadual do Piauí (UESPI), tendo como objetivo aliar teoria e prática para desenvolver o raciocínio crítico, o pensamento científico e habilitar os seus participantes a atuarem no campo da neonatologia.

\section{OBJETIVOS}

Relatar a experiência vivenciada por acadêmicos de fisioterapia na participação em um grupo de estudos e extensão voltado para a abordagem da assistência fisioterapêutica em neonatologia. 
Este estudo consiste em um relato de experiência com caráter descritivo, tendo como base a vivência de acadêmicos de fisioterapia como membros de um projeto de pesquisa e extensão denominado 'Grupo de Estudos e Extensão de Fisioterapia em Neonatologia, desenvolvido no Centro de Ciências da Saúde da Universidade Estadual do Piauí, no município de Teresina-PI, entre os meses de março à dezembro de 2019.

Respeitando-se as diretrizes das resoluções 466/2012 e 510/2016 do Conselho Nacional de Saúde, este estudo não foi submetido a um Comitê de Ética em Pesquisa, em virtude de se tratar de um relato descritivo, portanto, sem a necessidade do uso de dados de seres humanos.

\section{RESULTADOS}

O projeto contou com a participação de cerca de dez discentes, matriculados regularmente nas mais diversas instituições de ensino localizadas em Teresina-PI, selecionados por meio de processo seletivo. Os encontros, por sua vez, aconteciam uma vez por mês, sempre às segundas no turno da noite, tendo duração média de uma hora. Além de palestras e momentos práticos, era oportunizado aos membros discussão de artigos e incentivo ao desenvolvimento de produções científicas sobre as temáticas abordadas nos encontros.

Ao longo dessa iniciativa de extensão universitária, foram desenvolvidos temas como: intervenção fisioterapêutica em utin, desenvolvimento motor precoce em bebês prematuros, estimulação precoce, reabilitação na mielomeningocele, análise radiológica de tórax, osteopatia pediátrica, reanimação neonatal, entre outros temas, que foram explanados por convidados especializados em assistência fisioterapêutica em neonatologia. Ressalta-se que o ponto forte da extensão foi a possibilidade de entrar em contato e compreender o funcionamento de técnicas como tapotagem, vibração, manobras com ambú (bag-squeezing), aspiração de vias aéreas e endotraqueal, estímulo de tosse, drenagem postural, corretos posicionamentos, entre outros, que são capazes de proporcionar aumento na sobrevida e reduzir sequelas sistêmicas em recém-nascidos em estado crítico.

Diante das atividades desenvolvidas, inicialmente, compreendeu-se que embora os objetivos sejam semelhantes aos traçados para os indivíduos adultos, a assistência fisioterapêutica em neonatologia, apresenta peculiaridades relacionadas às diferenças 
anatômicas e fisiológicas existentes nestes pacientes. Ademais, foi possível perceber a relevância da atuação fisioterapêutica nas unidades de terapia intensiva neonatal, bem como os cuidados que devem ser preconizados com este público neste ambiente. Além disso, acredita-se que os conhecimentos adquiridos puderam potencializar a formação intelectual de todos os acadêmicos envolvidos, assim como fomentar o interesse pela pesquisa científica com neonatos.

Nessa direção, Maia (2015) aponta que a fisioterapia tem se mostrado uma intervenção prioritária, por promover a otimização da função respiratória, a facilitação correlacionada às trocas gasosas, a otimização da relação ventilação-perfusão, a manutenção da permeabilidade das vias aéreas e o desmame da ventilação mecânica e da oxigenoterapia. Assim, se houver uma assistência adequada de um fisioterapeuta, os agravantes para os neonatos graves podem ser minimizados, com evoluções promissoras.

Através dos relatos dos discentes que participaram do projeto, foi possível perceber que a inserção dos mesmos no projeto de extensão, contribuiu positivamente para o seu processo de formação acadêmica na área de neonatologia. Por outro lado, é oportuno destacar que os ganhos relacionados aos conhecimentos adquiridos, vão além do mero assistencialismo e do uso de técnicas manuais características da fisioterapia.

Nesse sentido, se faz importante compreender que é preciso mais do que o uso predominante de tecnologias duras no contexto atual. Entendendo essa necessidade, buscou-se empregar, nas atividades propostas, a abordagem das tecnologias leves no processo de trabalho frente ao recém-nascido no contexto da UTIN, como estabelecimento de relações por meio da escuta, do vínculo, do diálogo, do acolhimento, da autonomia e compromisso, ou seja, recursos que possibilitam meios para a construção de um processo terapêutico baseado na interação e na confiança para com os usuários (LORENZETTI et al., 2012).

Destaca-se que a tecnologia leve se refere às tecnologias relacionais, como aquelas de produção de vínculo, acolhimento e autonomização (LORENZETTI et al., 2012). Nesse sentido, o uso desses dispositivos pode potencializar as ações de fisioterapia, bem como modificar o seu processo de trabalho na UTIN, dessa forma qualificando a oferta do cuidado e contribuindo para o fortalecimento dos princípios que regem o Sistema Único de Saúde (SUS), tornando o usuário o objeto central desse processo. Dessa forma, ao possibilitar um trabalho diferenciado, faz-se necessário a discussão desse tema rotineiramente, pois o desafio está em adequar a inserção dessa tecnologia na prática do cuidado em saúde, não só de fisioterapeutas, mas também na prática clínica de todos os profissionais da saúde inseridos em unidades de terapia intensiva neonatal. 
O projeto de extensão surgiu como uma alternativa, sinalizando para uma mudança de paradigma e expectativas em relação às experiências de aprendizagem propiciadas no curso de fisioterapia quanto à assistência fisioterapêutica na área de neonatologia. Dessa forma, a inserção de acadêmicos de fisioterapia, na extensão universitária com foco na assistência à pacientes no contexto da unidade de terapia intensiva neonatal, possibilitou uma visão diferenciada da intervenção profissional nesse campo, nesse sentido, contribuindo para a melhor qualificação dos acadêmicos no manejo de recém-nascidos com diversos quadros clínicos e na oferta de atenção de qualidade para esses sujeitos.

Por fim, destaca-se que a possibilidade de inserção no projeto propiciou vivenciar a prática de maneira a preparar o acadêmico para questionar e construir novos modelos de assistência, desenvolvendo a autonomia e a capacidade de pensar acerca das questões clínicas, institucionais e suas intersecções.

\section{REFERENNCIAS}

BISPO JÚNIOR, J. P. Formação em fisioterapia no Brasil: reflexões sobre a expansão do ensino e os modelos de formação. Hist. cienc. Saúde-Manguinhos, Rio de Janeiro, v. 16, n. 3, p. 655-668, Sept. 2009.

CARDOSO, A. $\mathrm{C}$ et al. $\mathrm{O}$ estímulo à prática da interdisciplinaridade e do multiprofissionalismo: a extensão universitária como uma estratégia para a educação interprofissional. Rev. ABENO vol.15 no.2 Londrina Abr./Jun. 2015.

LORENZETTI, $\mathrm{J}$ et al. Tecnologia, inovação tecnológica e saúde: uma reflexão necessária. Texto contexto - enfermagem., Florianópolis, v. 21, n. 2, p. 432-439, June 2012.

MAIA, F. E. A. A fisioterapia nas unidades de terapia intensiva neonatal. Rev Fac Ciênc Méd Sorocaba.;18(1):64-5, 2016.

MINAYO, M. C. S.; GUERRIERO, I. C. Z. Reflexividade como éthos da pesquisa qualitativa. Ciênc. Saúde coletiva, Rio de Janeiro, v. 19, n. 4, p. 1103-1112, abr. 2014. 


\section{USO DA METODOLOGIA ATIVA "PROBLEM BASED LEARNING" NO ENSINO REMOTO DURANTE A PANDEMIA DA COVID-19 SOBRE NEONATOLOGIA EM UM GRUPO DE PESQUISA E ESTUDOS DE NUTRIÇÃO CLÍNICA: RELATO DE EXPERIÊNCIA}

Thalita Oliveira de Melo - Universidade Federal de Campina Grande, Cuité, Paraíba, Brasil. Sabrina Mércia Belarmino Gomes - Universidade Federal de Campina Grande, Cuité, Paraíba, Brasil.

Taelyson Costa de Medeiros - Universidade Federal de Campina Grande, Cuité, Paraíba,

Brasil.

Marina Lins Mendes Pinto - Universidade Federal de Campina Grande, Cuité, Paraíba, Brasil.

Larissa de Alcântara Santos - Universidade Federal de Campina Grande, Cuité, Paraíba,

Brasil.

Jaielison Yandro Pereira da Silva - Universidade Federal de Campina Grande, Cuité, Paraíba,

Brasil.

Área Temática: Nutrição.

E-mail: thalita.mello.89@gmail.com

\section{RESUMO}

Com a pandemia da Covid-19 muitas instituições de ensino tiveram que suspender suas atividades presenciais, adotando-se o ensino remoto. Diante disso, o Grupo de Pesquisa e Estudos em Atualidades da Nutrição Clínica (CLINUTRI) que propõe reuniões científicas entre alunos e professores teve que adaptar-se a essa nova realidade. Para tanto, utilizou a metodologia ativa de ensino Problem Based Learning (PBL) em suas reuniões científicas. Essa metodologia utiliza a discussão de problemas e suas soluções. Dentre as reuniões do grupo ao longo do semestre uma delas incluiu uma temática sobre neonatologia. Diante do exposto, o presente trabalho tem por objetivo relatar a experiência do uso da metodologia ativa PBL no ensino remoto durante a pandemia da Covid-19 sobre neonatologia aplicada a nutrição clínica. $\mathrm{O}$ trabalho trata-se de um estudo qualitativo, descritivo, do tipo relato de experiência. Para tanto, foi elaborado um caso clínico em conjunto com dois profissionais com experiência na área. Foram sorteadas três duplas de alunos para apresentarem as soluções e levantar questionamentos sobre o caso. $\mathrm{O}$ caso tratou-se de uma recém-nascida prematura extrema com baixas medidas antropométrica que fez uso de diversos fármacos e terapias nutricionais, ao longo da sua internação; apresentou inúmeras complicações, permitindo a abordagem de diversos assuntos. Os resultados obtidos demostraram eficiência do uso de PBL para o ensino remoto sendo percebido pela participação e motivação dos alunos em resolver o caso. Portanto, diante o cenário da Covid-19, o uso da metodologia ativa PBL é uma estratégia inovadora que contribui na interação e aprendizagem dos alunos sobre a temática abordada em seus diferentes aspectos. 
Palavras-chave: Prematuridade. Lactente. Amamentação.

\section{INTRODUÇÃO}

Ao final do ano de 2019 surgiu uma nova variante do coronavírus, denominada SARSCoV-2 a qual tornou-se uma pandemia, causando diversos impactos na população. Diante dessa nova realidade, medidas preventivas tiveram que ser tomadas a nível mundial a fim de conter a propagação do vírus. Dentre elas, a principal foi o isolamento social, o qual repercutiu na suspensão das aulas presenciais em instituições de ensino, afetando em torno de 1,5 bilhões de estudantes no mundo todo (KAWASAKI et al., 2021; MACIEL et al., 2020).

Nessa perspectiva, o Grupo de Pesquisa e Estudos em Atualidades da Nutrição Clínica (CLINUTRI) vinculado ao curso de Bacharelado em Nutrição do centro Educação e Saúde (CES) da Universidade Federal de Campina Grande (UFCG) o qual propõe a realização de encontros entre docentes e discentes com o objetivo de ampliar os conhecimentos e as experiências dos integrantes nas áreas de atuação do nutricionista, com ênfase para a área de Nutrição Clínica, teve que se adaptar a realidade do ensino remoto no semestre letivo 2020.1e.

As reuniões apresentaram um novo formato, foram realizadas por meio do uso da metodologia ativa de ensino Problem Based Learning (PBL), baseado na resolução de problemas utilizando o raciocínio lógico, estimulando os alunos a investigarem e solucionarem o caso, com ênfase na troca de experiência e conhecimento prévio entre docentes e discentes aliado a experiência com os profissionais (MACIEL et al., 2020; VIEIRA et al., 2019)

A coordenação do grupo ao avaliar as temáticas sugeridas pelos membros, observaram o pedido sobre neonatologia e com base na grade curricular do curso de nutrição, nota-se uma carência sobre essa área de atuação do nutricionista, que possui um papel de extrema importância nas Unidades de Cuidado Intensivo e Semi-intensivo Neonatal (UCIS). Logo, uma das reuniões científicas contou com um PBL sobre neonatologia com ênfase na atuação e condutas tomadas pelo nutricionista. 
Diante do exposto, o presente trabalho tem por objetivo relatar a experiência do uso da metodologia ativa "Problem Based Learning" (PBL) no ensino remoto durante a pandemia da Covid-19 sobre neonatologia no Grupo de Pesquisa e Estudos em Atualidades da Nutrição (CLINUTRI) em uma reunião científica.

\section{METODOLOGIA}

Trata-se de um estudo descritivo, qualitativo, do tipo relato de experiência vivenciada no processo de adaptação ao ensino remoto com metodologia ativa PBL. Foi realizado em âmbito virtual por meio da extensão Google Meet. O encontro foi voltado para os graduandos do curso de bacharelado em nutrição da UFCG/CES, integrantes do CLINUTRI, no semestre letivo 2020.1e.

A elaboração do PBL ocorreu da seguinte maneira: a coordenação do grupo entrou em contato com dois nutricionistas residentes, egressos da UFCG e do grupo, vinculados aos seus programas de residência multiprofissional com ênfase de formação em: "Assistência à Saúde Materno-infantil" e "Atenção à saúde da Criança e do Adolescente", para que fosse elaborado o seguinte estudo de caso: "Prematuridade em UTI Neonatal: aprendizagem baseada em problemas".

No período de uma semana anterior a apresentação desse caso foram sorteadas três duplas de alunos, a saber: 1) uma dupla de apresentadores, os quais iriam apresentar a solução para os problemas do caso clínico e 2) duas duplas de debatedores, responsáveis por levantar questionamentos e complementar a apresentação. Ao correr da semana a coordenação disponibilizou materiais de estudo, além de suporte para esclarecimento de possíveis dúvidas. No dia da reunião estiveram presentes os membros da coordenação, os convidados especiais, as duplas responsáveis pelo PBL e os demais membros do grupo.

O caso clínico tratou-se de uma recém-nascida pré-termo extrema que foi encaminhada logo após seu nascimento para a UCIS. A RN, ao chegar na unidade foi intubada e posta em manuseio mínimo. A paciente apresentou baixas medidas antropométricas como puderam ser vistas durante a avaliação e classificação. Fez uso de fototerapia, iniciou a nutrição enteral, além do uso de diversos fármacos. Apresentou complicações e ficou de dieta zero. Iniciou a nutrição parenteral em conjunto com a colostroterapia. Após estabilização iniciou a nutrição enteral mínima de leite materno ordenhado (trabalhando-se, assim, também com a mãe) e acompanhamento da evolução ponderal. Ao longo da internação apresentou novas intercorrências clínicas como: distensão 
abdominal significativa, alterações dos exames laboratoriais e uma suspeita de enterocolite necrotizante, suspendendo-se a dieta para observação clínica. Sendo reintroduzida a nutrição enteral após estabilização. O quadro foi evoluindo de forma estável até a paciente receber alta hospitalar.

Portanto, verifica-se que foram trabalhados diversos assuntos em um único caso clínico. Ao decorrer da apresentação, os estudantes e demais participantes presentes possuíam liberdade para realizar perguntas sobre o caso tanto pela via chat como por voz, por meio da ativação do microfone.

\section{RESULTADOS E DISCUSSÃO}

Ao longo da reunião observou-se uma grande interação entre os membros, apresentadores, convidados e alunos. Destaca-se que essa troca de conhecimentos é de extrema importância para a formação dos alunos da graduação, pois, eles já conseguem obter informações sobre a importância da atuação desse profissional no âmbito da neonatologia. Levar experiências reais engrandecem ainda mais essas trocas.

O aprendizado de forma remota muitas vezes é subestimado por não ofertar conhecimento da mesma intensidade que o passada em sala de aula. Ministrar aulas interativas e práticas com os alunos é um dos principais desafios no ensino remoto. Em contrapartida, a flexibilidade e a maior comodidade são uns dos principais destaques positivos desse formato (MACIEL et al., 2020).

O uso da metodologia no formato de PBL apresentou-se muito eficaz sendo uma experiência enriquecedora, uma vez que foi possível relacionar a nutrição com várias áreas de conhecimento, além de mostrar também o trabalho multiprofissional na realidade prática, contribuindo de forma positiva e inovadora para formação desses graduandos. A aquisição de conhecimento pelo PBL pode ser semelhante àquelas que são adquiridas em estágios por conta da autoaprendizagem e aprendizagem colaborativa (ROMÃO; BESTETTI; COUTO, 2020). O uso dessa metodologia apresenta inúmeras vantagens, logo que um dos objetivos principais é instigar e motivar os alunos a participarem das discussões (ROMÃO; BESTETTI; COUTO, 2020).

Conforme Vieira et al. (2019) na literatura são extensos os casos que mostram a eficácia de metodologias ativas para ensino, logo, destaca-se a necessidade de inserir novas formas de conduzir o ensino diante a atual realidade da Covi-19, promovendo práticas de 
inserção do aluno a fim de conseguir passar o conhecimento teórico relacionando com a prática, visando melhor qualificação do graduando, semelhante ao que foi passado aos alunos do referido grupo de pesquisa e estudos.

\section{CONCLUSÃO}

Portanto, conclui-se que mesmo diante desse cenário de pandemia e suspensão das aulas presenciais algumas estratégias de ensino podem ser utilizadas no intuito de melhorar o repasse de informações nesse ensino remoto, como o PBL. O uso dessa metodologia ativa foi essencial para o feedback positivo das reuniões, encorajando os alunos a interagirem mantendo-os interessados, melhorando assim a fixação do conteúdo sobre neonatologia aplicada à nutrição.

\section{REFERÊNCIAS}

KAWASAKI, H.; YAMASAKI, S.; MASUOKA, Y.; IWASA, M.; FUKITA, S.; MATSUYAMA, R. Remote Teaching Due to COVID-19: An Exploration of Its Effectiveness and Issues, International journal of environmental research and public health, , v. 18, n. 5, p. 2672, 2021. Disponível em: https://dx.doi.org/10.3390\%2Fijerph18052672. Acesso em: 17 maio 2021.

MACIEL, M. A. C.; ANDRETO, L. M.; FERREIRA., T. C. M.; MONGIOVI, V. G.; FERREIRA, M. C. S.; SILVA, S. L.; SANTOS, C. S.; FERREIRA, L. L. Os desafios do uso de metodologias ativas no ensino remoto durante a pandemia do Covid-19 em um curso superior de enfermagem: um relato de experiência. Brazilian Journal of Development, v. 6, n. 12, p. 98489-98504, 2020. Disponível em: https://doi.org/10.34117/bjdv6n12-367. Acesso em: 17 maio 2021.

ROMÃO, G. S.; BESTETTI, R.B.; COUTO, L. B. Aplicação do PBL Clínico na Atenção Primária em Cursos de Medicina. Revista Brasileira de Educação, v. 44, n. 4, 2020. Disponível em: https://doi.org/10.1590/1981-5271v44.4-20200115. Acesso em: 20 maio 2021.

VIEIRA, C. R. S. F.; VASCONCELOS, F. C.; CAMPOS, J. S. P.; MARQUES, R. F. S. V.; PORTELLA, M. B. Utilização de metodologia ativa de ensino na formação do profissional de nutrição. Revista Eletrônica Acervo Saúde, v. 11, n. 9, p. e297-e297, 2019. Disponível em: https://doi.org/10.25248/reas.e297. Acesso em: 20 maio 2021. 


\section{USO DA FERRAMENTA LATCH PELO NUTRICIONISTA NA OBSERVAÇÃO DO ALEITAMENTO MATERNO NO BINÔMIO MÃE-BEBÊ DURANTE INTERNAÇÃ̃o NA UCINCo: RELATO DE EXPERIÊNCIA}

Thalita Oliveira de Melo - Universidade Federal de Campina Grande, Cuité, Paraíba, Brasil.

Sabrina Mércia Belarmino Gomes - Universidade Federal de Campina Grande, Cuité, Paraíba, Brasil.

Nayane Gabriela Ferreira Macêdo e Silva - Universidade Federal de Campina Grande, Cuité, Paraíba, Brasil.

Larissa de Alcântara Santos - Universidade Federal de Campina Grande, Cuité, Paraíba, Brasil. Maria Eduarda Wanderley de Barros Silva - Universidade Federal de Campina Grande, Cuité, Paraíba, Brasil. Jaielison Yandro Pereira da Silva - Universidade Federal de Campina Grande, Cuité, Paraíba, Brasil.

\section{Área Temática: Nutrição.}

E-mail: thalita.mello.89@gmail.com

\section{RESUMO}

O nascimento de um bebê prematuro torna-se um grande desafio para a assistência em neonatologia, pois seu estado de saúde depende de inúmeros fatores. Esses pacientes necessitam de um encaminhamento para uma unidade especializada como, por exemplo, a Unidade de Cuidado Intermediário Neonatal Convencional que presta cuidado a recémnascidos de médio risco e estáveis, mas que demandam de uma assistência contínua, porém, de menor intensidade. Nesse cenário destaca-se o nutricionista que atua no sentido apoiar o aleitamento materno, pois em alguns casos o binômio mãe-bebê apresenta alguma dificuldade o sucesso da prática, podendo, para tanto, utilizar a ferramenta LATCH. Diante disso, objetivou-se descrever a experiência do profissional de nutrição em um caso com a utilização da ferramenta LATCH na UCINCo. Tratou-se de um estudo descritivo, qualitativo, do tipo relato de experiência em um caso de internação na UCINCo com dificuldade no momento do aleitamento materno. Essa ferramenta avalia os itens: "pega"; "deglutição", "tipo de mamilo", "conforto" e "colo". Logo, o nutricionista residente, realizou uma abordagem inicial com a aplicação da ferramenta LATCH; realizou orientações verbais e ajustes e estímulos práticos com o binômio, e por fim, reavaliou. Durante o estímulo ao seio observou-se certa dificuldade no posicionamento do bebê, aliado ao fato que a pega e sucção ainda estavam em desenvolvimento. Após as orientações observou-se uma melhora dos itens: "pega", "deglutição" e "colo". Por meio do uso da ferramenta é possível identificar quais são os itens que necessitam de maior atenção para o sucesso do AM. Portanto, conclui-se que que a 
ferramenta LATCH pode atuar como instrumento diagnóstico e de fácil aplicação que pode alinhar os discursos e padronizar condutas, podendo ser utilizada por qualquer profissional da saúde que trabalhe como apoiador do AM.

Palavras-chave: Prematuridade Neonatal. Lactente. Amamentação.

\section{INTRODUÇÃO}

Recém-nascidos pré-termo (RNPT) podem se tornar grandes desafios para a assistência em neonatologia, pois seu estado de saúde depende de inúmeros fatores. Logo, esses pacientes necessitam de uma assistência especializada, sendo necessária sua transferência quase que de imediata para uma Unidade de Cuidados Intermediários e Semiintensivos Neonatais (UCIS). No âmbito da UCIS existe a Unidade de Cuidado Intermediário Neonatal Convencional (UCINCo) a qual é voltada para os cuidados de recém-nascidos de médio risco e estáveis, mas que demandam de uma assistência contínua, porém, de menor intensidade. Há estímulo a amamentação e participação dos pais e familiares juntamente com os profissionais no cuidado e monitoramento dos bebês (BRASIL, 2017).

Dentre os membros da equipe multiprofissional da UCINCo, destaca-se o nutricionista, que possui papel de extrema importância para esses pacientes, pois, além de ser responsável pela alimentação e nutrição, incentiva o aleitamento materno (AM) como prática mais comum, eficaz e segura de garantir os nutrientes adequados para seu crescimento e desenvolvimento (CONCEIÇÃO et al., 2017). No entanto, durante o AM podem ocorrer algumas intercorrências que dificultam essa prática, sendo necessária a adequada avaliação e intervenção.

Dentre as ferramentas que podem ser utilizadas para avaliar AM destaca-se o uso da ferramenta LATCH. Essa ferramenta apresenta princípios referentes a cada letra de sua sigla, sendo: "L" (Latch), relacionado à qualidade da pega da criança com a mama; "A" (Audible swallowing), referente à probabilidade de se ouvir a deglutição do bebê durante mamando; “T” (Type of nipple), analise do tipo de mamilo; "C" (Comfort), observa o nível de conforto da mãe com a mama e ao mamilo e "H" (Hold), refere-se a circunstância da mãe precisar ou não de ajuda para posicionar a criança (CONCEIÇÃO et al., 2017). 
Diante disso, o presente estudo tem por finalidade descrever a experiência do profissional de nutrição em um caso com a utilização da ferramenta LATCH na observação do aleitamento materno no binômio mãe-bebê durante a internação na UCINCo.

\section{METODOLOGIA}

Trata-se de um estudo descritivo, qualitativo, do tipo relato de experiência. Foi realizado na UCINCo de um Hospital Universitário no interior do Rio Grande do Norte. A experiência foi de um caso no qual binômio mãe-bebê foi admitido na UTI Neo para acompanhamento do quadro de cianose periférica. Com o passar da internação e estabilidade do caso o estímulo ao seio foi liberado. No entanto, foi observado pela equipe uma dificuldade no momento do AM.

O nutricionista residente foi solicitado para a fazer avaliação. Logo, foi 1) feita uma abordagem inicial para identificar os possíveis problemas, além dos pontos da ferramenta LATCH; 2) realização de orientações, e por fim, 3) uma nova observação e posteriormente após orientações, uma segunda observação com a ferramenta proposta. Para cada um dos cinco itens avaliados foi gerado uma pontuação de $0-2$, podendo chegar até 10 como pode ser observado no Quadro 1.

Quadro 1 - Descrição dos itens e pontuações atribuídas na ferramenta LATCH.

\begin{tabular}{|c|c|c|c|}
\hline \multirow{2}{*}{ ITENS } & \multicolumn{3}{|c|}{ PONTUACC̃̃O } \\
\hline & 0 & 1 & 2 \\
\hline Pega & $\begin{array}{l}\text { Muito sonolento ou } \\
\text { relutante } \\
\text { Não consegue sustentar } \\
\text { a pega ou sucção }\end{array}$ & $\begin{array}{c}\text { Tentativas } \\
\text { repetidas para } \\
\text { sustentar a pega ou } \\
\text { sucção }\end{array}$ & $\begin{array}{c}\text { Agarra a mama } \\
\text { Língua abaixada } \\
\text { Lábios curvados para } \\
\text { fora } \\
\text { Sucção rítmica }\end{array}$ \\
\hline Deglutição & Nenhuma & $\begin{array}{l}\text { Um pouco, com } \\
\text { estímulo }\end{array}$ & $\begin{array}{c}\text { Espontânea e } \\
\text { intermitente } \\
(<24 \text { horas de vida }) \\
\text { Espontânea e frequente } \\
(>24 \text { horas de vida })\end{array}$ \\
\hline Tipo de mamilo & Invertido & Plano & $\begin{array}{c}\text { Protruso } \\
\text { (Após estimulação) }\end{array}$ \\
\hline $\begin{array}{l}\text { Conforto } \\
\text { (mama/mamilo) }\end{array}$ & $\begin{array}{c}\text { Ingurgitada, com } \\
\text { fissura, sangrando, } \\
\text { grandes vesículas ou } \\
\text { equimoses } \\
\text { desconforto severo }\end{array}$ & $\begin{array}{c}\text { Cheia } \\
\text { Avermelhado/ } \\
\text { pequenas vesículas } \\
\text { ou equimoses } \\
\text { Desconforto } \\
\text { suave/moderado }\end{array}$ & $\begin{array}{c}\text { Macias } \\
\text { Não dolorosas }\end{array}$ \\
\hline
\end{tabular}




\begin{tabular}{|l|c|c|c|}
\hline & & $\begin{array}{c}\text { Ajuda mínima } \\
\text { Ensinar a mãe em } \\
\text { uma mama, depois }\end{array}$ & $\begin{array}{c}\text { Sem ajuda da equipe } \\
\text { Colo }\end{array}$ \\
(posição) & $\begin{array}{c}\text { Ajuda completa } \\
\text { (Equipe segura o bebê à à no outro } \\
\text { mama) }\end{array}$ & $\begin{array}{c}\text { lado } \\
\text { e segurar } \\
\text { o bebê }\end{array}$ \\
& $\begin{array}{c}\text { Equipe segura o } \\
\text { bebê, depois a mãe } \\
\text { assume }\end{array}$ & \\
\hline
\end{tabular}

Fonte: Adaptado de Conceição et al. (2017).

\section{RESULTADO E DISCUSSÃO}

Observou-se que a genitora era primigesta, logo, estava vivenciando os primeiros momentos como mãe. Durante o estímulo ao seio observou-se certa dificuldade em como posicionar seu bebê, aliado ao fato que o bebê ainda estava desenvolvendo as práticas de pega e sucção. Das dificuldades mais expressadas pelas puérperas, destacam-se a pega e o posicionamento do bebê, sendo elas os maiores obstáculos da continuação do AM (AMARAL et al., 2015).

Inicialmente foi feita uma primeira observação acerca da pratica do aleitamento e em seguida foram realizadas orientações verbais, além de ajustes posicionais com a mãe, e sucção não-nutritiva e correção de pega com o RN. Posteriormente as orientações, houve uma segunda observação para averiguar se as orientações e ajustes feitos surtiram efeitos. As pontuações para cada um dos itens da ferramenta podem ser observadas na Tabela 1.

Tabela 1 - Avaliação da amamentação por meio do uso da ferramenta LATCH.

\begin{tabular}{lcc}
\hline ITENS & $\mathbf{1}^{\mathbf{0}}$ OBSERVAÇÃO & $\mathbf{2}^{\mathbf{0}}$ OBSERVAÇÃO \\
\hline Pega & 0 & 1 \\
Deglutição & 1 & 2 \\
Tipo de mamilo & 2 & 2 \\
Conforto (mama/mamilo) & 2 & 2 \\
Colo (posicionamento) & 0 & 2 \\
\hline TOTAL & 5 & 9
\end{tabular}

Fonte: Próprio autor (2020).

Com base nos dados, verifica-se que na observação inicial a nota atingida foi cinco pontos, porém, após as reavaliações e orientações observou-se uma melhora dos itens: "pega", “deglutição" e "colo (posicionamento)". Logo, como a dedicação e da equipe de saúde é 
fundamental para que essas mães consigam se sentir bem no momento da amamentação, uma vez orientadas adequadamente e incentivadas os resultados obtidos serão positivos para o binômio (AMARAL et al., 2015).

Nessa perspectiva, observa-se como ajustes, muitas vezes mínimos, podem gerar um grande impacto para promover a melhora da segurança e confiança da mãe em relação ao AM. Por meio do uso da ferramenta é possível identificar quais são os itens que necessitam de maior atenção para o sucesso do AM. Ressalta-se ainda a praticidade da ferramenta em que o profissional preenche os pontos, com base na sua observação do caso. Além disso, é uma ferramenta que pode ser utilizada por qualquer profissional da saúde que trabalhe com AM, servindo também como uma forma de alinhar o discurso e padronizar condutas (CONCEIÇÃO et al., 2017).

\section{CONCLUSÃO}

Portanto, conclui-se que que a ferramenta LATCH mostrou ser efetiva para observar os principais itens do sucesso do AM, servindo com um instrumento de fácil aplicação, sem ser invasivo, sendo possível identificar os problemas apenas com observações. Além de sua praticidade, ele contribui para alinhar os discursos e padronizar condutas, tanto para mães primíparas ou multíparas, quanto para seus respectivos bebês. Ressalta-se ainda, que a ferramenta não é de uso único e exclusivo do nutricionista e pode ser utilizada por qualquer profissional da saúde que trabalhe como apoiador do AM, mostrando a sua importância de adoção na rotina de hospitais-maternidades.

\section{REFERÊNCIAS}

AMARAL, L. J.; SALES, S. S.; CARVALHO, D. P. S. R.; CRUZ, G. K.P.; AZEVEDO, I.C.; FERREIRA JÚNIOR, M. A. Fatores que influenciam na interrupção do aleitamento materno exclusivo em nutrizes. Revista gaúcha de enfermagem, v. 36, p. 127-134, 2015. Disponível em: https://doi.org/10.1590/1983-1447.2015.esp.56676. Acesso em: 20 maio 2021

BRASIL. Ministério da Saúde. Secretaria de Atenção à Saúde. Departamento de Ações Programáticas Estratégicas. Atenção humanizada ao recém-nascido: Método Canguru : manual técnico 3. ed. Brasília: Ministério da Saúde, 2017.

CONCEIÇÃO, C. M.; COCA, K. P.; ALVES, M. R.; ALMEIDA, F. A. Validação para língua portuguesa do instrumento de avaliação do aleitamento materno LATCH. Acta Paulista de Enfermagem, v. 30, p. 210-216, 2017. Disponível em: https://doi.org/10.1590/19820194201700032. Acesso em: 27 abr. 2021. 